\title{
Glucose-dependent miR-125b is a negative regulator of $\beta$-cell function
}

\author{
Rebecca Cheung ${ }^{\S 1}$, Grazia Pizza ${ }^{\S 1}$, Pauline Chabosseau', Delphine Rolando², \\ Alejandra Tomas ${ }^{1}$, Thomas Burgoyne ${ }^{3}$, Anna Salowka ${ }^{1}$, Annabel Macklin'1, Yufei Cao', \\ Marie-Sophie Nguyen-Tu ${ }^{1}$, Piero Marchetti ${ }^{4}$, James Shapiro5, Lorenzo Piemonti6, \\ Eelco de Koning ${ }^{7}$, Isabelle Leclerc ${ }^{1}$, Kei Sakamoto ${ }^{8}$, David M. Smith ${ }^{9}$, \\ Guy A. Rutter ${ }^{1,10,11}$ and Aida Martinez-Sanchez*1
}

${ }^{1}$ Section of Cell Biology and Functional Genomics, Department of Medicine, Imperial College London, U.K.

${ }^{2}$ Beta Cell Genome Regulation Laboratory, Department of Medicine, Imperial College London, U.K. ${ }^{3}$ UCL Institute of Ophthalmology, University College London, London, U.K.

${ }^{4}$ Department of Clinical and Experimental Medicine, University of Pisa, Pisa, Italy.

${ }^{5}$ Clinical Islet Laboratory and Clinical Islet Transplant Program, University of Alberta, Edmonton, Canada.

${ }^{6}$ Vita-Salute San Raffaele University, Milan, Italy.

${ }^{7}$ Department of Medicine, Leiden University Medical Center, Leiden, The Netherlands.

${ }^{8}$ Novo Nordisk Foundation Center for Basic Metabolic Research, University of Copenhagen, Copenhagen, Denmark

${ }^{9}$ Emerging Innovations Unit, Discovery Sciences, R\&D AstraZeneca, Cambridge, UK 10Lee Kong Chian School of Medicine, Nanyang Technological University, Singapore ${ }^{11} \mathrm{CR}-\mathrm{CHUM}$, University of Montreal, QC, Canada

\footnotetext{
$\S$ Authors contributed equally

*Correspondence to: a.martinez-sanchez@imperial.ac.uk
}

Keywords: MiRNAs, miR-125b, islets, $\beta$-cell, insulin, hyperglycaemia, lysosomes, mitochondria, type 2 diabetes 


\section{SUMMARY}

Impaired pancreatic $\beta$-cell function and insulin secretion are hallmarks of type 2 diabetes. MicroRNAs are short non-coding RNAs that silence gene expression, vital for the development and function of $\beta$-cells. MiR-125b-5p (miR-125b), a highly conserved miRNA, is abundant in $\beta$-cells, though its role in these cells is unclear. Here we show that miR-125b levels in human islets correlate with body mass index (BMI), and its expression is regulated by glucose in an AMP-activated protein kinase-dependent manner. An unbiased high-throughput screen identified multiple miR-125b targets, including the transporter of lysosomal hydrolases $\mathrm{M} 6 \mathrm{pr}$ and the mitochondrial fission regulator Mtfp1. Inactivation of miR-125b in human $\beta$-cells shortened mitochondria and enhanced glucose-stimulated insulin secretion, whilst mice overexpressing miR-125b selectively in $\beta$-cells were glucose intolerant. $\beta$-cells from these animals contained enlarged lysosomal structures and showed reduced insulin content and secretion. Thus, we identify miR125b as a glucose-controlled regulator of organelle dynamics that modulates insulin secretion.

\section{Highlights}

- Islet miR-125b correlates with BMI and is regulated by glucose via AMP-activated protein kinase in $\beta$-cells

- miR-125b targets dozens of genes including several involved in the regulation of mitochondrial (Mtfp1) and lysosomal (M6pr) morphology or function

- Deletion of miR-125b results in shorter mitochondria and improves glucose stimulated insulin secretion (GSIS)

- Selective overexpression of miR125b in $\beta$-cells causes the appearance of enlarged lysosomes, reduced GSIS and insulin content, loss of $\beta$-cell identity and impaired insulin secretion and glucose tolerance in vivo 


\section{MAIN}

\section{INTRODUCTION}

Pancreatic $\beta$-cells are essential regulators of glucose homeostasis, secreting insulin in response to post-prandial increases in circulating levels of the sugar ${ }^{1}$. Whereas an autoimmune-mediated loss of $\beta$-cell mass characterizes type 1 diabetes (T1D), type 2 diabetes (T2D) usually results from the failure of $\beta$-cells to secrete sufficient insulin to compensate for peripheral insulin resistance. Changes in $\beta$-cell function and identity ${ }^{2}$, alongside more limited decreases in mass $^{3}$, all contribute to disease development ${ }^{4}$. Whereas glucose metabolism is an important positive regulator of $\beta$-cell function, chronic hyperglycaemia has a negative effect on $\beta$-cell function and survival, further exacerbating the disease ${ }^{5}$

MicroRNAs (miRNAs) are tiny ( 21 ntd (nucleotide)) non-coding RNAs that silence gene expression post-transcriptionally. Since their discovery almost two decades ago, miRNAs have been widely demonstrated to play important regulatory roles in most biological processes and in many diseases ${ }^{6}$. Even though it is now well established that miRNAs are essential for endocrine cell development and function ${ }^{7}$ and that $\beta$-cells contain hundreds of different miRNAs, the function of only a few of these has been studied in detail.

MiR-125b (miR-125b-5p) is a highly conserved miRNA widely studied in the context of tumorigenesis and immunology and an important regulator of cellular proliferation, differentiation and apoptosis 8 . We have previously shown that miR-125b expression increases in islets after $\beta$-cell specific deletion of the AMP-activated protein kinase (AMPK) catalytic subunits $\alpha 1$ and $\alpha 2(\beta A M P K d K O)^{9}$, suggesting that AMPK may act as a negative regulator of miR-125b expression. AMPK is an evolutionarily-conserved protein kinase whose activity is suppressed acutely in the $\beta$-cell by high glucose ${ }^{10}$, and lowered in islets from subjects with T2D diabetes ${ }^{11,12}$.

The above observations have led us to hypothesize that inhibition of AMPK in response to high glucose would result in islet miR-125b up-regulation which may mediate some of the 
deleterious effects of hyperglycaemia in $\beta$-cells. We aimed to test this hypothesis here and to explore the possible implications for disease pathogenesis. We show that high glucose increases islet miR-125b expression and that miR-125b has an important negative effect in $\beta$ cell function both in vitro and in vivo by targeting genes involved in regulating lysosomal and mitochondrial function.

\section{RESULTS}

\section{Glucose stimulates miR-125b expression via AMPK repression}

In order to determine whether glucose regulates miR-125b expression in islets, we measured miR-125b in mouse and human islets cultured at increasing glucose concentrations. As shown in Figure 1a, miR-125b expression was significantly increased after culture for $48 \mathrm{~h}$ at high (11$25 \mathrm{mM})$ vs low (3.5-5.5 mM) glucose concentrations. Consistent with the possible in vivo relevance of these findings, expression of miR-125b in human islets was positively correlated with the body mass index (BMI) of (non-diabetic) donors (Figure 1b). The latter parameter is associated with increased blood glucose ${ }^{13}$. No association was found between miR-125b expression in islets and the age or sex of the donors (Supp Figure 1).

Islets from $\beta A M P K d K O$ mice displayed significantly higher miR-125b levels than controls when cultured at a low $(5.5 \mathrm{mM})$ glucose concentration (Figure 1c) whereas miR-125b expression remained unchanged when islets were cultured at high glucose (25mM). To determine whether this glucose/AMPK-dependent regulation of miR-125b also occurred in vivo, we fed control, $\beta A M P K d K O$ or $\beta$ LKB1KO (mice with a $\beta$-cell specific deletion of the AMPK-upstream kinase Liver kinase B1, LKB1/STK1 $1{ }^{14}$ ) animals a ketogenic (low sugar) diet. In agreement with our previously published data ${ }^{9}, \beta A M P K d K O$ islets displayed higher levels of miR-125b than controls (Figure 1d) and, as expected, the same islet miR-125b upregulation was observed in $\beta$ LKB1KO islets (Figure 1d). As demonstrated in figure 1d, feeding a low-sugar diet for 28 days resulted in a significant decrease in islet miR-125b in control animals. Nevertheless, miR-125b levels remained identical in islets from $\beta A M P K d K O$ and 
$\beta$ LKB1KO mice fed a chow or a ketogenic diet (Figure 1d). Moreover, culture of human islets with the selective AMPK activators $\mathrm{C} 13$ and $991^{9}$ caused a small but significant reduction in miR-125b expression (Figure 1e). Taken together, these results suggest that high glucose stimulates miR-125b expression in both mouse and human islets, in vivo and in vitro, by inhibiting AMPK.

MiRNAs are transcribed as longer primary transcripts (pri-miRNAs) that are first processed in the nucleus into 70 ntd hairpins (pre-miRNAs) and later, within the cytoplasm, into mature ( 21 ntd) miRNAs ${ }^{15}$. Consequently, mature miRNA expression can be controlled at different levels, including transcription, processing and stability. MiR-125b is encoded by two independent loci, MIR125B-1 and MIR125B-2 in humans and mice, located on Chr11 and Chr21 (humans) and Chr9 and Chr16 (mice), respectively. Several (2-3) transcriptional initiation (start) sites (TSS) as close as $\sim 2 \mathrm{~KB}$ and as far as $\sim 200 \mathrm{~KB}$ upstream the annotated pre-miR-125b have previously been identified ${ }^{8}{ }^{16}$. RT-qPCR of pri-miR-125b-1/2 demonstrated that, as for (mature) miR-125b, $\beta$ AMPKdKO islets expressed significantly higher levels of primiR-125b-1 than controls (Figure 1f), suggesting that AMPK inhibits the production of miR$125 \mathrm{~b}$ precursors and therefore transcription. Of note, we were not able to detect pri-miR-125b2 , indicating low transcription rate and/or fast processing of this precursor.

Ottaviani and co-workers ${ }^{17}$ have recently demonstrated that miR-125b is induced by TGF- $\beta$ via Smad2/3 activation of the MIR125B-1 locus in pancreatic ductal adenocarcinoma cells (PDAC). Interestingly, Smad2/3 ChIP-seq in mouse islets showed binding to an annotated miR-125b TSS (Supp Figure 2) located in a chromatin region with increased accessibility in $\beta$ LKB1KO islets (Cebola et al. in preparation, Supp Fig 2). Nevertheless, contrary to what we expected, transfection of MIN6 cells with siRNAs against Smad3 siRNAs resulted in a small increase in miR-125b, whereas no effect was observed with Smad2 siRNAs (Supp Figure 3), suggesting that Smad2/3 are not transcriptional activators of miR-125b in MIN6 cells.

\section{MiR-125b regulates insulin secretion in $\beta$-cell lines}


The most important characteristic of the $\beta$-cell is its capacity to respond to high levels of circulating glucose by secreting insulin, a process that is tightly regulated ${ }^{1}$. We thus set to determine whether miR-125b plays a role in this process by short-term (48h) over-expression of miR-125b in the mouse insulinoma cell line MIN6. Glucose-stimulated insulin secretion from MIN6 cells transfected with miR-125b mimics was $30 \%$ lower $(p=0.1)$ vs control transfected cells and, more strikingly, these cells contained $40 \%$ less insulin ( $p=0.03$ ) (Figure 2a).

To explore whether miR-125b regulated insulin secretion from human $\beta$-cells and under physiological conditions, we next generated human EndoC $\beta-\mathrm{H} 1$ cells $^{18}$ with miR-125b loss-offunction using CRISPR-Cas9. EndoC $\beta-\mathrm{H} 1$ cells were infected with a lentiviral vector expressing one of two different pairs of gRNAs targeting each MIR125B locus (MIR125B-1 and MIR125B-2) and a rat Insulin promoter-driven hSpCas9 expression cassette (Supp Figure 4a). Independently, both gRNA pairs targeting the MIR125B-2 locus (MIR125B2-KO1 and MIR125B2-KO2) resulted in cell populations with strongly reduced ( $80 \%)$ levels of mature miR-125b while gRNAs targeting MIR125B-1 resulted in a marginal reduction of the miRNA (Supp Figure 4b) and cells infected with lentivirus bearing gRNAs against both loci showed a more limited ( 40-60\%) decrease in miR-125b expression (Supp Figure 4c). These results indicate that most mature miR-125b is transcribed from MIR125B-2 in EndoC $\beta-\mathrm{H} 1$ cells. Consequently, we used our MIR125B-2 CRISPR-cells (KO1, hereafter EndoCßH1MIR125B2-KO) for further characterization. Expression in EndoCßH1-MIR125B2-KO cells of the other member of the miR-125 family, miR-125a and of miR-99a, annotated in the same genomic cluster as MIR125B-2 (Supp Figure 4b) did not differ from control (Cas9-expressing) cells. As anticipated, EndoC $\beta \mathrm{H} 1-\mathrm{MIR} 125 \mathrm{~B} 2-\mathrm{KO}$ cells secreted more insulin in response to high glucose than controls, although no differences were detected in insulin content (Figure $2 d)$.

\section{High-through identification of miR-125b target genes}

MiRNAs can target hundreds of genes simultaneously and in a cell type-specific manner ${ }^{19}$ providing the capacity to tightly regulate biological processes. To further explore the genes 
and molecular pathways regulated by miR-125b, as well as its mechanism of action, we sought to explore the impact of the miRNA on $\beta$-cell gene expression and to identify direct targets in a high throughput manner. MiRNAs guide the miRNA-induced silencing complex (miRISC), including an ARGONAUTE protein to the target mRNAs via partial sequence complementarity. Thus, an mRNA that is actively repressed by miRNAs will be bound to miRISC. MiRISC's action will result in target mRNA destabilization ${ }^{20}$ and/or inhibition of target mRNA translation without observable changes in transcript levels. Thus, we used an experimental approach that combined overexpression of miR-125b in MIN6 cells, immunoprecipitation of miRISC/target mRNAs using an antibody against AGO2 and high-throughput sequencing and differential analysis of cellular total and immunoprecipitated RNAs ${ }^{17,21}$ (Figure 3a). As a consequence of miR-125b overexpression, we expected miR-125b targets to be reduced or unchanged (if repression occurs exclusively at the level of translation) in the total mRNA (T-RNA, Sup Table 1) fraction and increased in the precipitated (RIP-RNA, Supp Table 1) fraction. Thus, for miR125b direct targets we expect a RIP-RNA to T-RNA ratio $>1$ following miR-125b overexpression. In order to validate our approach we sorted all detected genes according to RIP-RNA/T-RNA ratio (Supp Table 1) and performed unbiased word enrichment analysis using $\mathrm{cWords}^{22}$. As anticipated, cWords found a significant enrichment of miR-125b seedmatching sequences in highly ranked (high RIP-RNA/T-RNA ratio) genes (Figure 3b). Importantly, enrichment on seed-complementary sequences was found in both the 3' nontranslated (3'UTR) and coding (CDS) sequences of highly ranked genes, though a higher Zscore (>20) was obtained for 3'UTRs (Figure 3b). This suggests that miR-125b-mRNA target interactions occur both via the 3'UTR and CDS. 182 mRNAs were enriched in miRISC following miR-125b overexpression with an RIP-RNA/T-RNA > 1.5 (Figure 3c, Table 1). Out of these, only 60 were significantly down-regulated at the mRNA level following miR-125b overexpression (Table 1, padj < 0.1 ) and 87 contained predicted binding sites in their 3'UTRs according to TargetScan (Table 1). 
We decided to further validate the six targets (Taz, M6pr, Tor2a, Mtfp1, Tnks1bp1 and Gnpat) with the highest RIP-RNA/T-RNA ratios using luciferase-based assays ${ }^{23}$. Whereas Taz, M6pr, Tor2a and Mtfp1 contain predicted binding sites in their 3'UTRs, Tnks1bp1 and Gnpat contained sequences complementary to miR-125b in their CDS (RNAhybrid, mfe: 32.5 and $24.3 \mathrm{kca} / \mathrm{mol}$, respectively). Therefore, we generated constructs containing the 3'UTR of Taz, M6pr, Tor2a and Mtfp1 and the CDS of Tnks1bp1 and Gnpat under the Firefly open reading frame (ORF) in the bicistronic plasmid pMiRGlo which also encodes for Renilla luciferase. As expected, co-transfection of miR-125b mimics reduced Firefly/Renilla activity in cells transfected with constructs containing the Taz, M6pr, Tor2a and Mtfp1 3'UTRs and Gnpat CDS, demonstrating that miR-125b silence gene expression through those sequences (Figure 4a). We failed to validate miR-125b action through Tnks 1 bp 1 CDS, since cells transfected with this construct displayed the same Firefly/Renilla activity in the presence of miR-125b or control mimics, perhaps due to the location of the binding site downstream the luciferase CDS and not within the CDS itself ${ }^{24}$. As expected, miR-125b mimics strongly reduced Firefly/Renilla activity of a reporter containing three perfectly complementary sequences to miR-125b and did not affect Firefly/Renilla activity of the empty vector or in the presence of the 3'UTR of Gnpat which doesn't contain predicted miR-125b binding sites.

\section{MiR-125b targets genes encoding mitochondrial and lysosomal proteins}

To identify biological pathways and functions regulated by miR-125b we submitted the list of genes dysregulated at the RNA level (T-RNA, 306 genes down-regulated and 317 upregulated padj $<0.1$, Supp Table 1 ) as well as those genes identified as miR-125b direct targets with a RIP/T-RNA > 1.5 (Table 1) to a Database for Annotation, Visualization and Integrated Discovery, DAVID ${ }^{25}$. We applied DAVID's newly-added clustering tool to group similar annotations from UniProtein Keywords (Functional category), Biological Processes, Cellular Compartments and Molecular Functions (Gene Ontology terms, GO) and Kyoto Encyclopedia of Genes and Genomes (KEGGs) Pathways. Functional annotations with high enrichment scores included mitochondrion, tricarboxylate (TCA) cycle, sterol biosynthesis, 
protein transport, Golgi apparatus and endosome (Figure 4b, Supp Table 2), all closely associated to the capacity of the $\beta$-cells to produce and secrete insulin in response to glucose.

The lysosomal/Golgi-associated M6pr (Manose-6-phosphate receptor-cation dependent, M6PR-CD) is one of the genes at the top of our list of newly-identified miR-125b targets in MIN6 cells. M6PR-CD controls trafficking of lysosomal hydrolases from the Golgi via endosomes ${ }^{26}$ and thus may influence protein turnover and lysosomal function. Luciferase assays further confirmed the interaction of miR-125b via a predicted conserved miR-125b binding site in its 3'UTR (Figure 5a). Even though we were not able to detect mouse M6PR protein, Western-(Immuno) blot of EndoC $\beta-H 1$ cells overexpressing miR-125b and EndoCßH1-MIR125B2-KO cells showed a strong down- and up-regulation in M6PR protein, respectively (Figure 5b) without significant changes at the mRNA level (Figure 5c and Supp Table 3). These results confirm that miR-125b targets M6PR to repress protein production in both mouse and human $\beta$-cells.

We next hypothesized that miR-125b overexpression might lead to M6PR downregulation, and consequently to a defect in lysosomal hydrolases. This may in turn lead to an accumulation of lysosomal structures with non-digested organelles and proteins. To test our hypothesis, we performed electron microscopy (EM) on MIN6 cells transfected with control or miR-125b mimics. Interestingly, miR-125b overexpressing cells displayed an accumulation of aberrant lysosomal structures with enlarged lysosomes (Figure 5d).

As mentioned above, GO of genes dysregulated upon miR-125b overexpression also revealed a significant over-representation of genes involved in mitochondrial function and oxidoreductase activity (Supp Table 2, Figure 4b), including one of the top miR-125b direct targets, mitochondrial fission process 1 (Mtfp1, also known as MTP18). As shown in Figure 6a, Mtfp1 3'UTR cloned downstream Firefly ORF mediated Firefly/Renilla luciferase reduction in the presence of miR-125b mimics. Importantly, mutation of the predicted and conserved miR-125b binding site de-repressed luciferase activity (Figure 6a), demonstrating that the direct interaction of miR-125b with this binding site is responsible for the repression. 
MTFP1 has previously been implicated in mitochondrial fission and apoptosis in mammalian cells ${ }^{27}$. Mitochondria undergo constant fusion and fission processes that ensure quality control and adequate function ${ }^{28}$. To explore a possible role for miR-125b in controlling mitochondrial morphology, we stained MIN6 cells transfected with control or miR-125b mimics with a mitochondria-targeted green fluorescent probe (Mitotracker green). MIN6 cells overexpressing miR-125b contained the same number and overall mitochondrial area, though their mitochondria were slightly more elongated and less circular (Figure 6b). In contrast, mitotracker green staining of EndoC $\beta \mathrm{H} 1-M I R 125 B 2-K O$ cells revealed a marked reduction in mitochondrial area and a higher number of mitochondria with a smaller perimeter, and which were also less elongated and more circular (Figure 6c). These findings suggest that whereas endogenous miR125b levels are sufficient to exert maximal effects on mitochondrial structure, relief from miR125-mediated repression of the fission machinery leads to disruption of the tubule-vesicular network.

Further emphasizing the importance of miR-125b for mitochondrial homeostasis, GO analysis following RNAseq of EndoCBH1-MIR125B2-KO confirmed a strong enrichment in dysregulated genes associated with mitochondrial function (Figure 6d, Supp Table 4). Of note, whilst we identified 609 and 81 genes up- and down-regulated, respectively (Sup Table 3, padj<0.1) in EndoCßH1-MIR125B2-KO, miRNA binding site enrichment analysis of upregulated genes using cWords or Mienturnet ${ }^{29}$ failed to identify an enrichment in genes with predicted miR-125b binding sites ( $p=0.2$ ), with only 30 genes containing conserved predicted miR-125b binding sites (Supp Table 3) and an additional 108 containing at least one nonconserved binding site (data not-shown). Even though we were we unable to detect MTFP1 protein in MIN6 or EndoCßH1 cells with two different commercial antibodies tested, upregulation of MTFP1 mRNA was confirmed by the RNA-seq data in EndoCBH1-MIR125B2KO cells (MTFP1, 1.5 fold, p-value: 0.006, padj 0.1, Sup Table 4). 
Taken together, these data indicate that long-term reduction of miR-125b expression in human EndoC $\beta-\mathrm{H} 1$ cells has a strong direct and indirect effect in the expression of genes involved in mitochondrial homeostasis which may underlie the observed improvement in insulin secretion.

\section{MiR-125b overexpression in $\beta$-cells impairs glucose tolerance in vivo}

Given the powerful effect of miR-125b manipulation on $\beta$-cell gene expression and function in vitro, we decided to study the role of miR-125b in vivo by generating a mouse with $\beta$-cell specific, inducible overexpression of miR-125b using the Tet-ON system ${ }^{30}$. Mice bearing a transgene expressing miR-125b under the control of an rtTA-inducible rat insulin promoter (MIR125B-Tg: RIP7-rtTA ${ }^{+-}$, MIR125B $\mathrm{Tg}^{+/}$) and controls (Control: RIP7-rtTA ${ }^{+/}$) were continuously administered doxycycline (from parental mating) in the drinking water and were born at the expected mendelian ratios (50\% each). RT-qPCR in islets isolated from 6-10 week old MIR125B-Tg animals revealed $\sim 60$-fold more mature miR-125b in comparison to Control mice (Figure 7a). On the other hand, miR-125b levels remained unchanged in the hypothalamus of MIR125B-Tg animals, a potential site for activity of the RIP2 promoter ${ }^{31}$ (Supp Figure 5a).

MIR125B-Tg mice showed indistinguishable weight gain than controls as measured between 5-10 weeks of age (Supp Figure 5b). In contrast, random-fed glycaemia was significantly higher in MIR-125B-Tg when measured at 5 and 9 weeks of age, in both male and females (Figure 7b). Consistently, both male and female MIR125B-Tg mice were highly glucose intolerant at both 6 and 10 weeks of age (Figure 7c/d), though fasting glycaemia was unaffected. No changes in glucose tolerance were observed in animals bearing the transgene in the absence of rtTA (-rtTA Control: RIP7-rtTA ${ }^{-/}$, MIR125B OE ${ }^{+/}$, Supp Figure 5c), demonstrating that the defects observed were not due to an off-target genomic event resulting from transgene integration. Blood glucose levels were efficiently reduced by administration of exogenous insulin, as measured by intraperitoneal insulin tolerance test in male and female MIR125B-Tg and Control mice at 7 weeks of age, excluding insulin insensitivity as a major player in the glucose intolerance observed in MIR125B-Tg animals (Supp Figure 5d). 
Moreover, MIR125B-Tg mice failed to secrete insulin in response to an intraperitoneal injection of glucose (Figure 7e) suggesting impaired $\beta$-cell secretory function. $\beta$-cell mass and $\beta$ - to $\alpha$ cell ratio remained unchanged in the transgenic animals (Figure 7f). Accordingly, no differences were observed in $\beta$-cell proliferation or apoptosis (Supp Figure 5e/f).

Taken together, these data suggest that increased miR-125b in the $\beta$-cell results in hyperglycaemia and glucose intolerance due to impaired $\beta$-cell secretory function but not $\beta$ cell mass.

\section{MiR-125b transgenic islets contain and secrete less insulin}

To further explore a cell autonomous defect in insulin secretion, we measured glucosestimulated insulin secretion (GSIS) in islets isolated from control and MIR125B-Tg mice. Islets isolated from MIR125B-Tg mice showed a strong reduction in insulin secretion in response to glucose or depolarisation by $\mathrm{KCl}$ (Figure 8a). Consistent with our previous data in MIN6 cells, MIR125B-Tg islets contained less intracellular insulin (Figure 8b), as further confirmed by Western blot (Figure 8c). The latter revealed lower levels of both intracellular pro-insulin and insulin. These data indicate a reduced capacity of miR-125b-overexpressing $\beta$-cells to produce and secrete insulin, a defect likely to underlie glucose intolerance in the transgenic mice.

Upon entry in the $\beta$-cell, glucose is rapidly metabolized by mitochondria which causes a sharp increase in intracellular ATP/ADP ratio which, in turn, closes the ATP-sensitive $\mathrm{K}^{+}\left(\mathrm{K}_{\mathrm{ATP}}\right)$ channels leading to plasma membrane depolarization and $\mathrm{Ca}^{2+}$ influx into the cytosol to trigger insulin exocytosis ${ }^{1}$. The fact that secretory responses to both high glucose and $\mathrm{KCl}$ were impaired in MIR125B-Tg islets suggested a defect downstream of glucose metabolism. Interestingly, the glucose-mediated ATP/ADP rise was identical in MIR125B-Tg and Control isolated islets (Figure 8d), and basal ATP/ADP ratio was slightly but not significantly higher in transgenic islets versus control islets (Figure 8e). In contrast, MIR125B-Tg islets showed a strong reduction in glucose-induced changes in intracellular $\mathrm{Ca}^{2+}$ (Figure 8f). $\mathrm{KCl}$-induced rises 
in free $\mathrm{Ca}^{2+}$ were, on the other hand, similar between MIR-125B-Tg and Control islets, suggesting that MIR125B-Tg $\beta$-cells contained functional voltage-gated calcium channels (Figure 8f).

To assess the rate and kinetics of vesicle exocytosis we used total internal reflection of fluorescence (TIRF) imaging to image neuropeptide $\mathrm{Y}$ (NPY)-Venus-expressing vesicles near the plasma membrane ${ }^{32}$. As shown in figure $8 \mathrm{~g}$, the kinetics of individual fusion events were similar in cells from MIR125B-Tg or Control islets, indicating that vesicle fusion itself was not affected by miR-125b overexpression.

\section{Enlarged lysosomes/autophagolysosomes are abundant in miR-125b transgenic islets}

Our previous experiments in MIN6 and EndoC $\beta-\mathrm{H} 1$ cells pointed to miR-125b as a regulator of mitochondrial and lysosomal function, which could contribute to defective insulin secretion. To determine whether a similar mechanism was involved in primary $\beta$-cells, we stained transgenic and control islets with mitotracker- and lysotracker-green to visualize mitochondria and lysosomes, respectively. In contrast to our observations in cell lines, but consistent with an efficient capacity to generate ATP in response to glucose, mitochondrial area and morphology (i.e. circularity) were comparable in MIR125B-Tg and Control (Figure 9a), as well as the levels of mitochondrial DNA (mtDNA, Figure 9b). Even though no significant differences were found in the total number of lysosomes or in the lysosomal area in MIR125B-OE islets as measured by lysotracker imaging (Supp Figure $5 \mathrm{~g}$ ), transmission electron microscopy (TEM) analysis identified the presence of enlarged lysosomes and autophagosomes in the transgenic islets which were rarely found in Control samples (Figure 9c,d). TEM also revealed a sharp reduction in the mature/immature insulin granule ratio in MIR125B-Tg islets, with significantly fewer mature (dense core) and more immature (with defective crystalization) insulin granules (Figure 9e). Importantly, fewer secretory granules were present within 200nm of the plasma membrane in MIR125B-Tg than in control islets (Figure 9e).

\section{$\beta$-cell identity is altered in MIR125b-Tg islets}


To shed more light into the molecular mechanisms underlying the secretory defects of miR125B-Tg islets, we performed RNA-seq on MIR125B-Tg and Control islets from 6 week old mice. 320 genes were significantly (padj <0.1) down-regulated and 398 up-regulated, respectively (Supp Table 5). Mienturnet identified an enrichment of predicted miR-125b binding sites within the down-regulated genes ( $p$-value $<0.001, F D R=0.02$ ), though only 31 genes contained predicted conserved targets (Supp Table 5) and 85 poorly conserved targets (data not shown), suggesting that many of the effects observed following $\beta$-cell specific, longterm overexpression of this miRNA, are indirect.

Several important $\beta$-cell identity genes such as Ucn3, Pdx1, NeuroD1, Nkx2.2, Slc2a2 and Nkx6.1 were significantly reduced in MIR125B-Tg islets and, accordingly, GO analysis of downregulated genes identified a strong enrichment within pathways and processes associated with mature $\beta$-cell function. These included regulation of insulin secretion, response to glucose, glucose homeostasis and endocrine pancreas development (Supp Table 6 , Figure $10 \mathrm{a}, \mathrm{b})$. Further supporting a loss of $\beta$-cell identity, up-regulated genes were significantly associated with neuronal features (nervous system development, axon, neuronal cell body, etc. Supp Table 6, Figure 10a). Moreover, we observed an upregulation of many glycoprotein genes (Supp Table 6, Figure 10a) and of genes associated with cellular and focal adhesion, migration, signalling pathways and voltage-gated and potassium channels. Golgiassociated genes were both up and down-regulated (Supp Table 6, Figure 10a).

\section{MiR-125b alters gene expression in human islets}

To further explore the relevance of miR-125b in human $\beta$-cells, we performed RNA-seq in dissociated human islets from three different donors infected with an adenovirus expressing miR-125b, achieving a $\sim 3$ fold increase in miR-125b levels (Supp Figure 6a). Principal component analysis (PCA) showed that most of the variation was due to the donor origin of the islets (Supp Figure 6b) and, thus this experiment was underpowered due to the high variability observed in gene expression between individuals (power achieved is $\sim 20 \%$ to detect a $2 x$ Fold change with $p<0.01$, as calculated using Scotty $\left.{ }^{33}\right)$. Thus, we only detected four 
dysregulated genes with a padj value $<0.1$ although the expression of hundreds of genes tent to be altered ( $p$-value $<0.05$, Sup Table 7). Gene Set Enrichment analysis of all the detected genes ranked by fold change in gene expression identified a significant enrichment in several biological pathways (Figure 10c, Sup Table 8) notably including lysosomal $(p<0.0001$, $F D R=0.07)$ and calcium signalling $(p<0.0001, F D R=0.06)$ amongst the down- and upregulated pathways.

\section{DISCUSSION}

Despite being highly expressed in $\beta$-cells ${ }^{34}$, the function and mechanism of action of miR-125b in these cells have remained elusive until now. Here, we show that hyperglycaemia induces islet miR-125b expression and that elevated expression of this miRNA in $\beta$-cells impairs secretory function in vitro and in vivo.

$\beta$-cell dysfunction is a key element in the development of diabetes although the molecular and cellular nature of these changes are contested and are likely to be multifactorial ${ }^{35}$. Hyperglycaemia impairs $\beta$-cell function and insulin secretion by several mechanisms including loss of cellular identity, impaired glucose metabolism and increased apoptosis ${ }^{36}$. Three independent studies identified higher levels of circulating miR-125b in association with higher $\mathrm{HbA} 1 \mathrm{c}$ in $\mathrm{T}_{1} \mathrm{D}^{37}, \mathrm{~T} 2 \mathrm{D}^{38}$ and in patients with gestational diabetes (GDM) ${ }^{39}$, though the levels of miR-125 in pancreatic islets or other metabolic tissues were not assessed. Even though the human islets used in this study originated from different sources and $\mathrm{HbA} 1 \mathrm{c}$ data was not usually available, we were able to observe a significant correlation between islet miR-125b levels and donor BMI, which often associates itself with $\mathrm{HbA1c}{ }^{13}$. More importantly, glucoseinduced miR-125b expression in both mouse and human islets in vitro and feeding mice a lowsugar (ketogenic) diet strongly reduced islet miR-125b levels.

Our studies, which used both chemical activation and genetic ablation of AMPK, demonstrate that AMPK mediates glucose regulation of mouse and human islet miR-125b, possibly at the transcriptional level. Nevertheless, the molecular players responsible of miR-125b 
transcriptional regulation remain to be identified and our results do not discard posttranscriptional mechanisms, such as pri-/pre-miRNA processing or mature miR-125b stability, as additional contributors to glucose/AMPK-mediated regulation of miR-125b expression.

Here, we have generated a transgenic model capable of $\beta$-cell selective overexpression of miR-125b. These animals were hyperglycaemic and strongly glucose intolerant and presented a drastic reduction in circulating insulin following a glucose challenge. In a paper published during the preparation of this manuscript, Wei and colleagues ${ }^{40}$ showed that whole-body MIR125B-2 knockout mice on a high-fat diet, but not on a normal diet, develop insulin resistance and glucose intolerance possibly due to the accumulation of epididymal and inguinal white fat. Consequently, these authors suggest the systemic delivery of miR-125b mimics to intervene obesity-related diseases. Nevertheless, insulin secretion or an effect in other metabolic organs was not assessed in these mice, nor were the molecular mechanism(s) underlying the accumulation of adipocytes explored. Additionally, other studies contest whether miR-125b overexpression might be beneficial for adipocyte function $\begin{array}{lll}41 & 42 & 42\end{array}$ Consistent with this view, systemic, non-targeted injection of miR-125b in vivo led to randomfed hyperglycaemia and glucose and insulin intolerance in mice ${ }^{43}$.

The present study provides compelling evidence of a role for miR-125b in controlling insulin secretion, and strongly indicates that non-targeted administration of miR-125b mimics may reach the islet and lead to defective $\beta$-cell function and worsen diabetes. The findings suggest two main causes for the glucose intolerance observed in MIR125B-Tg mice: strong defects in insulin secretion in response to glucose and reduced insulin content of the transgenic islets.

Unlike ATP, cytosolic $\mathrm{Ca}^{2+}$ increases following glucose stimulation were substantially lower in MIR125b-Tg islets though, paradoxically, similar levels of $\mathrm{Ca}^{2+}$ were observed upon membrane depolarization with $\mathrm{KCl}$, even though $\mathrm{KCl}$-stimulated insulin secretion was also strongly impaired. These results point towards defects at different levels on the secretory pathway, as supported by the striking changes in gene expression. First, several $\mathrm{K}_{\mathrm{ATP}}$ independent amplification pathways have been extensively demonstrated to play important 
roles in GSIS $^{44}$. For example, Gooding and colleagues $^{45}$ showed that glucose induces changes in purine pathway intermediates that promote exocytosis in an ATP/ADP ratio independent manner. Accordingly, inhibitors of Inosine-5'-monophosphate dehydrogenase (IMPDH), a rate-limiting enzyme for the production of guanine nucleotides impaired GSIS by reducing S-AMP levels and Sentrin-specific protease 1 (SENP1)-dependent exocytosis. Interestingly, MIR125B-Tg islets displayed a 40\% reduction on Imphd1 mRNA (padj 0.016) as well as lower levels of glutamine synthetase (GS, GLUL), a limiting enzyme for glutamine synthesis the inhibition of which reduced GSIS ${ }^{46}$. Of note, glutamine has been shown to strongly increase $\mathrm{Ca}^{2+}$ influx in the presence of glucose, without changes in ATP content ${ }^{47}$. Secondly, decreased insulin secretion following $\mathrm{KCl}$-mediated membrane depolarization in the absence of reduced intracellular $\mathrm{Ca}^{2+}$ suggests the presence of functional voltage-dependent $\mathrm{Ca}^{2+}$ channels in transgenic islets and points towards defects in the final steps of exocytosis. Further supporting this idea, expression of genes encoding $\mathrm{Ca}^{2+}$ channels was not significantly altered in MIR125B-Tg islets. Whereas TIRF experiments revealed no changes in the kinetics of granule fusion at the plasma membrane, TEM revealed fewer granules in close proximity to the plasma membrane $(<200 \mathrm{~nm})$ in MIR125B-Tg vs Control $\beta$-cells. Regarding the mechanism resulting in reduced granule docking, our RNAseq identified a strong reduction in granuphilin (Syt/4 0,58 fold, p-adj 0.002) which mediates dense core granules docking to the plasma membrane though, paradoxically, works as an inhibitor of insulin exocytosis ${ }^{48}$. Nevertheless, we also observed a significant downregulation of the soluble $\mathrm{N}$-ethyl maleimide sensitive factor associated receptor (SNARE) protein Vamp3 (also known as cellubrevin) and an upregulation of Syt1 (synaptotagmin 1), as well as Syt17 and Syt12. Interplay between these, and potentially other, components of the docking/fusion machinery could contribute to the defective docking and secretion observed in these animals ${ }^{49}$.

Additionally, many $\beta$-cell signature genes were down-regulated in MIR125B-Tg islets whereas neuronal genes were up-regulated. It is important to acknowledge that we cannot exclude the possibility that moderate fed hyperglycaemia in MIR125B-Tg mice indirectly contributes to the 
loss of $\beta$-cell identity ${ }^{36}$. Ebrahimi and colleagues ${ }^{50}$ have recently characterized in detail the changes in gene expression associated with mild and high hyperglycaemia. Most genes associated with $\beta$-cell identity that were downregulated in MIR125B-Tg islets, such as $\beta$-cell transcription factors $(P d x 1, \quad N k x 6.1,|s|)$, islet-associated polypeptide (lapp) and GLUT2/SIc2a2 were also downregulated by hyperglycaemia. Nevertheless, hyperglycaemia also up-regulated genes associated with epithelial-mesenchymal transition, inflammatory response, interleukin-6-Janus kinase (IL6-JaK-Stat3) signalling, apoptosis and several other pathways, none of whose genes were up-regulated in MIR125B-Tg islets. Also, key genes for $\beta$-cell function strongly downregulated by hyperglycaemia such as Kcnj11 (ATP-dependent potassium channel), Abcc8 (sulfonylurea receptor), Gck (glucokinase) and Cacna1a (voltagedependent calcium channel subunits) were not significantly reduced in MIR125B-Tg, suggesting that the mild hyperglycaemia in these mice was not a major contributor to the effects observed in gene expression. It is also worth noting that the expression of the transgene, driven by rtTA under the control of a RIP7 promoter, is expected to occur as early as day (E) 11.5 and it is therefore possible that these defects are residual from impaired maturation rather than loss of identity. Interestingly, we have previously demonstrated that $\beta A M P K d K O$ and $\beta L K B 1$ islets present up-regulation of neuronal genes so it is tempting to hypothesize that increased miR-125b in these islets contribute to this phenotype.

It is worth mentioning that our findings contradict the work published in 2019 by $\mathrm{Yu}$ and colleagues $^{51}$. Whereas both dishevelled binding antagonist of beta catenin 1 (DACT1) mRNA and $\beta$-cell proliferation remained unchanged upon miR-125 manipulation in all our experimental models, $\mathrm{Yu}$ and colleagues claimed miR-125b to have a positive effect on diabetic mouse $\beta$-cells through repressing DACT1 (at the mRNA level) and improving $\beta$-cell proliferation. A plausible explanation is the presence of other pancreatic, highly proliferative cells in the $\beta$-cell samples studied by these authors that observed unexpected doubling times of $\sim 48 \mathrm{~h}$. 
In the present study, we integrated RIP-seq and RNA-seq data ${ }^{17,21}$ of MIN6 cells transfected with control or miR-125 mimics which allowed us to identify dozens of miR-125b targets in an unbiased and high-throughput manner. One of the genes at the top of this list, M6pr, encodes the cation-dependent manose-6-phosphate protein MP6R (CD-M6PR). Even though the function of CD-M6PR has not been studied in $\beta$-cells, this receptor is necessary for adequate lysosomal targeting of several hydrolases, including $\beta$-hexosaminidase, $\beta$-galactosidase, $\beta$ glucuronidase and arylsulfatases ${ }^{52}{ }^{53}$, which were increasingly secreted in M6PR KO animals $^{52}$. Remarkably, both miR-125b-overexpressing cells and MIR125B-Tg islets contained enlarged lysosomes/autophagolysosomes. Importantly, the presence of these structures can represent increased lysosomal function or, most probably, the accumulation of undigested cargos, including autophagic and endocytic substrates. Similar to our MIR125B$\mathrm{Tg}$ islets, Masini et al. ${ }^{54}$, observed enlarged autophagosomes in T2D islet micrographs. Whereas a decrease in macroautophagy has been suggested in both type $1^{55}$ and type $2^{56}$ diabetes, in mouse models of diabetes an early compensatory increase in macroautophagy is followed by compromised autophagy. Also, elimination of essential autophagy genes results in glucose intolerance and reduced insulin in response to HFD-induced diabetes possibly through preventing the formation of amyloid plaques that often appear in T2D ${ }^{57}$. Early studies indicated that chronic high glucose promotes $\beta$-cell autophagy while AMPK negatively regulates autophagy ${ }^{57}$. Whether elevated miR-125b during hyperglycamia/loss of AMPK activity contribute to this process and how, remains to be studied.

Undigested cargoes that cannot be recycled can compromise the whole membrane trafficking system $^{58}$. Importantly, lysosomal, Golgi, endosomal and ER pathways consistently appear on the top of significantly associated pathways with genes dysregulated upon modulation of miR$125 \mathrm{~b}$ activity in both cell lines and mouse and human islets. Moreover, our RIP-RNA-seq experiments identified additional miR-125b targets involved in these processes. For example, PGAP3 encodes a glycophosphatidylinositol (GPI)-specific phospholipase A2 expressed in the Golgi critical for the association of GPI-anchored proteins and lipid rafts ${ }^{59}$ and thus the 
regulation of signalling pathways ${ }^{60}$. Also, VPS29, VPS4B and RAB17 are involved in endosomal function which plays a pivotal and often overlooked role in several aspects of $\beta$ cell function, including receptor trafficking, signalling and/or degradation (i.e. GLP1R ${ }^{61}$, Glut ${ }^{62}$ ) and recycling of calcium channels ${ }^{63}$. Another example is the lysosomal palmitoyl protein thioesterase-2 (PPT2) whose whole-body disruption causes a lysosomal storage disorder and neurodegeneration, though a role in the pancreatic islets has not been investigated ${ }^{64}$.

It is also likely that the defects on the lysosomal/trafficking machinery affect the maturation, packaging and location of the secretory granules within the cell ${ }^{65} 66$ and might contribute to the reduced insulin content and to the crystallization defects observed in the MIR125B-Tg mice. MIR125B-Tg islets contain a 30\% reduction in the zinc transporter Znt8 mRNA ( $p$ 0.007, padj 0.11 ), which may also contribute to defective granule crystallization ${ }^{67}$.

Even though we had identified several genes encoding mitochondrial proteins (i.e. Mtfp1, Tor2a, Taz, Gnpat) as miR-125b targets in MIN6 cells, no mitochondrial defects were detected in the transgenic islets that had similar morphology, DNA content and ATP-increases in response to glucose than control islets. Further supporting a lack of mitochondrial phenotype, GO analysis of genes altered in MIR125B-Tg islets failed to identify enrichment of mitochondria-associated pathways. Nevertheless, 35 significantly downregulated genes (including Gnpat) were annotated to mitochondria, opening the possibility of a compensatory effects.

On the other hand, deletion of miR-125b in EndoC $\beta-\mathrm{H} 1$ cells resulted in a strong alteration of mitochondrial morphology and in the expression of mitochondrial proteins, including the miR125b targets Mtfp 1 and Gnpat. Although this is the first study to identify Gnpat as a miR-125b target, Mtfp1 is targeted by miR-125b in monocytes to promote elongation of the mitochondrial network and apoptosis ${ }^{68}$. GNPAT acts to stabilize DRP169, which is required for mitochondrial fission and which deletion in $\beta$-cells results in elongated mitochondria, reduced mitochondria autophagy and, notably, impaired insulin secretion ${ }^{70},{ }^{72}$. In line with these earlier studies, 
EndoC $\beta-H 1-M I R 125 B 2-K O$ cells contained shorter, more circular mitochondria which correlated with increased GSIS in these cells. It has, however, been contested whether mitochondrial fragmentation promotes apoptosis or correlates with hyperglycaemia or diabetes $^{28}$. For example, prevention of mitochondrial fusion as a result of deletion of mitofusin genes results in secretory deficiencies and hyperglycaemia likely due to increased $\beta$-cell apoptosis ${ }^{71}$. Nevertheless, we did not observe any differences in cellular death or number in EndoCß-H1-MIR125B2-KO (data not shown). Moreover, no differences in Ddit3 (CHOP) mRNA levels were identified in our RNA-seq data, suggesting an absence of mitochondrialinduced ER stress in the KO cells. Future experiments are required to determine whether defective mitochondria generated by excessive fission in EndoC $\beta-\mathrm{H} 1-\mathrm{MIR} 125 \mathrm{~B}-\mathrm{KO}$ cells are efficiently cleared by thanks to a concomitant improvement in lysosomal function and mitophagy, and whether the positive effects of miR-125b elimination in $\beta$-cell function persist under conditions of cellular stress.

In summary, our results suggest that $\beta$-cell miR-125b has the potential to act as a glucoseregulated metabolic switch between the lysosomal system and mitochondria dynamics. Our in vitro and in vivo results strongly indicate that non-targeted administration of miR-125b mimics will lead to defective $\beta$-cell function and worsen diabetes. In contrast, islet-specific inhibition of miR-125b has the potential to improve glycaemic outcomes and limit the deleterious effect of hyperglycamia in $\beta$-cell function. Future studies focussed on cell-specific targeting of miR-125b will be essential to confirm the potential therapeutic benefit of targeting this miRNA for the treatment of diabetes.

\section{METHODS}

\section{Cells and islets culture}

MIN6 cells were cultured in $4.5 \mathrm{~g} / \mathrm{L}$ glucose Dulbecco's modified Eagle's medium (DMEM) containing 15\% FBS, 2mM L-glutamine, 20nM HEPES and $50 \mu \mathrm{M} \beta$-mercaptoethanol. EndoC$\beta \mathrm{H} 1$ cells were cultured in $1 \mathrm{~g} / \mathrm{L}$ glucose DMEM supplemented with $2 \%$ Bovine Serum Albumin 
Fraction V, Fatty Acids Free, $10 \mathrm{mM}$ nicotinamide, $5.5 \mu \mathrm{g} / \mathrm{ml}$ transferrin6.7 $\mathrm{ng} / \mathrm{ml}$ sodium selenite and $50 \mu \mathrm{M}$ 2-mercaptoethanol ${ }^{73}$. Mouse pancreatic islets were isolated with collagenase as described previously ${ }^{74}$ and allowed for recovery from digestion overnight in culture medium (RPMI 1640, 10\% FBS, L-glutamine and 11mM glucose) or directly used for experiments. Human islets were cultured in RPMI 1640, 10\% FBS, L-glutamine and $5.5 \mathrm{mM}$ glucose. The characteristics of the human donors are shown in Sup Table 9. Cells and islets were mantained at $37^{\circ} \mathrm{C}$ with $95 \% \mathrm{O}_{2} / 5 \% \mathrm{CO}_{2}$. AMPK activation was performed with $20 \mathrm{mM}$ compound $13(\mathrm{C} 13)^{75}$ and $50 \mathrm{mM}$ compound $991^{76}$ as indicated in the figure legends.

\section{Plasmids generation}

To generate adenovirus expressing miR-125b, a 426-nucleotide sequence containing premiR-125b was amplified by PCR from C57BL6/J mice genomic DNA with the primers 5'AGGGAGCCAGGATGTAGTCA-3' and 5'-CGGGTCACCTGATCCCATCTA-3' and subcloned into pAdTrackCMV (pAd-MIR125B). Adenovirus were then generated using the AdEasy system ${ }^{77}$. Adenovirus containing the empty vector were used as controls.

As above, the PCR-amplified pre-miR-125b-containing region was subcloned into pBI-LTet to generate pBI-LTet-MIR125B.

For reporter assays, full length Taz, M6pr, Tor2a1, Mtfp1 and Gnpat 3'UTRs and Tnksbp1 and Gnpat CDS were amplified by PCR from MIN6 cDNA and subcloned into pmirGLO (Promega), downstream the Firefly ORF. MiR-125b binding sites in M6pr and Mtfp1 were identified with TargetScan ${ }^{78}$ and three and two point mutations were introduced, respectively, in the sequences complementary to the miR-125b seed using site directed mutagenesis with the primers (mutated ntds in bold): M6PR: 5'-CTCTCCTGCTGGCTACTGGAAGTGTCTGACCC-

3' and 5'-GGGTCAGACACTTCCAGTAGCCAGCAGGAGAG-3'; Mtfp1: 5'GTATTTGGGACACTCTAGGCAGAGTCTCTGG-3' and 5'CCAGAGACTCTGCCTAGAGTGTCCCAAATAC-3'.

All the constructs were verified by sequencing. 


\section{Transfection of miRNA mimics, siRNAs and plasmidic DNA}

Cells were transfected at 60-80\% confluence with $5 \mathrm{nM} / 1 \mathrm{nM}$ (MIN6, EndoC $\beta-\mathrm{H} 1$, respectively) control or miR-125b mimics (Qiagen) or $50 \mathrm{nM}$ of a mixture of four ONTARGETplus siRNAs against mouse Smad2, Smad3 or non-targeting (Horizon Discovery) as previously described ${ }^{9}$, 30. For luciferase assays MIN6 cells were plated at $\sim 70 \%$ confluency in 48 -well plates, and, the following day, transfected with $0.4 \mu$ Lipofectamine 2000 (ThermoFisher Scientific), 5ng plasmid and $5 \mathrm{nM}$ control or miR-125b mimics. After $24 \mathrm{~h}$, cells were lysed and luciferase activity determined with the Dual-Glo luciferase assay system (Promega, UK), following the manufacturer's instructions.

\section{CRISPR-Cas9-mediated deletion of miR-125b in EndoC $\beta-H 1$ cells}

MIR125B-1 and MIR125B-2 sequences were downloaded from miRBase ${ }^{79}$. Using the website tool available at http://crispr.mit.edu/, we designed two independent pair of gRNAs targeting the seed region of the mature $\mathrm{miR}-125 \mathrm{~b}$ and/or the regions in the pri/pre-miR-125b essential for DROSHA and/or DICER processing (Supplemental figure/table 4) as $\mathrm{in}^{80}$. Two different gRNA pairs targeting each locus were subcloned under an $\mathrm{H} 1$ and $\mathrm{U} 6$ promoter within a lentiviral vector in which hSpCas9 expression is driven by a RIP (rat Insulin promoter) using the cloning strategy described in Beucher and Cebola in Nature Protocol exchange (https://protocolexchange.researchsquare.com/article/nprot-7395). EndoC $\beta-\mathrm{H} 1$ cells were transfected with lentivirus expressing these gRNAs and the hSpCas9 and integrating cells were selected by subculture in the presence of $4 \mu \mathrm{g} / \mathrm{ml}$ puromycin, encoded by the vector. Cells infected with lentiviral vectors containing the RIP-hSpCas9 cassette but without gRNAs were used as control. RT-qPCR for mature miR-125b was performed to assess the levels of the mature miR-125b in the resultant cell populations. All the experiments were performed with controls and $\mathrm{KO}$ cell populations generated from at least three independent infections.

\section{Generation and maintenance of transgenic mice}


The cassette expressing miR-125b under the control of a rtTA-inducible promoter, was excised from pBI-LTet-MIR125B and used for pronuclear microinjection of C57BL6/J oocytes at the Centre for Transgenic Models, Basel (http://www.ctm-basel.ch/). A founder was obtained containing one copy of the transgene as determined by qPCR (data not shown) and bred for two generations with C57BL6/J wild-type to ensure unique transgene insertion. The resulting animals were bred with mice expressing the reverse tetracyclin-regulated

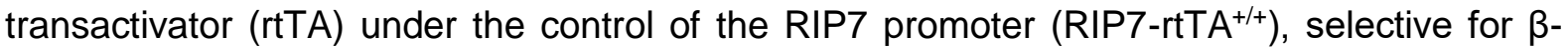
cells. Mice bearing the transgene (MIR125B-Tg: RIP7-rtTA ${ }^{+-}$, MIR125B $\mathrm{Tg}^{+/}$) and controls (Control: RIP7-rtTA ${ }^{+/}$) were born at the expected mendelian ratios (50\% each) and were used in subsequent experiments. Doxycycline $(0.5 \mathrm{~g} / \mathrm{L})$ was continuously administered to these animals and to their parents from the time of mating in the drinking water.

ßAMPKdKO (AMPKa1fl/fl, AMPKa2fl/fl, Ins1-Cre+/-), control (AMPKa1fl/fl, AMPKa2fl/fl, Ins1Cre-/-), $\beta L K B 1 K O$ (LKB1fl/fl, Ins1-Cre+/-) and control (LKB1fl/fl, Ins1-Cre-/-) were previously generated and maintained as in ${ }^{9,14}$.

All animals were granted free access to standard chow diet or, when indicated, ketogenic diet (Ssniff, Germany). All the in vivo procedures were approved by the UK Home Office Animal Scientific Procedures Act, 1986 (Licences PPL 70/7349 and PA03F7F0F to I.L.).

\section{RNA extraction, reverse transcription (RT) and qPCR}

Total RNA was extracted using Trizol (Thermofisher) following manufacturer's instructions. RT-qPCR was performed as previously described ${ }^{9}$ with miRCURY LNA RT and SYBR Green PCR miRNA kits and miRCURY LNA probes for miRNAs (Qiagen) and High-capacity cDNA transcription kit and Fast SYBR Green (Qiagen) for mRNA and pri-miRNAs. For the latter, an anchored oligo dT primer was used in the RT reaction. MiR-7d-3p and miR-573-3p were used as endogenous controls due to their high stability in our system ${ }^{9}$.

\section{MiRISC immunoprecipitation.}


MiRISC-immunoprecipitation was performed as previously described ${ }^{17}$. Briefly, MIN6 cells were seeded in $15 \mathrm{~cm}$ dishes and transfected with $5 \mathrm{nM}$ of control or miR-125b mimic for 24 h. Following transfection cells were washed in cold PBS, scraped in PBS and collected by centrifugation. Pellets were then resuspended in 500 ul of lysis buffer $(20 \mathrm{mM}$ Tris- $\mathrm{HCl} \mathrm{pH} 7.5$, $150 \mathrm{mM} \mathrm{KCl}, 0.5 \% \mathrm{NP} 40,2 \mathrm{mM}$ EDTA, $1 \mathrm{mM} \mathrm{NaF}$, , $160 \mathrm{U} \mathrm{ml}-1 \mathrm{RNAsin}$ and protease inhibitors) and pre-cleared with Dynabeads Protein G beads (Thermo Fisher Scientific) for 2 $\mathrm{h}$ at $4^{\circ} \mathrm{C}$. Precleared extract was incubated with Dynabeads Protein $\mathrm{G}$ beads conjugated with $6 \mu \mathrm{g}$ of mouse-anti-AGO2 (clone E12-1C9, Abnova) or mouse lgG (NXA931, Merck) and $1 \mathrm{mg} / \mathrm{ml}$ of heparin for at $4^{\circ} \mathrm{C}$ for 16 hours with end-over-end rotation. After washing, the beads-

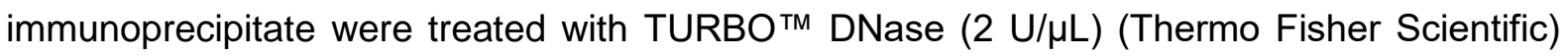
and proteinase $\mathrm{K}(20 \mathrm{mg} / \mathrm{ml})$ (Thermo Fisher Scientific) for $20 \mathrm{~min}$ at room temperature. RNA was extracted using phenol/ chloroform and ethanol/sodium acetate precipitation.

\section{RNA sequencing library preparation, sequencing and analysis}

Quantity and integrity of total RNA from MIN6, EndoC $\beta-\mathrm{H} 1$ and mouse islets was determined with an Agilent Bioanalyzer and mRNA enrichmed was performed from 500-1000ng of RNA using a NEBNext Poly(A) mRNA Magnetic Isolation Kit (NEB). Library preparation from mRNA and from miRISC-isolated RNA was performed using a NEBNext Ultra II Directional RNA Library Prep Kit for Illumina (NEB) and Universal i5 and i7 primers following manufacturer's instructions. Library preparation from human islets total RNA (200ng) was performed using a NEBNext Low Input RNA Library Prep kit (NEB). Sequencing was performed on a HiSeq4000 using 75 bp paired end reads according to Illumina specifications. For total mRNA 25-40 million reads/sample and for miRISC RNA 12 million reads/sample were obtained. FastQC (http://www.bioinformatics.babraham.ac.uk/projects/fastqc/) was used to assess the quality of the reads obtained and reads were then mapped to the mouse or human transcriptome (GRCm38 and GRCh37, respectively) using Salmon v1.3.081. Differential expression analysis was performed with the R package DESeq2 ${ }^{82}$. 
For miRNA target identification, Total mRNA (T-RNA) and immunoprecipitated RNA (RIPRNA) samples were treated as separate datasets and the two resulting gene lists of differential analysis were used to calculate the ratio of immunoprecipitated RNA to total mRNA (IPRNA/T-RNA) for each gene detected in both datasets. Genes were ranked by RIP-RNA/TRNA ratio and subjected to motif discovery and enrichment analysis in their 3'UTRs and CDS with $\mathrm{cWords}^{22}$. Cytoscape ${ }^{83}$ was used to visualize genes with RIP-RNA/T-RNA >1.5 (arbitrary cut-off). Gene set enrichment analysis (GSEA) was performed for genes with a baseMean (average of the normalized count values) $>10$ ranked by fold change in gene expression in human islets infected with pAd-MIR125B or pAd-empty (Control) virus against the curated KEGG gene sets collection from MSigDB (Molecular Signature Database). DAVID ${ }^{25}$ was used for Gene Ontology enrichment analysis of genes differentially dysregulated (padj $<0.1$ ) in MIR125B-Tg islets, EndoC $\beta-H 1$ MIR125B2-KO and in MIN6 cells overexpressing miR-125b.

\section{Immunoblot and Immunohistochemistry}

For Western blotting, whole EndoC $\beta-\mathrm{H} 1$ cells and mouse islets lysates were prepared in RIPA buffer. $5-15 \mu \mathrm{g}$ of EndoC $\beta-\mathrm{H} 1$ total protein extract or 10-20 islets extract was submitted to SDSPAGE electrophoresis and transferred to $0.2 \mu \mathrm{M}$ PVDF membranes. Membranes were incubated o/n with anti-M6PR (sc-365196 Santa Cruz Biotechnology) or anti-Insulin (L6B10, Cell Signalling).

Slides for immunohistochemistry were prepared from isolated pancreata and visualized as previously detailed ${ }^{84}$. For $\beta$-cell mass and proliferation measurements, slides were blotted with the following primary antibodies: anti-insulin (IR00261-2, 1:4; Agilent Techologies) and antiglucagon (g2654, 1:100; Sigma) and/or anti-Ki67 (ab15580, 1:100 Abcam) antibodies and mounted using DAPI-containing Prolong Diamond (Life Technologies). To quantify apoptosis, pancreatic sections were submitted to terminal deoxynucleotidyl transferase dUTP nick-end labeling (TUNEL) assay using a DeadEnd Fluorometric TUNEL system kit (Promega) according to the manufacturer's instructions. Slides were visualized with an Axiovert 200M 
microscope (Zeiss). ImageJ software was used to quantify the area positively stained for insulin and glucagon and the number of Insulin-, Ki67-, TUNEL- and DAPI-positive cells of all visible islets. For $\beta$-cell mass we calculated the percentage of pancreatic surface that was positive, as measured in whole pancreas sections separated by at least $25 \mu \mathrm{m}$ in the z-axis. For $\beta$-to- $\alpha$ cell mass we calculated the ratio of insulin to glucagon positive area in all visible islets.

\section{Electron microscopy}

MIN6 and EndoC $\beta-H 1$ cells grown on Thermanox (Thermofisher Scientific) and whole isolated islets were fixed for 30 minutes or $2 \mathrm{hrs}$, respectively, at room temperature in suspension with $2 \%$ paraformaldehyde (EM grade), $2 \%$ glutaraldehyde, and $3 \mathrm{mM} \mathrm{CaCl} 2$ in $0.1 \mathrm{M}$ cacodylate buffer before post-fixation and embedding for conventional electron microscopy as in Jones et $\mathrm{al}^{85}$. Ultrathin 70 -nm sections were cut using a Leica ultramicrotome prior to examination in a Tecnai Spirit or JEOL 1400 plus transmission electron microscopes. Images at 2000x magnification were subsequently analysed in ImageJ as in Pasquier et al. ${ }^{86}$, with quantifications performed blindly.

Intraperitoneal Glucose and Insulin tolerance tests (IPGG, ITT) and In vivo Insulin secretion

Mice were fasted overnight (IPGTT) or for $5 \mathrm{~h}$ (ITT) prior the administration of $1 \mathrm{~g} / \mathrm{kg}$ body weight (IPGTT) or 1.2U/kg exogenous insulin (NovoRapid, ITT). Blood glucose measurement was recorded at time point 0 (basal glucose) and 15, 30, 60 and 120 minutes post-injection from the tail vein, using an automatic glucometer (Contour). For insulin secretion, mice were fasted overnight and injected with $3 \mathrm{~g} / \mathrm{kg}$ body weight glucose. EDTA coated tubes (Sarsdtedt) were used to collect blood from the tail vein from mice at time 0 (basal glucose) and 15 minutes post-injection. Plasma was separated by centrifugation at $2000 \mathrm{x} g$ for 20 minutes. Insulin levels were measured using an ultra-sensitive mouse insulin enzyme-linked immunosorbent assay (ELISA kit; Crystal Chem, Netherlands). 


\section{Insulin secretion (In vitro):}

15 size-matched islets per condition, in triplicates, were pre-incubated for 1 hour at $370^{\circ} \mathrm{C}$ in a Krebs-Ringer-bicarbonate Hepes (KRBH) solution (140mM NaCl, 3.6mM KCL, 1.5mM CaCl2, 0.5mM MgSO4, 0.5mM Na2PO4, 2mM NaHCO3, 10mM HEPES and 0.1\% [wt/vol] BSA, bubbled with $95 \% \mathrm{O} 2 / 5 \% \mathrm{CO} 2$ for 20 minutes and adjusted to $\mathrm{pH} 7.4$ ) containing 3mM glucose. Islets were subsequently transferred to Eppendorf tubes and sequentially incubated with $3 \mathrm{mM}, 17 \mathrm{mM}$ glucose or $3 \mathrm{mM}$ glucose plus $20 \mathrm{mM} \mathrm{KCl}$ for 30 minutes. Supernatant containing secreted insulin was collected for analysis and whole islets were lysed in 500ul acidified ethanol solution. Secreted insulin and total insulin were quantified using an HTRF insulin kit (Cisbio) in a PHERAstar reader (BMG Labtech, UK) following the manufacturer's guidelines.

Insulin secretion from MIN6 and EndoC $\beta-\mathrm{H} 1$ cells was performed as above with the following modifications: cells were seeded at $70 \%$ confluence $48 \mathrm{~h}$ ahead of the assay and kept at $3 \mathrm{mM}$ glucose overnight before the experiment. Cells were incubated in $\mathrm{KRBH}$ containing $3 \mathrm{mM}$ or $0.5 \mathrm{mM}$ Glucose for $1 \mathrm{~h}$ and stimulated with 17 or $15 \mathrm{mM}$ glucose (MIN6 and EndoC $\beta-\mathrm{H} 1$, respectively) for $1 \mathrm{~h}$ as previously described ${ }^{30,73}$.

\section{Islet fluorescence imaging}

For $\mathrm{Ca}^{2+}$ Imaging, whole isolated islets were incubated with Cal-520 (4.5uM; Stratech) for 45 min at $37^{\circ} \mathrm{C}$ in $\mathrm{KRBH}$ containing $3 \mathrm{mM}$ glucose. For ATP imaging, 48 hours prior to experiment, islets were infected with an adenovirus containing encoding the ATP sensor Perceval ${ }^{87}$. Islets were incubated in $\mathrm{KRBH}$ buffer supplemented with $3 \mathrm{mM}$ glucose for 45 minutes before imaging. Excitation of the probes was achieved using $491 \mathrm{~nm}$ and emitted light was filtered at $525 \mathrm{~nm}$. Islets were kept at $37^{\circ} \mathrm{C}$ and constantly perifused with $\mathrm{KRBH} B$ containing $3 \mathrm{mM}$ or $17 \mathrm{mM}$ glucose or $20 \mathrm{mM} \mathrm{KCl}$. Fluorescence live imaging was performed using a Nipkow spinning disk head and Velocity software (PerkinElmer). Data were analyzed with ImageJ software using an in-house-made macro, available upon request. 
For TIRF experiments, mouse islet were infected with an adenovirus construct for NPY-venus 48 hour prior to the experiments. Before imaging, islets were dissociated using accutase, pelleted, resuspended in normal culture media and left to attach on a glass slide treated with polylysine. After incubation in $\mathrm{KRBH}$ buffer containing $3 \mathrm{mM}$ glucose, slide was mounted in an imaging chamber. Imaging of cells expressing NPY-venus in the secreting vesicle was performed as described previously ${ }^{88}$ using a Nikon Eclipse Ti microscope equipped with a $\times 100 / 1.49$ numerical aperture (NA) TIRF objective, a TIRF iLas2 module to control laser angle (Roper Scientific), and a Quad Band TIRF filter cube (TRF89902, Chroma). Acquisitions were performed using a 488-nm laser line, and images were captured with an ORCA-Flash 4.0 camera (Hamamatsu). Metamorph software (Molecular Devices) was used for data capture, acquisition speed was set at $3 \mathrm{~Hz}$ and the laser angle was selected for an imaged section thickness at the cell membrane of $150-180 \mathrm{~nm} . \mathrm{KCl}$ at $20 \mathrm{mM}$ was used to stimulate insulin secretion and added to the well during acquisition after 3 minutes in $\mathrm{KRBH} 3 \mathrm{mM}$ Glucose. Image analysis was performed using ImageJ to measure mean fluorescence intensity at the cell membrane over time.

For mitochondria morphology analysis MIN6 and EndoC $\beta-\mathrm{H} 1$ cells and dissociated mouse islets cultured in coverslips were pre-incubated for 45 minutes in $\mathrm{KRBH}$ solution supplemented with 25,5 or $11 \mathrm{mM}$ glucose, respectively, and Mitotracker Green ${ }^{\mathrm{TM}}$ (100nM for MIN6 and islets, $70 \mathrm{nM}$ for EndoC $\beta-\mathrm{H} 1$; ThermoFisher) in a $37^{\circ} \mathrm{C}$ humidified incubator with $95 \% \mathrm{O}_{2} / 5 \%$ $\mathrm{CO}_{2}$. Mitotracker green was washed with $\mathrm{KRBH}$ buffer before imaging. Cell images were acquired with a $60 x$ oil immersion objective lens (Olympus) in a Nikon ECLIPSE Ti microscope. Dissociated islets were imaged on a LSM780 inverted confocal microscope (Carl Zeiss, Cambridge, UK) using a $\times 631.4$ numerical aperture (NA) oil objective. Two to three randomly selected fields of view were taken per acquisition, containing 5-15 MIN6/EndoCß$\mathrm{H} 1$ cells or a single dissociated mouse $\beta$-cell. Images were deconvoluted using Huygens software (Scientific Volume Imaging). Mitochondria morphological characteristics (i.e. number, area, elongation, circularity and perimeter) were quantified with ImageJ using an in-house 
macro (available upon request) as described by Wiemerslage et al ${ }^{89}$. Quantifications were performed in z-stacks of 10 images for EndoC- $\beta \mathrm{H} 1$ and MIN6 cells and in three stacks of three images each at the top, middle and bottom of the primary $\beta$-cells.

\section{Mitochondria DNA / Nuclear DNA (mtDNA/nDNA) ratio analysis}

DNA from islets was extracted with SNET buffer (20mM TRIS pH 8.0, 5mM EDTA pH 8.0, $400 \mathrm{mM} \mathrm{NaCl}, 1 \%$ SDS) supplemented with $40 \mathrm{ug} / \mathrm{ml}$ Proteinase K. qPCR was performed with Fast SYBR-Green (Life Technologies) and primers for mitochondrial DNA (Mt9/Mt11 5'GAGCATCTTATCCACGCTTCC-3' and 5'-GGTGGTACTCCCGCTGTAAA-3') and genomic DNA (Cxcl12, 5'-CGGTAGGAGGTTTACAGCATGA-3'

and 5'GGTGTCAGCCACGGTGTATT-3').

\section{Statistical analysis}

Statistical significance was evaluated with GraphPad Prism 9.0 software as indicated in the Figure legends. All data are shown as means \pm SEM. $p<0.05$ was considered statistically significant unless otherwise specified.

\section{AUTHOR CONTRIBUTIONS}

R. Cheung \& G.Pizza (equal contribution) performed most experiments, designed research studies and obtained and analyzed data; P. Chabosseau performed research studies (TIRF) and designed microscopy macros. D. Rolando assisted with computational analysis of RNAseq and RIP-seq data. A. Tomas and T. Burgoyne performed TEM experiments. A. Salowka, A. Macklin and Y. Cao performed research studies ( $\beta$-cell mass and apoptosis and Western blot, respectively). M.-S. Nguyen-Tu assisted with animal studies (In vivo Insulin secretion). P. Marchetti, J.Shapiro, L. Piemonti and E. de Koning, provided human islets. I. Leclerc assisted with maintenance of animal colonies. K. Sakamoto and D. M. Smith provided C13 and C991, respectively. G. A. Rutter contributed to the study design, with reagents and AMPK and LKB1 KO animals, and in writing the manuscript. A. Martinez-Sanchez conceived the study, designed and performed experiments, analyzed data, and wrote the paper; All authors 
read and approved the manuscript. A. Martinez-Sanchez is the guarantor of this work and, as such, had full access to all the data in the study and takes responsibility for the integrity of the data and the accuracy of the data analysis.

\section{ACKNOLEDMENTS \& FUNDING}

The authors thank Stephen M. Rothery from the Facility for Imaging by Light Microscopy (FILM) at Imperial College London for support with confocal and widefield microscopy image acquisition and analysis. A.M-S was supported by an MRC New Investigator Research Grant MR/P023223/1. G.A.R. was supported by a Wellcome Trust Senior Investigator Award (WT098424AIA) and Investigator Award (212625/Z/18/Z) and MRC Programme grants (MR/R022259/1,MR/J0003042/1, MR/L020149/1). A.T was funded by the MRC (MR/R010676/1). IL was supported by a Diabetes UK project grant (16/0005485). This project has received funding from the European Union's Horizon 2020 research and innovation programme via the Innovative Medicines Initiative 2 Joint Undertaking under grant agreement No. 115881 (RHAPSODY) to G.R. and P.M. Human islet preparations (Milan, Italy) were obtained from the European Consortium for Islet Transplantation; the Human Islet Distribution program was supported by Juvenile Diabetes Research Foundation Grant 3-RSC-2016-160I-X.. The authors declare no conflicts of interest

1. Rutter, G. A.; Pullen, T. J.; Hodson, D. J.; Martinez-Sanchez, A., Pancreatic beta cell identity, glucose sensing and the control of insulin secretion. Biochem J, 2015; Vol. 466, pp 202-218.

2. Talchai, C.; Xuan, S.; Lin, H. V.; Sussel, L.; Accili, D., Pancreatic beta cell dedifferentiation as a mechanism of diabetic beta cell failure. Cell 2012, 150 (6), 1223-34.

3. Rahier, J.; Guiot, Y.; Goebbels, R. M.; Sempoux, C.; Henquin, J. C., Pancreatic beta-cell mass in European subjects with type 2 diabetes. Diabetes Obes Metab 2008, 10 Suppl 4, 32-42.

4. Chen, C.; Cohrs, C. M.; Stertmann, J.; Bozsak, R.; Speier, S., Human beta cell mass and function in diabetes: Recent advances in knowledge and technologies to understand disease pathogenesis. Mol Metab 2017, 6 (9), 943-957.

5. Swisa, A.; Glaser, B.; Dor, Y., Metabolic Stress and Compromised Identity of Pancreatic Beta Cells. Front Genet 2017, 8, 21.

6. Sun, K.; Lai, E. C., Adult-specific functions of animal microRNAs. Nat Rev Genet 2013, 14 (8), $535-48$.

7. Martinez-Sanchez, A.; Rutter, G. A.; Latreille, M., MiRNAs in $\beta$-Cell Development, Identity, and Disease. Front Genet 2016, 7, 226. 
8. Sun, Y. M.; Lin, K. Y.; Chen, Y. Q., Diverse functions of miR-125 family in different cell contexts. J Hematol Oncol 2013, 6, 6.

9. Martinez-Sanchez, A.; Nguyen-Tu, M. S.; Cebola, I.; Yavari, A.; Marchetti, P.; Piemonti, L.; de Koning, E.; Shapiro, A. M. J.; Johnson, P.; Sakamoto, K.; Smith, D. M.; Leclerc, I.; Ashrafian, H.; Ferrer, J.; Rutter, G. A., MiR-184 expression is regulated by AMPK in pancreatic islets. FASEB J 2018, $32(5), 2587-2600$.

10. Salt, I. P.; Johnson, G.; Ashcroft, S. J.; Hardie, D. G., AMP-activated protein kinase is activated by low glucose in cell lines derived from pancreatic beta cells, and may regulate insulin release. Biochem J 1998, 335 ( Pt 3), 533-9.

11. Del Guerra, S.; Lupi, R.; Marselli, L.; Masini, M.; Bugliani, M.; Sbrana, S.; Torri, S.; Pollera, M.; Boggi, U.; Mosca, F.; Del Prato, S.; Marchetti, P., Functional and molecular defects of pancreatic islets in human type 2 diabetes. Diabetes 2005, 54 (3), 727-35.

12. Jaafar, R.; Tran, S.; Shah, A. N.; Sun, G.; Valdearcos, M.; Marchetti, P.; Masini, M.; Swisa, A.; Giacometti, S.; Bernal-Mizrachi, E.; Matveyenko, A.; Hebrok, M.; Dor, Y.; Rutter, G. A.; Koliwad, S. K.; Bhushan, A., mTORC1 to AMPK switching underlies $\beta$-cell metabolic plasticity during maturation and diabetes. J Clin Invest 2019, 129 (10), 4124-4137.

13. Yi, S. W.; Park, S.; Lee, Y. H.; Park, H. J.; Balkau, B.; Yi, J. J., Association between fasting glucose and all-cause mortality according to sex and age: a prospective cohort study. Sci Rep 2017, 7 (1), 8194.

14. Kone, M.; Pullen, T. J.; Sun, G.; Ibberson, M.; Martinez-Sanchez, A.; Sayers, S.; Nguyen-Tu, M. S.; Kantor, C.; Swisa, A.; Dor, Y.; Gorman, T.; Ferrer, J.; Thorens, B.; Reimann, F.; Gribble, F.; McGinty, J. A.; Chen, L.; French, P. M.; Birzele, F.; Hildebrandt, T.; Uphues, I.; Rutter, G. A., LKB1 and AMPK differentially regulate pancreatic beta-cell identity. Faseb j 2014, 28 (11), 4972-85.

15. Gulyaeva, L. F.; Kushlinskiy, N. E., Regulatory mechanisms of microRNA expression. J Trans/ Med 2016, 14 (1), 143.

16. de Rie, D.; Abugessaisa, I.; Alam, T.; Arner, E.; Arner, P.; Ashoor, H.; Åström, G.; Babina, M.; Bertin, N.; Burroughs, A. M.; Carlisle, A. J.; Daub, C. O.; Detmar, M.; Deviatiiarov, R.; Fort, A.; Gebhard, C.; Goldowitz, D.; Guhl, S.; Ha, T. J.; Harshbarger, J.; Hasegawa, A.; Hashimoto, K.; Herlyn, M.; Heutink, P.; Hitchens, K. J.; Hon, C. C.; Huang, E.; Ishizu, Y.; Kai, C.; Kasukawa, T.; Klinken, P.; Lassmann, T.; Lecellier, C. H.; Lee, W.; Lizio, M.; Makeev, V.; Mathelier, A.; Medvedeva, Y. A.; Mejhert, N.; Mungall, C. J.; Noma, S.; Ohshima, M.; Okada-Hatakeyama, M.; Persson, H.; Rizzu, P.; Roudnicky, F.; Sætrom, P.; Sato, H.; Severin, J.; Shin, J. W.; Swoboda, R. K.; Tarui, H.; Toyoda, H.; Vitting-Seerup, K.; Winteringham, L.; Yamaguchi, Y.; Yasuzawa, K.; Yoneda, M.; Yumoto, N.; Zabierowski, S.; Zhang, P. G.; Wells, C. A.; Summers, K. M.; Kawaji, H.; Sandelin, A.; Rehli, M.; Hayashizaki, Y.; Carninci, P.; Forrest, A. R. R.; de Hoon, M. J. L.; Consortium, F., An integrated expression atlas of miRNAs and their promoters in human and mouse. Nat Biotechnol 2017, 35 (9), 872-878.

17. Ottaviani, S.; Stebbing, J.; Frampton, A. E.; Zagorac, S.; Krell, J.; de Giorgio, A.; Trabulo, S. M.; Nguyen, V. T. M.; Magnani, L.; Feng, H.; Giovannetti, E.; Funel, N.; Gress, T. M.; Jiao, L. R.; Lombardo, Y.; Lemoine, N. R.; Heeschen, C.; Castellano, L., TGF- $\beta$ induces miR-100 and miR-125b but blocks let-7a through LIN28B controlling PDAC progression. Nat Commun 2018, 9 (1), 1845. 18. Scharfmann, R.; Pechberty, S.; Hazhouz, Y.; von Bülow, M.; Bricout-Neveu, E.; GrenierGodard, M.; Guez, F.; Rachdi, L.; Lohmann, M.; Czernichow, P.; Ravassard, P., Development of a conditionally immortalized human pancreatic $\beta$ cell line. J Clin Invest 2014, 124 (5), 2087-98.

19. Bartel, D. P., MicroRNAs: target recognition and regulatory functions. Cell 2009, 136 (2), 215-

33.

20. Eichhorn, S. W.; Guo, H.; McGeary, S. E.; Rodriguez-Mias, R. A.; Shin, C.; Baek, D.; Hsu, S. H.; Ghoshal, K.; Villén, J.; Bartel, D. P., mRNA destabilization is the dominant effect of mammalian microRNAs by the time substantial repression ensues. Mol Cell 2014, 56 (1), 104-15. 
21. Martinez-Sanchez, A.; Lazzarano, S.; Sharma, E.; Lockstone, H.; Murphy, C. L., HighThroughput Identification of MiR-145 Targets in Human Articular Chondrocytes. Life (Basel) 2020, 10 (5).

22. Rasmussen, S. H.; Jacobsen, A.; Krogh, A., cWords - systematic microRNA regulatory motif discovery from mRNA expression data. Silence 2013, 4 (1), 2.

23. Martinez-Sanchez, A.; Murphy, C. L., MicroRNA Target Identification-Experimental Approaches. Biology (Basel) 2013, 2 (1), 189-205.

24. Zhang, K.; Zhang, X.; Cai, Z.; Zhou, J.; Cao, R.; Zhao, Y.; Chen, Z.; Wang, D.; Ruan, W.; Zhao, Q.; Liu, G.; Xue, Y.; Qin, Y.; Zhou, B.; Wu, L.; Nilsen, T.; Zhou, Y.; Fu, X. D., A novel class of microRNA-recognition elements that function only within open reading frames. Nat Struct Mol Biol 2018, 25 (11), 1019-1027.

25. Huang, d. W.; Sherman, B. T.; Lempicki, R. A., Systematic and integrative analysis of large gene lists using DAVID bioinformatics resources. Nat Protoc 2009, 4 (1), 44-57.

26. Schweizer, A.; Kornfeld, S.; Rohrer, J., Proper sorting of the cation-dependent mannose 6phosphate receptor in endosomes depends on a pair of aromatic amino acids in its cytoplasmic tail. Proc Natl Acad Sci U S A 1997, 94 (26), 14471-6.

27. Tondera, D.; Czauderna, F.; Paulick, K.; Schwarzer, R.; Kaufmann, J.; Santel, A., The mitochondrial protein MTP18 contributes to mitochondrial fission in mammalian cells. J Cell Sci 2005, 118 (Pt 14), 3049-59.

28. Wada, J.; Nakatsuka, A., Mitochondrial Dynamics and Mitochondrial Dysfunction in Diabetes. Acta Med Okayama 2016, 70 (3), 151-8.

29. Licursi, V.; Conte, F.; Fiscon, G.; Paci, P., MIENTURNET: an interactive web tool for microRNA-target enrichment and network-based analysis. BMC Bioinformatics 2019, 20 (1), 545.

30. Martinez-Sanchez, A.; Pullen, T. J.; Chabosseau, P.; Zhang, Q.; Haythorne, E.; Cane, M. C.; Nguyen-Tu, M. S.; Sayers, S. R.; Rutter, G. A., Disallowance of Acot7 in beta-Cells Is Required for Normal Glucose Tolerance and Insulin Secretion. Diabetes 2016, 65 (5), 1268-82.

31. Wicksteed, B.; Brissova, M.; Yan, W.; Opland, D. M.; Plank, J. L.; Reinert, R. B.; Dickson, L. M.; Tamarina, N. A.; Philipson, L. H.; Shostak, A.; Bernal-Mizrachi, E.; Elghazi, L.; Roe, M. W.; Labosky, P. A.; Myers, M. G.; Gannon, M.; Powers, A. C.; Dempsey, P. J., Conditional gene targeting in mouse pancreatic ß-Cells: analysis of ectopic Cre transgene expression in the brain. Diabetes 2010, 59 (12), 3090-8.

32. Tsuboi, T.; Ravier, M. A.; Parton, L. E.; Rutter, G. A., Sustained Exposure to High Glucose Concentrations Modifies Glucose Signaling and the Mechanics of Secretory Vesicle Fusion in Primary Rat Pancreatic -Cells. Diabetes 2006, 55 (4), 1057-1065.

33. Busby, M. A.; Stewart, C.; Miller, C. A.; Grzeda, K. R.; Marth, G. T., Scotty: a web tool for designing RNA-Seq experiments to measure differential gene expression. Bioinformatics 2013, 29 (5), 656-7.

34. Klein, D.; Misawa, R.; Bravo-Egana, V.; Vargas, N.; Rosero, S.; Piroso, J.; Ichii, H.; Umland, O.; Zhijie, J.; Tsinoremas, N.; Ricordi, C.; Inverardi, L.; Domínguez-Bendala, J.; Pastori, R. L., MicroRNA expression in alpha and beta cells of human pancreatic islets. PLoS One 2013, 8 (1), e55064.

35. White, M. G.; Shaw, J. A.; Taylor, R., Type 2 Diabetes: The Pathologic Basis of Reversible $\beta$ Cell Dysfunction. Diabetes Care 2016, 39 (11), 2080-2088.

36. Brereton, M. F.; Rohm, M.; Shimomura, K.; Holland, C.; Tornovsky-Babeay, S.; Dadon, D.; Iberl, M.; Chibalina, M. V.; Lee, S.; Glaser, B.; Dor, Y.; Rorsman, P.; Clark, A.; Ashcroft, F. M., Hyperglycaemia induces metabolic dysfunction and glycogen accumulation in pancreatic $\beta$-cells. Nat Commun 2016, 7, 13496.

37. Satake, E.; Pezzolesi, M. G.; Md Dom, Z. I.; Smiles, A. M.; Niewczas, M. A.; Krolewski, A. S., Circulating miRNA Profiles Associated With Hyperglycemia in Patients With Type 1 Diabetes.

Diabetes 2018, 67 (5), 1013-1023. 
38. de Candia, P.; Spinetti, G.; Specchia, C.; Sangalli, E.; La Sala, L.; Uccellatore, A.; Lupini, S.; Genovese, S.; Matarese, G.; Ceriello, A., A unique plasma microRNA profile defines type 2 diabetes progression. PLoS One 2017, 12 (12), e0188980.

39. Lamadrid-Romero, M.; Solís, K. H.; Cruz-Reséndiz, M. S.; Pérez, J. E.; Díaz, N. F.; FloresHerrera, H.; García-López, G.; Perichart, O.; Reyes-Muñoz, E.; Arenas-Huertero, F.; Eguía-Aguilar, P.; Molina-Hernández, A., Central nervous system development-related microRNAs levels increase in the serum of gestational diabetic women during the first trimester of pregnancy. Neurosci Res 2018, 130, 8-22.

40. Wei, L. M.; Sun, R. P.; Dong, T.; Liu, J.; Chen, T.; Zeng, B.; Wu, J. H.; Luo, J. Y.; Sun, J. J.; Xi, Q. Y.; Zhang, Y. L., MiR-125b-2 knockout increases high-fat diet-induced fat accumulation and insulin resistance. Sci Rep 2020, 10 (1), 21969.

41. Strycharz, J.; Wróblewski, A.; Zieleniak, A.; Świderska, E.; Matyjas, T.; Rucińska, M.; Pomorski, L.; Czarny, P.; Szemraj, J.; Drzewoski, J.; Śliwińska, A., Visceral Adipose Tissue of Prediabetic and Diabetic Females Shares a Set of Similarly Upregulated microRNAs Functionally Annotated to Inflammation, Oxidative Stress and Insulin Signaling. Antioxidants (Basel) 2021, 10 (1).

42. Giroud, M.; Pisani, D. F.; Karbiener, M.; Barquissau, V.; Ghandour, R. A.; Tews, D.; FischerPosovszky, P.; Chambard, J. C.; Knippschild, U.; Niemi, T.; Taittonen, M.; Nuutila, P.; Wabitsch, M.; Herzig, S.; Virtanen, K. A.; Langin, D.; Scheideler, M.; Amri, E. Z., miR-125b affects mitochondrial biogenesis and impairs brite adipocyte formation and function. Mol Metab 2016, 5 (8), 615-625.

43. Du, X.; Li, X.; Chen, L.; Zhang, M.; Lei, L.; Gao, W.; Shi, Z.; Dong, Y.; Wang, Z.; Liu, G., Hepatic miR-125b inhibits insulin signaling pathway by targeting PIK3CD. J Cell Physiol 2018, 233 (8), 6052-6066.

44. Kalwat, M. A.; Cobb, M. H., Mechanisms of the amplifying pathway of insulin secretion in the $\beta$ cell. Pharmacol Ther 2017, 179, 17-30.

45. Gooding, J. R.; Jensen, M. V.; Dai, X.; Wenner, B. R.; Lu, D.; Arumugam, R.; Ferdaoussi, M.; MacDonald, P. E.; Newgard, C. B., Adenylosuccinate Is an Insulin Secretagogue Derived from Glucose-Induced Purine Metabolism. Cell Rep 2015, 13 (1), 157-167.

46. Li, C.; Buettger, C.; Kwagh, J.; Matter, A.; Daikhin, Y.; Nissim, I. B.; Collins, H. W.; Yudkoff, M.; Stanley, C. A.; Matschinsky, F. M., A signaling role of glutamine in insulin secretion. J Biol Chem 2004, 279 (14), 13393-401.

47. Han, G.; Takahashi, H.; Murao, N.; Gheni, G.; Yokoi, N.; Hamamoto, Y.; Asahara, S. I.; Seino, Y.; Kido, Y.; Seino, S., Glutamate is an essential mediator in glutamine-amplified insulin secretion. J Diabetes Investig 2021.

48. Kato, T.; Shimano, H.; Yamamoto, T.; Yokoo, T.; Endo, Y.; Ishikawa, M.; Matsuzaka, T.; Nakagawa, Y.; Kumadaki, S.; Yahagi, N.; Takahashi, A.; Sone, H.; Suzuki, H.; Toyoshima, H.; Hasty, A. H.; Takahashi, S.; Gomi, H.; Izumi, T.; Yamada, N., Granuphilin is activated by SREBP-1c and involved in impaired insulin secretion in diabetic mice. Cell Metab 2006, 4 (2), 143-54.

49. Kreutzberger, A. J. B.; Kiessling, V.; Doyle, C. A.; Schenk, N.; Upchurch, C. M.; Elmer-Dixon, M.; Ward, A. E.; Preobraschenski, J.; Hussein, S. S.; Tomaka, W.; Seelheim, P.; Kattan, I.; Harris, M.; Liang, B.; Kenworthy, A. K.; Desai, B. N.; Leitinger, N.; Anantharam, A.; Castle, J. D.; Tamm, L. K., Distinct insulin granule subpopulations implicated in the secretory pathology of diabetes types 1 and 2. Elife 2020, 9.

50. Ebrahimi, A. G.; Hollister-Lock, J.; Sullivan, B. A.; Tsuchida, R.; Bonner-Weir, S.; Weir, G. C., Beta cell identity changes with mild hyperglycemia: Implications for function, growth, and vulnerability. Mol Metab 2020, 35, 100959.

51. Yu, C. Y.; Yang, C. Y.; Rui, Z. L., MicroRNA-125b-5p improves pancreatic $\beta$-cell function through inhibiting JNK signaling pathway by targeting DACT1 in mice with type 2 diabetes mellitus. Life Sci 2019, 224, 67-75.

52. Ludwig, T.; Ovitt, C. E.; Bauer, U.; Hollinshead, M.; Remmler, J.; Lobel, P.; Rüther, U.; Hoflack, B., Targeted disruption of the mouse cation-dependent mannose 6-phosphate receptor results in partial missorting of multiple lysosomal enzymes. EMBO J 1993, 12 (13), 5225-35. 
53. Baldwin, A. C.; Naatz, A.; Bohnsack, R. N.; Bartosiak, J. T.; Oleson, B. J.; Hansen, P. A.; Dahms, N. M.; Corbett, J. A., Cation-Independent Mannose 6-Phosphate Receptor Deficiency Enhances $\beta$-Cell Susceptibility to Palmitate. Mol Cell Biol 2018, 38 (8).

54. Masini, M.; Bugliani, M.; Lupi, R.; del Guerra, S.; Boggi, U.; Filipponi, F.; Marselli, L.; Masiello, P.; Marchetti, P., Autophagy in human type 2 diabetes pancreatic beta cells. Diabetologia 2009, 52 (6), 1083-6.

55. Muralidharan, C.; Conteh, A. M.; Marasco, M. R.; Crowder, J. J.; Kuipers, J.; de Boer, P.; Linnemann, A. K., Pancreatic beta cell autophagy is impaired in type 1 diabetes. Diabetologia 2021, 64 (4), 865-877.

56. Mizukami, H.; Takahashi, K.; Inaba, W.; Tsuboi, K.; Osonoi, S.; Yoshida, T.; Yagihashi, S., Involvement of oxidative stress-induced DNA damage, endoplasmic reticulum stress, and autophagy deficits in the decline of $\beta$-cell mass in Japanese type 2 diabetic patients. Diabetes Care 2014, 37 (7), 1966-74.

57. Mészáros, G.; Pasquier, A.; Vivot, K.; Goginashvili, A.; Ricci, R., Lysosomes in nutrient signalling: A focus on pancreatic $\beta$-cells. Diabetes Obes Metab 2018, 20 Supp/ 2, 104-115.

58. Xu, H.; Ren, D., Lysosomal physiology. Annu Rev Physiol 2015, 77, 57-80.

59. Muñiz, M.; Riezman, H., Trafficking of glycosylphosphatidylinositol anchored proteins from the endoplasmic reticulum to the cell surface. J Lipid Res 2016, 57 (3), 352-60.

60. Manea, E., A step closer in defining glycosylphosphatidylinositol anchored proteins role in health and glycosylation disorders. Mol Genet Metab Rep 2018, 16, 67-75.

61. Fang, Z.; Chen, S.; Manchanda, Y.; Bitsi, S.; Pickford, P.; David, A.; Shchepinova, M. M.; Corrêa, I. R.; Hodson, D. J.; Broichhagen, J.; Tate, E. W.; Reimann, F.; Salem, V.; Rutter, G. A.; Tan, T.; Bloom, S. R.; Tomas, A.; Jones, B., Ligand-Specific Factors Influencing GLP-1 Receptor PostEndocytic Trafficking and Degradation in Pancreatic Beta Cells. Int J Mol Sci 2020, 21 (21).

62. Ding, L.; Han, L.; Dube, J.; Billadeau, D. D., WASH Regulates Glucose Homeostasis by Facilitating Glut2 Receptor Recycling in Pancreatic $\beta$-Cells. Diabetes 2019, 68 (2), 377-386.

63. Ye, Y.; Barghouth, M.; Luan, C.; Kazim, A.; Zhou, Y.; Eliasson, L.; Zhang, E.; Hansson, O.; Thevenin, T.; Renström, E., The TCF7L2-dependent high-voltage activated calcium channel subunit $\alpha 2 \delta-1$ controls calcium signaling in rodent pancreatic beta-cells. Mol Cell Endocrinol 2020, 502, 110673.

64. Gupta, P.; Soyombo, A. A.; Shelton, J. M.; Wilkofsky, I. G.; Wisniewski, K. E.; Richardson, J. A.; Hofmann, S. L., Disruption of PPT2 in mice causes an unusual lysosomal storage disorder with neurovisceral features. Proc Natl Acad Sci U S A 2003, 100 (21), 12325-30.

65. Omar-Hmeadi, M.; Idevall-Hagren, O., Insulin granule biogenesis and exocytosis. Cell Mol Life Sci 2020.

66. Arvan, P.; Halban, P. A., Sorting ourselves out: seeking consensus on trafficking in the betacell. Traffic 2004, 5 (1), 53-61.

67. Mitchell, R. K.; Hu, M.; Chabosseau, P. L.; Cane, M. C.; Meur, G.; Bellomo, E. A.; Carzaniga, R.; Collinson, L. M.; Li, W.-H.; Hodson, D. J.; Rutter, G. A., Molecular Genetic Regulation ofSIc30a8/ZnT8 Reveals a Positive Association With Glucose Tolerance.

68. Duroux-Richard, I.; Roubert, C.; Ammari, M.; Présumey, J.; Grün, J. R.; Häupl, T.; Grützkau, A.; Lecellier, C. H.; Boitez, V.; Codogno, P.; Escoubet, J.; Pers, Y. M.; Jorgensen, C.; Apparailly, F., miR-125b controls monocyte adaptation to inflammation through mitochondrial metabolism and dynamics. Blood 2016, 128 (26), 3125-3136.

69. Gu, L.; Zhu, Y.; Lin, X.; Li, Y.; Cui, K.; Prochownik, E. V., Amplification of Glyceronephosphate O-Acyltransferase and Recruitment of USP30 Stabilize DRP1 to Promote Hepatocarcinogenesis. Cancer Res 2018, 78 (20), 5808-5819.

70. Hennings, T. G.; Chopra, D. G.; Deleon, E. R.; VanDeusen, H. R.; Sesaki, H.; Merrins, M. J.; Ku, G. M., In Vivo Deletion of $\beta$-Cell Drp1 Impairs Insulin Secretion Without Affecting Islet Oxygen Consumption. Endocrinology 2018, 159 (9), 3245-3256. 
71. Georgiadou, E.; Muralidharan, C.; Martinez, M.; Chabosseau, P.; Tomas, A.; Su Wern, F. Y.; Stylianides, T.; Rothery, S. M.; Di Gregorio, A.; Leclerc, I.; Ali, Y.; Linnemann, A. K.; Rodriguez, T. A.; Rutter, G. A., Pancreatic beta cell selective deletion of mitofusins 1 and $2(<e m>M f n 1</ e m>$ and $<\mathrm{em}>\mathrm{Mfn} 2</ \mathrm{em}>$ ) disrupts mitochondrial architecture and abrogates glucose-stimulated insulin secretion <em>in vivo</em>. bioRxiv 2020, 2020.04.22.055384.

72. Twig, G.; Elorza, A.; Molina, A. J.; Mohamed, H.; Wikstrom, J. D.; Walzer, G.; Stiles, L.; Haigh, S. E.; Katz, S.; Las, G.; Alroy, J.; Wu, M.; Py, B. F.; Yuan, J.; Deeney, J. T.; Corkey, B. E.; Shirihai, O. S., Fission and selective fusion govern mitochondrial segregation and elimination by autophagy. EMBO J 2008, 27 (2), 433-46.

73. Ravassard, P.; Hazhouz, Y.; Pechberty, S.; Bricout-Neveu, E.; Armanet, M.; Czernichow, P.; Scharfmann, R., A genetically engineered human pancreatic $\beta$ cell line exhibiting glucose-inducible insulin secretion. J Clin Invest 2011, 121 (9), 3589-97.

74. Martinez-Sanchez, A.; Nguyen-Tu, M. S.; Leclerc, I.; Rutter, G. A., Manipulation and Measurement of AMPK Activity in Pancreatic Islets. Methods Mol Biol 2018, 1732, 413-431.

75. Hunter, R. W.; Foretz, M.; Bultot, L.; Fullerton, M. D.; Deak, M.; Ross, F. A.; Hawley, S. A.; Shpiro, N.; Viollet, B.; Barron, D.; Kemp, B. E.; Steinberg, G. R.; Hardie, D. G.; Sakamoto, K., Mechanism of action of compound-13: an $\alpha 1$-selective small molecule activator of AMPK. Chem Biol 2014, 21 (7), 866-79.

76. Xiao, B.; Sanders, M. J.; Carmena, D.; Bright, N. J.; Haire, L. F.; Underwood, E.; Patel, B. R.; Heath, R. B.; Walker, P. A.; Hallen, S.; Giordanetto, F.; Martin, S. R.; Carling, D.; Gamblin, S. J., Structural basis of AMPK regulation by small molecule activators. Nat Commun 2013, 4, 3017.

77. Luo, J.; Deng, Z. L.; Luo, X.; Tang, N.; Song, W. X.; Chen, J.; Sharff, K. A.; Luu, H. H.; Haydon, R. C.; Kinzler, K. W.; Vogelstein, B.; He, T. C., A protocol for rapid generation of recombinant adenoviruses using the AdEasy system. Nat Protoc 2007, 2 (5), 1236-47.

78. Agarwal, V.; Bell, G. W.; Nam, J. W.; Bartel, D. P., Predicting effective microRNA target sites in mammalian mRNAs. Elife 2015, 4.

79. Kozomara, A.; Griffiths-Jones, S., miRBase: annotating high confidence microRNAs using deep sequencing data. Nucleic Acids Res 2014, 42 (Database issue), D68-73.

80. Chang, H.; Yi, B.; Ma, R.; Zhang, X.; Zhao, H.; Xi, Y., CRISPR/cas9, a novel genomic tool to knock down microRNA in vitro and in vivo. Sci Rep 2016, 6, 22312.

81. Patro, R.; Duggal, G.; Love, M. I.; Irizarry, R. A.; Kingsford, C., Salmon provides fast and biasaware quantification of transcript expression. Nat Methods 2017, 14 (4), 417-419.

82. Love, M. I.; Huber, W.; Anders, S., Moderated estimation of fold change and dispersion for RNA-seq data with DESeq2. Genome Biol 2014, 15 (12), 550.

83. Shannon, P.; Markiel, A.; Ozier, O.; Baliga, N. S.; Wang, J. T.; Ramage, D.; Amin, N.; Schwikowski, B.; Ideker, T., Cytoscape: a software environment for integrated models of biomolecular interaction networks. Genome Res 2003, 13 (11), 2498-504.

84. Martinez-Sanchez, A.; Nguyen-Tu, M. S.; Rutter, G. A., DICER Inactivation Identifies Pancreatic beta-Cell "Disallowed" Genes Targeted by MicroRNAs. Mol Endocrinol 2015, 29 (7), 106779.

85. Jones, B.; Buenaventura, T.; Kanda, N.; Chabosseau, P.; Owen, B. M.; Scott, R.; Goldin, R.; Angkathunyakul, N.; Corrêa, I. R.; Bosco, D.; Johnson, P. R.; Piemonti, L.; Marchetti, P.; Shapiro, A. M. J.; Cochran, B. J.; Hanyaloglu, A. C.; Inoue, A.; Tan, T.; Rutter, G. A.; Tomas, A.; Bloom, S. R., Targeting GLP-1 receptor trafficking to improve agonist efficacy. Nat Commun 2018, 9 (1), 1602.

86. Pasquier, A.; Vivot, K.; Erbs, E.; Spiegelhalter, C.; Zhang, Z.; Aubert, V.; Liu, Z.; Senkara, M.; Maillard, E.; Pinget, M.; Kerr-Conte, J.; Pattou, F.; Marciniak, G.; Ganzhorn, A.; Ronchi, P.; Schieber, N. L.; Schwab, Y.; Saftig, P.; Goginashvili, A.; Ricci, R., Lysosomal degradation of newly formed insulin granules contributes to $\beta$ cell failure in diabetes. Nat Commun 2019, 10 (1), 3312. 87. Ravier, M. A.; Rutter, G. A., Isolation and culture of mouse pancreatic islets for ex vivo imaging studies with trappable or recombinant fluorescent probes. Methods $\mathrm{Mol}$ Biol 2010, 633, 171-84. 
88. Mitchell, R. K.; Nguyen-Tu, M. S.; Chabosseau, P.; Callingham, R. M.; Pullen, T. J.; Cheung, R.; Leclerc, I.; Hodson, D. J.; Rutter, G. A., The transcription factor. J Biol Chem 2017, 292 (21), 88928906.

89. Wiemerslage, L.; Lee, D., Quantification of mitochondrial morphology in neurites of dopaminergic neurons using multiple parameters. J Neurosci Methods 2016, 262, 56-65.

90. Martinez-Sanchez, A.; Nguyen-Tu, M.-S.; Cebola, I.; Yavari, A.; Marchetti, P.; Piemonti, L.; de Koning, E.; Shapiro, A. M. J.; Johnson, P.; Sakamoto, K.; Smith, D. M.; Leclerc, I.; Ashrafian, H.; Ferrer, J.; Rutter, G. A., MiR-184 expression is regulated by AMPK in pancreatic islets.

91. Lu, T. T.; Heyne, S.; Dror, E.; Casas, E.; Leonhardt, L.; Boenke, T.; Yang, C. H.; Sagar; Arrigoni, L.; Dalgaard, K.; Teperino, R.; Enders, L.; Selvaraj, M.; Ruf, M.; Raja, S. J.; Xie, H.; Boenisch, U.; Orkin, S. H.; Lynn, F. C.; Hoffman, B. G.; Grün, D.; Vavouri, T.; Lempradl, A. M.; Pospisilik, J. A., The Polycomb-Dependent Epigenome Controls $\beta$ Cell Dysfunction, Dedifferentiation, and Diabetes. Cell Metab 2018, 27 (6), 1294-1308.e7.

\section{FIGURE LEGENDS}

Figure 1. Glucose stimulates islet miR-125b expression via AMPK repression. RT-qPCR measurements of a-e, MiR-125b in a, mouse and human islets cultured at the indicated glucose concentrations for $48 \mathrm{~h}$ (b) human islets kept for $24 \mathrm{~h}$ at $5.5 \mathrm{mM}$ glucose plotted agains donor's BMI, (c) islets from $\beta A M P K d K O$ (green) and control $(\mathrm{C}$, black) mice cultured at 5.5 or $25 \mathrm{mM}$ Glucose for $48 \mathrm{~h}$, (d) islets from $\beta A M P K d K O$ (green), $\beta$ LKB1KO (red) and control (C, black) male and female mice fed a chow or a ketogenic (Keto) diet for 28 days and (e) human islets treated with the AMPK activators C-13 and C-991 for 24h. f, Pri-miR-125b in isolated islets from BAMPKdKO (green) and littermate control (C, black) mice. Each dot represents islets from a single mouse or human donor. MiR-125b expression is normalized to that of the endogenous control miR- $7 d-3 p^{90}$. ns $=$ no significant, ${ }^{*} p<0.05$, ${ }^{* *} p<0.01$, ${ }^{* *} p<0.001$, oneway ANOVA (repeated measures) and Dunnet multiple comparisons test (a), Pearson Correlation (b), two-way ANOVA (repeated measures) and Bonferroni multiple comparisons test (c), Student $t$ test (d-f).

Figure 2. MiR-125b regulates insulin secretion in insulinoma/ $\beta$-cell lines. Insulin content and Glucose-stimulated insulin secretion after 30 minutes of 17 or $15 \mathrm{mM}$ glucose stimulation following overnight preincubation at $3 \mathrm{mM}$ glucose. Data is presented as fold change of basal level. Each dot represent an independent experiment with three technical replicates. a, MIN6 cells were transfected with $5 \mathrm{nM}$ miR-125b or control mimics $48 \mathrm{~h}$ before the experiment. $\mathbf{b}$, 
Experiments were performed with three different populations of CRISPR-mediated miR-125b $\mathrm{KO}$ and control cells. ${ }^{*} p<0.05$, paired Student t test.

Figure 3. High-through identification of miR-125b target genes. a, Schematic overview of the steps of the experimental approach used for the identification of miR-125b targets. MIN6 cells were transfected with control of miR-125b mimics. Then, total RNA was extracted, poly $(A)$-enriched and prepared for sequencing $(n=5, T-R N A)$ or RNAs present in miRISC complexes were inmunoprecipitated with anti ago2-antibodies and submitted to RNA-seq ( $n=5$, RIP-RNA). Differential analysis of gene expression was performed for both datasets separately generating fold change gene expression (miR-125b vs control) for all genes detected. Then both lists were combined to generate a ratio of Immunoprecipitated vs Total (poly(A) RNA). b, Enrichment of miR-125b seed sites in the 3'UTRs (left hand-side panel) and CDSs (right hand-side panel) of the mRNAs ranked according to RIP-RNA/T-RNA. The scatter plot shows the maxima of enrichment profile. Each dot represents a 7-letter word. The Yposition shows the maximum score of an enriched word and the X-position shows the geneindex where the Z-score is maximum. Top-ranked words with a left-shift associate with geneexpression change (lower gene index represents a stronger upregulation in RIP-RNA/T-RNA upon miR-125b transfection). The sequence of mature miR-125b is shown on the right, with the seed region in red. The reverse complementary sequence $(R C)$ is also shown in red. c) Cytoscape-generated layout of genes with RIP-RNA/T-RNA ratio > 1.5 upon miR-125b overexpression. Node size represents the extent of the RIP-RNA/T-RNA ratio (the larger, the higher). The intensity of the gene node colour indicates the fold downregulation of each gene upon miR-125b expression (T-RNA). Downregulation at the transcript level was statistically significant for those genes represented in an octagonal shape. Lines connecting the nodes/genes with miR-125b indicate the presence of a predicted binding site for miR-125b as identified by TargetScan, with the intensity in the colour of the line representing the score (Total context score). 
Figure 4. MiR-125b targets genes encoding mitochondrial and lysosomal proteins. a, Validation of miR-125b binding to the regions (full-length CDS or 3'UTR, as indicated) containing predicted miR-125b binding sites of six identified targets with highest RIP-RNA/TRNA. Luciferase reporter assay of MIN6 cells cotransfected with pmirGLO plasmids containing the indicated target downstream the luciferase ORF and miR-125b (+) or non-targeting (-) control mimics. Samples were measured $24 \mathrm{~h}$ after transfection in technical replicates. Firefly luciferase values are normalised to Renilla's, independently expressed by the same vector and are shown as relative to that obtained for each construct cotransfected with the control miRNA mimic. Each dot represents and independent experiment. A construct containing three perfectly complementary binding sites for miR-125b (positive control) and the empty pmiRGlo vector (negative control) were included in the experiments. b, Gene Ontology enrichment analysis of the genes significanty up- and down-regulated upon miR-125b overexpression (TRNA) and putative miR-125b direct targets (RIP-RNA/T-RNA > 1.5) performed with DAVID. The graph shows enrichment scores for one representative term for each cluster grouped by semantic similarities and including terms with a padj (Benjamini) $<0.05$. See Supp Table 2 for a full list of terms. ${ }^{*} p<0.05,{ }^{* * *} p<0.001,{ }^{* * *} p<0.0001$, Student $t$ test values of the log[fold change] values.

Figure 5. MiR-125b represses M6PR and alters lysosomal morphology. a, MIN6 cells were transfected with luciferase reporters containing the M6pr 3'UTR with (mutated, MUT) or without (wild-type, WT) three point mutations in the sequence complementary to the miR-125b seed. Control (-) or miR-125b (+) mimics were co-transfected and Firefly luciferase values normalized to Renilla's. Each dot represents and independent experiment. b, Representative Western blot showing reduced (left-hand side panel) and increased (right hand-side panel) M6PR protein levels upon miR-125b overexpression or CRISPR-Cas9-mediated deletion of miR-125b in EndoC $\beta-H 1$ cells, respectively. Bar graphs show densitometry quantification of M6PR, using ImageJ, normalized by tubulin and presented relative to the control. c, Left handside panel: RT-qPCR measurement of M6PR mRNA in EndoC $\beta-\mathrm{H} 1$ cells transfected with 
control $(\mathrm{C})$ or miR-125b (125b) mimics, normalized by the housekeeping gene Ppia and presented as fold change of the control. Right hand-side panel: Normalized (Reads per Kilobase of transcript, per Million mapped reads (RPKM)) M6PR reads in Control vs MIR125B2-KO (KO) EndoC $\beta-H 1$ cells. d, Representative Transmission Electron Microscopy image of MIN6 cells transfected for 48h with control $(\mathrm{C})$ or miR-125b (125B) mimics. Red arrows show enlarged lysosomal structures. Scale bar $=1 \mu \mathrm{m}$. These were not observed in any of the imaged controls ( $n=3$ independent experiments). ${ }^{*} p<0.05,{ }^{* * *} p<0.001$, ${ }^{* * * *} p<0.0001$, Student $t$ test of the log[fold change] values.

Figure 6. MiR-125b represses MTFP1 and alters mitochondria morphology. a, MIN6 cells were transfected with luciferase reporters containing the Mtfp1 3'UTR with (mutated, MUT) or without (wild-type, WT) two point mutations in the sequence complementary to the miR-125b seed. Control (-) or miR-125b (+) mimics were co-transfected and Firefly luciferase values normalized to Renilla's. Each dot represents and independent experiment. b,c, Quantitative analysis of mitochondria number and morphology on deconvoluted confocal images of (B) MIN6 cells transfected with miR-125b (red) or control (black) mimics or (C) EndoC $\beta-\mathrm{H} 1$ with CRISPR/Cas9-mediated miR-125b deletion (green) or controls (black). Cells were stained with Mitotracker green. An ImageJ macro was generated and used to quantify number of mitochondria per cell, total mitochondria area, individual mitochondria length (elongation), circularity (0:elongated; 1 :circular) and perimeter. Each dot represents one acquisition ( $n=3$ (B), $n=4(C)$ independent experiments). Lower panels show representative confocal images of the mitochondrial network of EndoC $\beta-\mathrm{H} 1-\mathrm{MIR} 125 \mathrm{~B} 2-\mathrm{KO}$ and control cells. Scale bar: 10 $\mu \mathrm{m} .{ }^{*} p<0.05,{ }^{* *} \mathrm{p}<0.01,{ }^{* * *} \mathrm{p}<0.001,{ }^{* * * *} \mathrm{p}<0.0001$, Student $\mathrm{t}$ test values of the log[fold change] values (a); Student t test (b, c).

Figure 7. Mice with $\beta$-cell-selective overexpression of miR-125b are glucose intolerant and present impaired glucose stimulated insulin secretion. a, MiR-125b RT-qPCR in isolated islets from Control (RIP7-rtTA $\left.{ }^{+/}\right)$and MIR125B-Tg mice (RIP7-rtTA ${ }^{+-}$, MIR125B Tg ${ }^{+/-}$ ). Data are fold change vs Control. b, Glycaemia in 5 and 9 week old Control and MiR125B- 
Tg mice fed ad libitum. For A and B, each dot represents a single mouse. c, d, Glucose tolerance test in 6 and 10 week old MIR125B-Tg and littermate control male (C) and female (D) mice. $\mathrm{n}=7-8 \mathrm{C}, 5-7 \mathrm{Tg}$. e, Glucose (3 g/kg)-induced insulin secretion assessed in 10 week old MIR125B-Tg and littermate controls ( $n=13 \mathrm{C}, 11 \mathrm{Tg})$. f, Pancreata from MIR125B-Tg and littermate controls were fixed and subjected to immunocytochemical analysis for insulin and glucagon. $\beta$ - and $\alpha$-cell masses are presented as the $\beta$-cell/ $\alpha$-cell ratio and correspond to quantification of insulin-positive area/glucagon positive area ratio (left-hand side panel). $\beta$-Cell mass is presented as a percentage of the pancreatic surface and corresponds to quantification of the insulin-positive area per pancreas area quantified in whole pancreas sections. Each dot represents one pancreatic section with $\mathrm{n}=3$ mice/genotype. ${ }^{*} p<0.05,{ }^{* *} p<0.01,{ }^{* * *} p<0.001$, ${ }^{* \star *} \mathrm{p}<0.0001$, Student $t$ test $(\mathrm{a}, \mathrm{b}, \mathrm{f})$; two-way ANOVA (repeated-measures), Fisher least significance different test (c-e).

Figure 8. MIR125B-Tg islets contain and secrete less insulin than controls. a, Insulin secretion in response to 30 minutes low (3mM, LG) or high (17mM, HG) glucose or $\mathrm{KCl}(17 \mathrm{mM}$ $\mathrm{KCl}$ and 3mM Glucose) in islets from 10-11 week old Control (RIP7-rtTA ${ }^{+-}$) and MIR125B-Tg (RIP7-rtTA ${ }^{+-}, \mathrm{MIR}^{2} 25 \mathrm{~B} \mathrm{Tg}^{+-}$) mice (left hand-side panel). The right hand-side panel shows fold induction vs low glucose. b,c, Insulin and pro-insulin content in 10 week old Control (C) and MIR125B-Tg (Tg) mice quantified by $\operatorname{HTRF}(\mathrm{B})$ and Western blot (WB, C). A representative $\mathrm{WB}$ is shown with islets from $3 \mathrm{C}$ and $3 \mathrm{Tg}$ animals. Bar graphs show densitometry quantification of insulin and pro-insulin, using ImageJ, normalized by GAPDH and presented relative to the average control. d) ATP rises in response to high glucose $(17 \mathrm{mM}$ vs $3 \mathrm{mM}$ ) and e, ATP/ADP ratio at 3mM glucose in intact MIR125B-Tg and control islets infected with an adenoviral Perceval sensor. $n=4-5$ mice/genotype, with 1-2 acquisitions per mouse and an average of 5 islets/acquisition. $\mathbf{f}, \mathrm{Ca}^{2+}$ rises in response to high glucose $(17 \mathrm{mM}$ vs $3 \mathrm{mM})$ and $\mathrm{KCl}(20 \mathrm{mM} \mathrm{KCl}, 3 \mathrm{mM}$ Glucose) in intact MIR125B-Tg and control islets incubated with Cal-520. $n=4-5$ mice/genotype, with 1-2 acquisitions per mouse and an average of 5 islets/acquisition. For (D) and (F), AUC corresponding to HG incubation were 
determined and presented on the right. $\mathbf{g}, \mathrm{NP}-\mathrm{Y}$.Venus fluorescence increases in response to $20 \mathrm{mM} \mathrm{KCl}$ in cells from dissociated MIR125B-Tg and control islets infected with an adenoviral NP-Y-venus sensor. $n=3-4 C$ mice/genotype 2ith 2 acquisitions per mouse and 1-2 $\beta$-cells per acquisition. In all graphs, each dot represents a single mouse. ns=not significant ${ }^{*} p<0.05$, ${ }^{* *} p<0.01,{ }^{* *} p<0.001$, two-way ANOVA (repeated-measures) and Bonferroni multiple comparisons test (a), Student $t$ test (b-f).

Figure 9. Enlarged lysosomes/autophagolysosomes are abundant in miR-125b transgenic islets. a, Quantitative analysis of mitochondria number and morphology on deconvoluted confocal images of dissociated MIR125B-Tg and Control islets from 10-11 week old mice. Cells were stained with Mitotracker green. An ImageJ macro was generated and used to quantify number of mitochondria per cell, total mitochondria area, individual mitochondria length (elongation), circularity (0:elongated; 1 :circular) and perimeter. Each dot represents one cell ( $n=3$ mice/genotype). $\mathbf{b}$, Mitochondrial DNA copy number, calculated as the ratio of the mitochondrial encoded gene $\mathrm{mt}-\mathrm{Nd} 1$ to the nuclear $\mathrm{Cxcl12}$. Each dot represents a single mouse. c, Representative Transmission Electron Microscopy images of MIR125B-Tg and control $\beta$-cells. Red arrows: enlarged lysosomes with undigested cargos. Blue arrows: non-crystalized insulin granules, showing a rod like structure or a grey interior. Scale bar = $1 \mu \mathrm{m}, 40 \mathrm{~nm}$ (bottom right) interior. $\mathbf{d}$, Number of enlarged lysosomes per field imaged. e, $\beta$ cell granule density. For (D-E) each dot represents one image ( $n=3$ mice/genotype, 9-13 images/mouse). ${ }^{*} p<0.05,{ }^{* *} p<0.01,{ }^{* * * *} p<0.0001$, Student $\mathrm{t}$ test.

Figure 10. MiR125b overexpression alters gene expression in mouse and human islets.

a, Gene Ontology analysis of significantly (padj <0.1) down-regulated (left, red) and upregulated genes (right, green) in MIR125B-Tg islets from 6-week old mice vs controls performed with DAVID. The graph shows enrichment scores for one representative term for each cluster grouped by semantic similarities and including terms with padj (Benjamini) $<0.05$. See Supp Table 6 for a full list of terms. b, KEGG pathway "Insulin secretion". Red and blue stars indicate significantly down- and up-regulated genes in MIR125B-Tg islets vs control, 
respectively. Syt/4 (granuphilin) has been manually added to the pathway. c, Gene Set Enrichment Analysis (GSEA) of genes ranked by fold change in human islets infected with an adenovirus expressing miR-125 vs control during $24 \mathrm{~h}$. The graph shows enrichment scores for significantly $(\mathrm{p}<0.05)$ down- (red, top plot) and up-regulated (green, bottom plot) KEGG pathways terms. See Supp Table 8 for a full list of terms. Examples of enrichment plots (Lysosome and calcium signalling KEGG pathways) are shown in $\mathbf{d}$.

Table 1. MiR-125b direct targets identified by integration of RIP-seq and T-RNA-seq differential analysis. Genes (182) with RIP-seq to T-RNA ratio > 1.5 are shown. FoldC_TRNA and padj_T-RNA= Fold change and adjusted p-value of differential analysis of transcripts in MIN6 cells transfected with miR-125b mimics vs controls. FoldC_RIP and padj_RIP= Fold change and adjusted p-value of differential analysis of Ago2-immunoprecipitated RNAs in MIN6 cells transfected with miR-125b mimics vs controls. Predicted binding site TargetScan $=\mathrm{Y}$ indicates the presence of at least one predicted miR-125b binding site by TargetScan mouse v7.2.

Supplemental Figure 1. Human islet miR-125b expression does not correlated with age or sex of the donors. RT-qPCR measurements of miR-125b human islets cultured at $5.5 \mathrm{mM}$ glucose plotted against islet donor age (a) or sex (b). Each dot represents islets from a single human donor. MiR-125b expression is normalized to that of the endogenous control miR-7d$3 p^{90}$. Pearson Correlation (a).

\section{Supplemental Figure 2. Chromatin accessibility of MIR125B1/2 in mouse islets.}

Integration of ATAC-seq enrichment profiles in $\beta$ LKB1KO (red) and control (black) islets with SLIC-CAGE-determined TSS in control islets and with published datasets of ChIP-seq data of histone modifications (H3K4me3, blue) in mouse islets ${ }^{91}$ and Smad2/3 (Orange)in pancreatic ductal adenocarcinoma cells (PDAC) ${ }^{17}$ in the MIR125B-1 (a) and MIR125B-2 (b) loci. Red arrow indicates an ATAC-seq significantly more accessible (more open) in $\beta$ LKB1KO islets vs controls. Genecode VM23 transcript set is shown in dark blue. Alignment with the human DNA track is presented in black. 
Supplemental Figure 3. RT-qPCR measurements of Smad2 (a) and Smad3(b) mRNAs and miR-125b-5p (c) in MIN6 cells 48h after the transfection of Smad2, Smad3 or control siRNAs. Each dot represents an independent experiment. Values were normalized by the endogenous control Ppia (cyclophilin a, (a,b) or let-7d-3p (c) and are presented as fold change relative to control siRNA. ${ }^{* * *} p<0.001,{ }^{* *} \mathrm{p}<0.0001$, Student $\mathrm{t}$ test of the log[fold change] values.

\section{Supplemental Figure 4. Elimination of miR-125b by CRISPR-Cas9 in EndoC $\beta-\mathrm{H} 1$ cells.}

a, Schematic representation of the targeting location of the gRNAs in MIR125B-1 and MIR125B-2 human loci. Two independent pairs of gRNAs were designed for each loci, targeting the seed of miR-125b (miR-125b-5p) or the regions essential for DROSHA and/or DICER cleavage. b, RT-qPCR measurements of (mature) miR-125b in Control EndoC $\beta-\mathrm{H} 1$ (containing the RIP-Cas9 vector, but no gRNAs), MIR125B1-KO1 and MIR125B1-KO2 (containing RIP-Cas9 vector with gRNAs targeting the MIR125B1 locus, pair 1 (KO1) or pair 2(KO2)), MIR125B2-KO1 and MIR125B2-KO2 (containing RIP-Cas9 vector with gRNAs targeting the MIR125B2 locus, pair 1 (KO1) or pair 2(KO2)) or combinations of the above gRNAs as indicated. c, RT-qPCR of miR-99a and miR-125a in Control (C) and MIR125B2KO1 (KO) cells. Each dot represents an independent experiment. Values were normalized by the endogenous control let-7d-3p and are presented as fold change relative to control cells. ns=not significant, ${ }^{* *} p<0.01,{ }^{* * *} p<0.001,{ }^{* * *} p<0.0001$, Student $t$ test of the log[fold change] values.

\section{Supplemental Figure 5. $\beta$-cell-selective overexpression of miR-125b does not alter} hypothalamic miR-125b expression, body weight, insulin tolerance and $\beta$-cell growth and apoptosis. a, RT-qPCR of miR-125b in hypothalamus from Control (RIP7-rtTA ${ }^{+/}$) and MIR125B-Tg mice (RIP7-rtTA ${ }^{+/}$, MIR125B Tg ${ }^{+-}$). b, Body weight of male and female MIR125B-Tg and littermate control mice monitored weekly from the age of 5 weeks. $n=5-8$ mice/genotype. c, Glucose tolerance test in 6 week old mice containing the transgene in the absence of rtTA (-rtTA Control, MIR125B $\mathrm{Tg}^{+-}$) and littermate controls without the transgene or rtTA, showing that the presence of the transgene doesn't affect glucose tolerance. $n=4-6$ 
mice/genotype. d, Intraperitoneal Insulin tolerance test in 7 week old MIR125B-Tg and littermate control male and female mice. $n=5-8$ mice/genotype. e,f, Pancreata from 11 weekold MIR125B-Tg and littermate controls were fixed and subjected to (E) immunocytochemical analysis for insulin and Ki67. The number of Ki67-positive cells is expressed as a percentage of insulinpositive cells (F) TUNEL assay for in situ detection of apoptotic cells. The number of TUNEL-positive cells is presented as a percentage of insulin-positive cells. Each dot represents one pancreatic section with $n=3$ mice/genotype. g, Quantitative analysis of lysosomes number and total area on deconvoluted confocal images of dissociated MIR125B$\mathrm{Tg}$ and Control islets from 10-11 week old mice. Cells were stained with Lysotracker green. An ImageJ macro was generated and used to quantify number of lysosomes per cell and total lysosomal area. Each dot represents one cell ( $\mathrm{n}=3$ mice/genotype). ns=not significant, * $p$ $<0.05,{ }^{* * *} \mathrm{p}<0.001,{ }^{* * * *} \mathrm{p}<0.0001$, Student t test $(\mathrm{a}, \mathrm{e}-\mathrm{g})$, two-way ANOVA (repeatedmeasures), Fisher least significance different test (b-d)

Supplemental Figure 6. Overexpression of miR-125b in human islets. a, RT-qPCR of miR-125b in dissociated human islets $24 \mathrm{~h}$ hours following infection with $2 \mathrm{MOI}$ of an adenovirus expressing miR-125b (pAd-MIR125B) or control (pAd-empty). b, Principal Component Analysis of the RNA-seq data in human dissociated islets infected with pAdMIR125B or control (C) adenovirus. HI=Human islets. 3 independent experiments were performed with islets from three different donors $(\mathrm{H} 1-3) .{ }^{* * *} \mathrm{p}<0.0001$, Student $\mathrm{t}$ test of the log[fold change] values. 


\section{Graphical abstract}

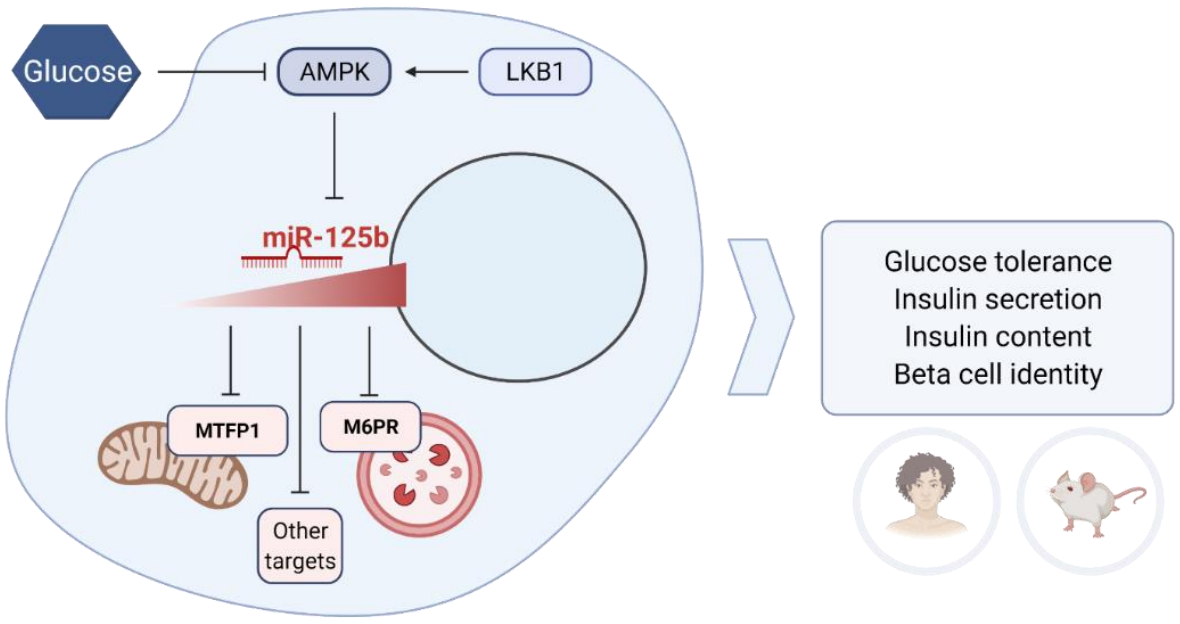


Figure 1

a

Mouse islets

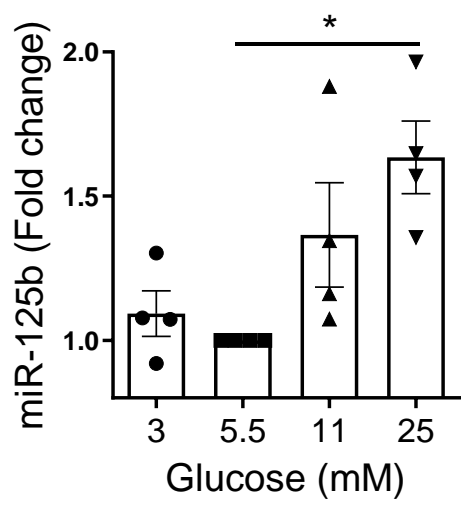

C

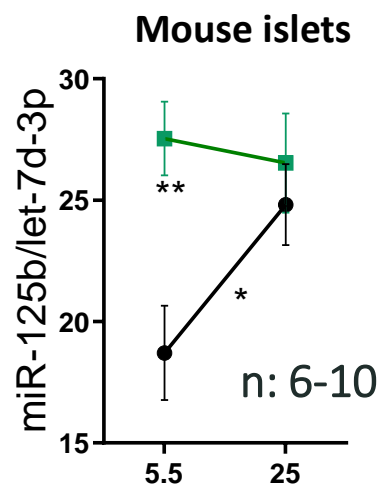

Glucose (mM)

- $\beta \mathrm{AMPKdKO}$

$\rightarrow C$

f

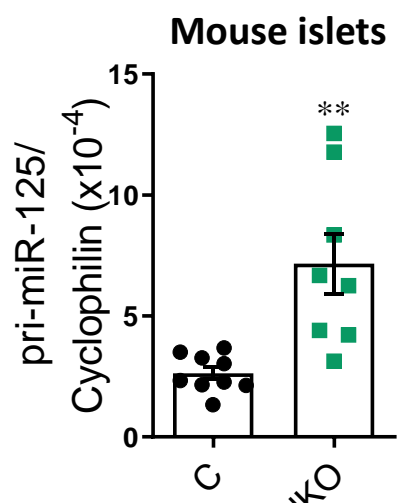

Human islets

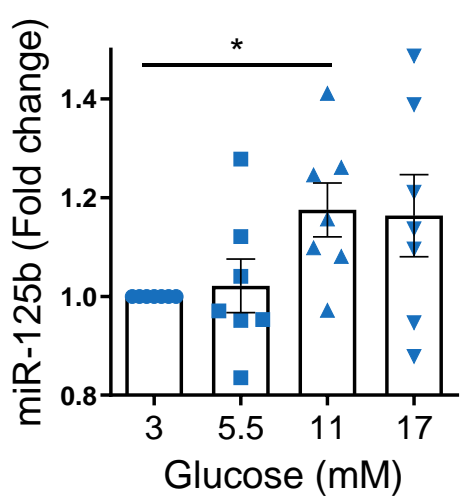

d

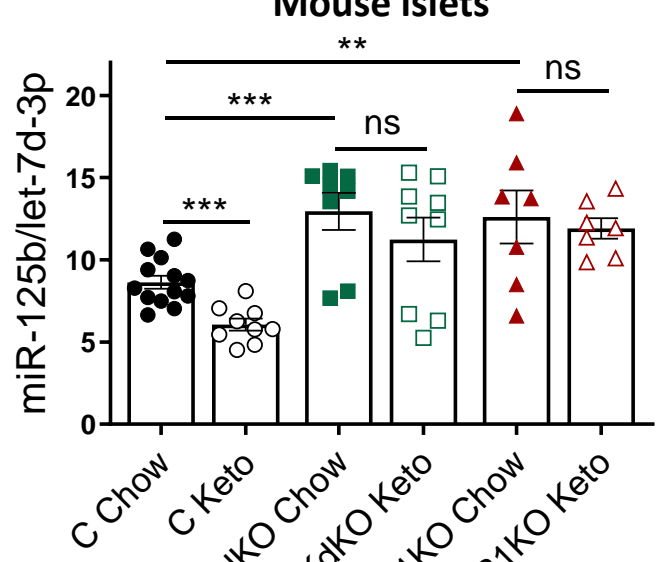

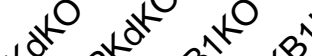

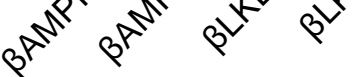

Human islets

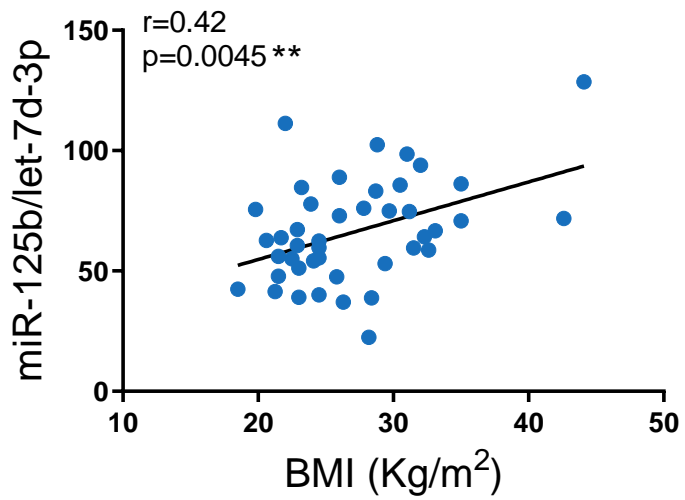

e Human islets

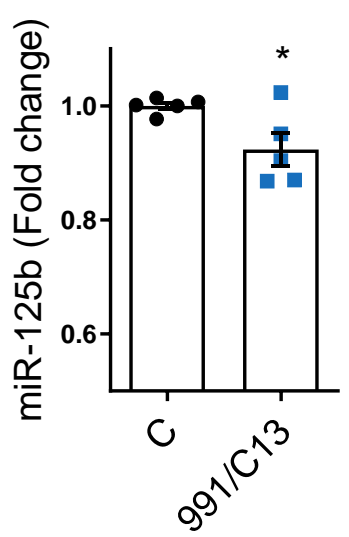


Figure 2

a MIN6-miR-125b mimics
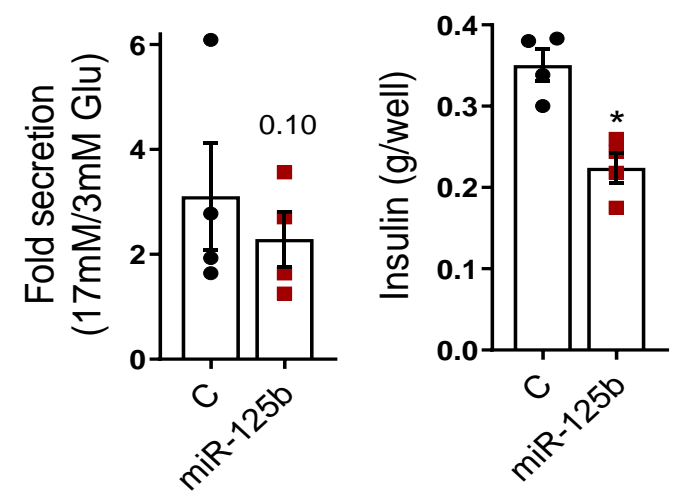

b EndoC $\beta$-H1-miR-125b CRISPR-KO

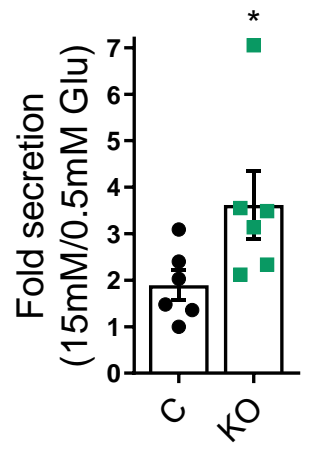

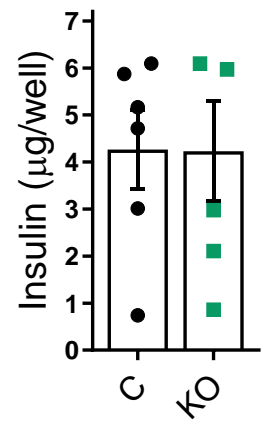


Figure 3

a

1. Transfection

2. AGO2-RIP

3. RNA-seq

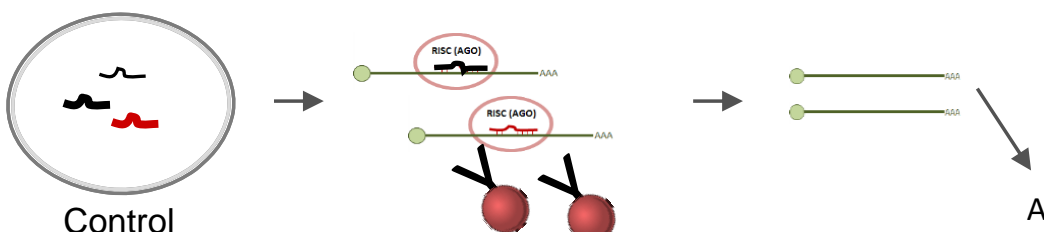

Control

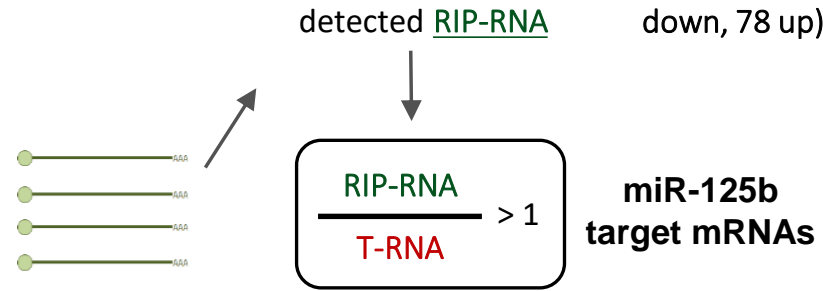

miR-125b mimics
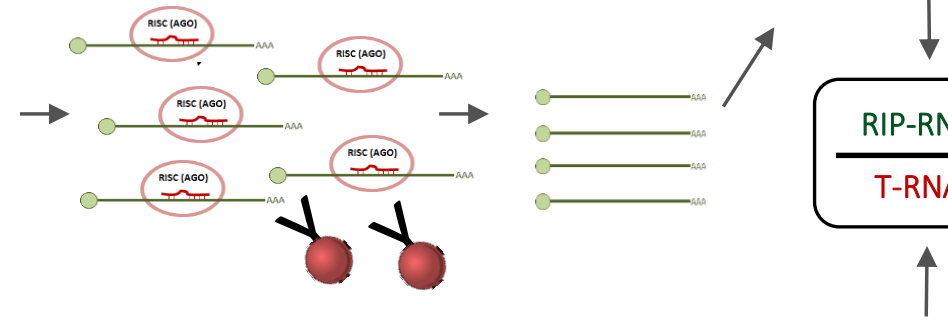

Analysis of differentially

623 genes ( 306

2. Cellular RNA-seq.

expressed (abundance)

down, 317 up)

T-RNA

b

3'UTRs

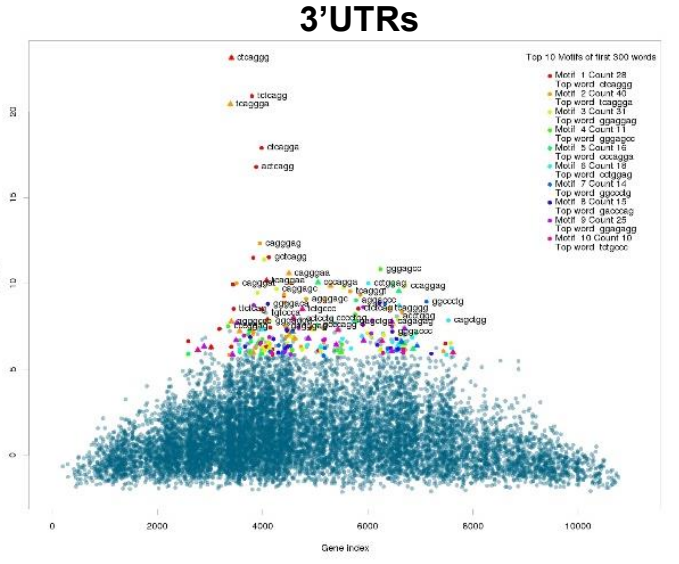

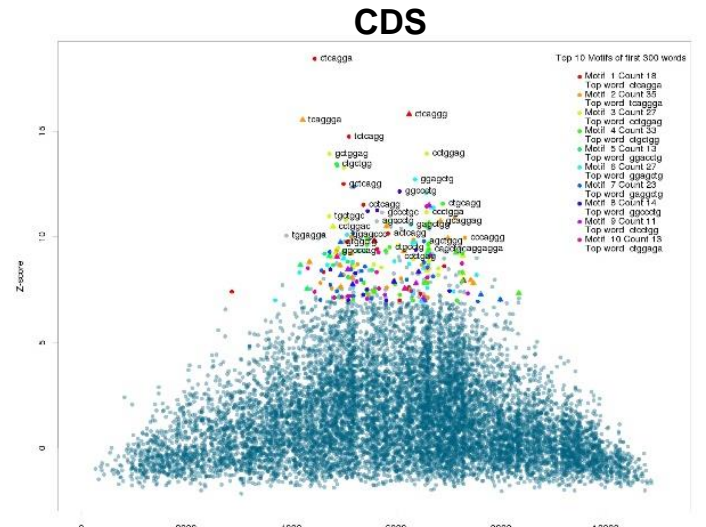

$>m m u-m i R-125 b-5 p$ UCCCUGAGACCCUAA CUUGUGA

RC: TCTCAGGGA
C

IP-RNA/T-RNA

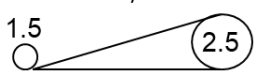

T-RNA fold change

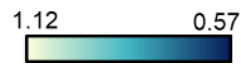

T-RNA fold change padj

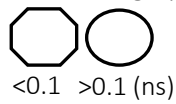

TargetScan prediction score

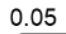

0.99

Zfyve27Gm43540 Konn? Akap2 Gm16892 Sned1 alfr374 Tep11120m436600raov1 Inpp4b Vps4b Dhitkd Prdm11

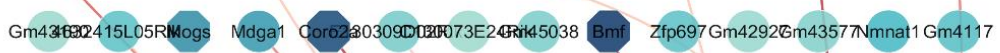

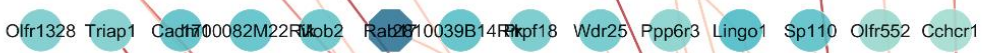

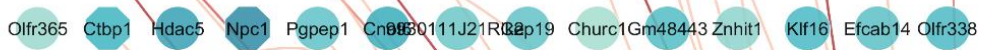

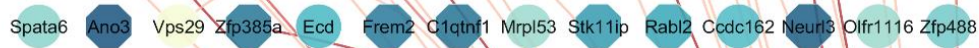

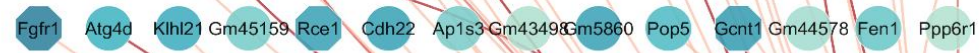

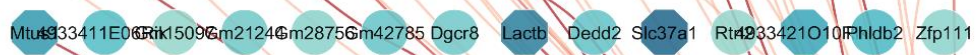

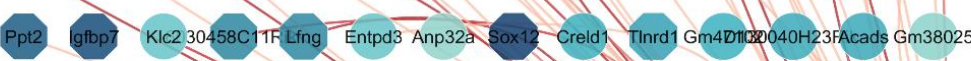

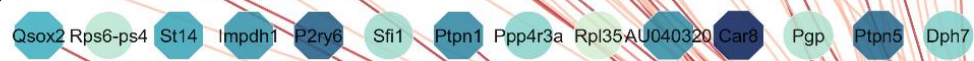

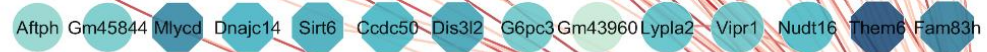

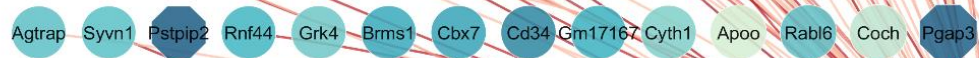
Nrm Src Stc1 Rnf113a2 Mfge8 Guk1 Kcnc2 Dusp23 Pex11 gGm10125Nectin2s Abtb1 Cpne5 Ceacam1 Trabd Lrrc10b- Mlxipl Lsm14 Rhot2 Trnp1 Gm473563npat nks1bp1 Mtfp1 Tor2a M6pr Taz 
Table 1

\begin{tabular}{|c|c|c|c|c|c|c|}
\hline Gene.name & $\begin{array}{l}\text { Predicted } \\
\text { binding site } \\
\text { TargetScan }\end{array}$ & FoldC_T-RNA & padj_T-RNA & FoldC_RIP & padj_RIP & RIP/T-RNA \\
\hline Taz & $\mathrm{Y}$ & 0.88 & 0.213 & 2.196 & 0 & 2.494 \\
\hline M6pr & $\mathrm{Y}$ & 0.818 & 0.006 & 2.039 & 0 & 2.494 \\
\hline Tor2a & $\mathrm{Y}$ & 0.722 & 0.002 & 1.786 & 0 & 2.476 \\
\hline Mtfp1 & $\mathrm{Y}$ & 0.762 & 0.018 & 1.865 & 0 & 2.449 \\
\hline Tnks1bp1 & & 0.927 & 0.607 & 2.194 & 0 & 2.366 \\
\hline Gnpat & & 0.901 & 0.44 & 2.067 & 0 & 2.294 \\
\hline Gm47356 & & 0.869 & 0.602 & 1.965 & 0.002 & 2.262 \\
\hline Trnp1 & & 1.018 & 0.968 & 2.201 & 0 & 2.163 \\
\hline Rhot2 & $\mathrm{Y}$ & 0.992 & 0.982 & 2.051 & 0 & 2.068 \\
\hline Lsm14b & & 0.924 & 0.611 & 1.833 & 0 & 1.985 \\
\hline Mlxipl & & 0.915 & 0.743 & 1.812 & 0 & 1.981 \\
\hline Lrrc10b & $\mathrm{Y}$ & 0.774 & 0.029 & 1.521 & 0.056 & 1.966 \\
\hline Trabd & & 0.867 & 0.416 & 1.697 & 0.001 & 1.957 \\
\hline Ceacam1 & $\mathrm{Y}$ & 0.66 & 0.002 & 1.284 & 0.608 & 1.944 \\
\hline Cpne5 & $Y$ & 0.694 & 0.016 & 1.345 & 0.613 & 1.937 \\
\hline Abtb1 & $\mathrm{Y}$ & 0.814 & 0.242 & 1.576 & 0.025 & 1.935 \\
\hline Nectin2 & & 0.821 & 0.114 & 1.572 & 0.05 & 1.915 \\
\hline Gm10125 & & 0.925 & 0.818 & 1.745 & 0.03 & 1.886 \\
\hline Pex11g & & 0.756 & 0.06 & 1.419 & 0.486 & 1.876 \\
\hline Dusp23 & $\mathrm{Y}$ & 0.703 & 0.006 & 1.319 & 0.768 & 1.875 \\
\hline Kcnc2 & $\mathrm{Y}$ & 0.6 & 0 & 1.118 & 0.999 & 1.864 \\
\hline Guk1 & & 1.045 & 0.896 & 1.944 & 0 & 1.86 \\
\hline Mfge8 & $\mathrm{Y}$ & 0.712 & 0.013 & 1.32 & 0.771 & 1.853 \\
\hline Rnf113a2 & & 1.088 & 0.494 & 1.998 & 0.001 & 1.836 \\
\hline Stc1 & Y & 0.785 & 0.142 & 1.44 & 0.406 & 1.833 \\
\hline Src & $Y$ & 0.712 & 0.011 & 1.285 & 0.852 & 1.804 \\
\hline $\mathrm{Nrm}$ & $\mathrm{Y}$ & 0.674 & 0 & 1.214 & 0.963 & 1.801 \\
\hline Pgap3 & Y & 0.698 & 0 & 1.257 & 0.802 & 1.801 \\
\hline Coch & & 1.027 & 0.954 & 1.849 & 0.004 & 1.8 \\
\hline Rabl6 & Y & 0.891 & 0.331 & 1.591 & 0.001 & 1.786 \\
\hline Apoo & & 1.059 & 0.689 & 1.886 & 0.004 & 1.781 \\
\hline Cyth1 & $Y$ & 0.94 & 0.514 & 1.658 & 0.001 & 1.763 \\
\hline Gm17167 & & 0.84 & 0.445 & 1.478 & 0.364 & 1.758 \\
\hline $\mathrm{Cd} 34$ & $\mathrm{Y}$ & 0.764 & 0.123 & 1.34 & 0.662 & 1.753 \\
\hline Cbx7 & $\mathrm{Y}$ & 0.817 & 0.13 & 1.431 & 0.379 & 1.753 \\
\hline Brms1 & $\mathrm{Y}$ & 0.826 & 0.11 & 1.446 & 0.428 & 1.75 \\
\hline Grk4 & & 0.914 & 0.787 & 1.597 & 0.175 & 1.746 \\
\hline Rnf44 & $\mathrm{Y}$ & 0.849 & 0.338 & 1.478 & 0.025 & 1.741 \\
\hline Pstpip2 & & 0.691 & 0.002 & 1.203 & 0.999 & 1.74 \\
\hline Syvn1 & $\mathrm{Y}$ & 0.886 & 0.393 & 1.54 & 0 & 1.738 \\
\hline Agtrap & $Y$ & 0.891 & 0.601 & 1.547 & 0.258 & 1.737 \\
\hline Fam83h & $\mathrm{Y}$ & 0.738 & 0.001 & 1.278 & 0.543 & 1.732 \\
\hline Them6 & $Y$ & 0.649 & 0.001 & 1.123 & 0.999 & 1.731 \\
\hline Nudt16 & & 0.849 & 0.234 & 1.467 & 0.402 & 1.728 \\
\hline Vipr1 & Y & 0.893 & 0.499 & 1.541 & 0 & 1.726 \\
\hline Lypla2 & $Y$ & 0.874 & 0.204 & 1.501 & 0.037 & 1.718 \\
\hline Gm43960 & & 1.035 & 0.938 & 1.767 & 0.029 & 1.707 \\
\hline G6pc3 & & 0.9 & 0.517 & 1.532 & 0.114 & 1.703 \\
\hline Dis312 & $Y$ & 0.805 & 0.012 & 1.367 & 0.64 & 1.699 \\
\hline Ccdc50 & & 0.841 & 0.073 & 1.429 & 0.233 & 1.698 \\
\hline Sirt6 & $\mathrm{Y}$ & 0.82 & 0.019 & 1.386 & 0.607 & 1.692 \\
\hline Dnajc14 & $\mathrm{Y}$ & 0.834 & 0.002 & 1.403 & 0.329 & 1.683 \\
\hline Mlycd & $Y$ & 0.754 & 0.002 & 1.267 & 0.775 & 1.681 \\
\hline Gm45844 & & 0.913 & 0.75 & 1.53 & 0.196 & 1.676 \\
\hline Aftph & & 0.956 & 0.747 & 1.597 & 0.018 & 1.671 \\
\hline Dph7 & & 0.941 & 0.774 & 1.571 & 0.209 & 1.669 \\
\hline Ptpn5 & & 0.706 & 0.011 & 1.176 & 0.999 & 1.666 \\
\hline Pgp & $Y$ & 1.01 & 0.98 & 1.682 & 0.004 & 1.665 \\
\hline Car8 & & 0.58 & 0 & 0.965 & 0.999 & 1.664 \\
\hline AU040320 & $\mathrm{Y}$ & 0.769 & 0 & 1.274 & 0.533 & 1.656 \\
\hline Rpl35 & & 1.06 & 0.839 & 1.75 & 0.003 & 1.651 \\
\hline Ppp4r3a & $Y$ & 0.95 & 0.789 & 1.564 & 0.003 & 1.646 \\
\hline Ptpn1 & $Y$ & 0.759 & 0 & 1.248 & 0.805 & 1.645 \\
\hline Sfi1 & & 0.984 & 0.954 & 1.615 & 0.146 & 1.642 \\
\hline P2ry6 & & 0.687 & 0 & 1.127 & 0.999 & 1.641 \\
\hline Impdh1 & & 0.785 & 0.003 & 1.286 & 0.379 & 1.639 \\
\hline St14 & $Y$ & 0.811 & 0.087 & 1.327 & 0.752 & 1.636 \\
\hline Rps6-ps4 & & 1.021 & 0.957 & 1.668 & 0.078 & 1.633 \\
\hline Qsox2 & $\mathrm{Y}$ & 0.832 & 0.026 & 1.357 & 0.096 & 1.632 \\
\hline Gm38025 & & 0.957 & 0.89 & 1.561 & 0.243 & 1.631 \\
\hline \begin{tabular}{|l|l} 
Acads \\
\end{tabular} & $Y$ & 0.823 & 0.183 & 1.342 & 0.441 & 1.629 \\
\hline $\mathrm{D} 130040 \mathrm{H} 23 \mathrm{R} / \mathrm{k}$ & $Y$ & 0.828 & 0.28 & 1.348 & 0.673 & 1.628 \\
\hline \begin{tabular}{l|l} 
Gm47102 \\
\end{tabular} & & 0.837 & 0.442 & 1.361 & 0.428 & 1.626 \\
\hline TInrd1 & & 0.809 & 0.097 & 1.315 & 0.533 & 1.626 \\
\hline Creld1 & $Y$ & 0.838 & 0.189 & 1.36 & 0.517 & 1.623 \\
\hline Sox12 & $\mathrm{Y}$ & 0.639 & 0 & 1.036 & 0.999 & 1.622 \\
\hline Anp32a & & 0.963 & 0.908 & 1.559 & 0.006 & 1.619 \\
\hline Entpd3 & $\mathrm{Y}$ & 0.903 & 0.604 & 1.456 & 0.078 & 1.613 \\
\hline Lffng & Y & 0.767 & 0.075 & 1.236 & 0.845 & 1.613 \\
\hline 6030458C11Rik & $\mathrm{Y}$ & 0.764 & 0 & 1.228 & 0.684 & 1.608 \\
\hline \begin{tabular}{|l|l} 
Klc2 \\
\end{tabular} & $Y$ & 0.903 & 0.536 & 1.45 & 0.11 & 1.606 \\
\hline Igfbp7 & & 0.66 & 0.002 & 1.059 & 0.999 & 1.604 \\
\hline Ppt2 & Y & 0.69 & 0 & 1.106 & 0.999 & 1.603 \\
\hline Zfp111 & $Y$ & 0.958 & 0.842 & 1.534 & 0.111 & 1.601 \\
\hline Phldb2 & $Y$ & 0.86 & 0.455 & 1.377 & 0.375 & 1.6 \\
\hline \multicolumn{2}{|l|}{ 4933421010Rik } & 0.818 & 0.035 & 1.307 & 0.8 & 1.598 \\
\hline Rtn2 & & 0.966 & 0.896 & 1.544 & 0.037 & 1.597 \\
\hline Slc37a1 & & 0.702 & 0 & 1.12 & 0.999 & 1.596 \\
\hline Dedd2 & & 0.899 & 0.682 & 1.431 & 0.286 & 1.592 \\
\hline
\end{tabular}


Table 1-cont

\begin{tabular}{|c|c|c|c|c|c|c|}
\hline Gene.name & $\begin{array}{l}\text { Predicted } \\
\text { binding site } \\
\text { TargetScan }\end{array}$ & FoldC_T-RNA & padj_T-RNA & FoldC_RIP & padj_RIP & RIP/T-RNA \\
\hline Lactb & $\mathrm{Y}$ & 0.751 & 0.027 & 1.195 & 0.999 & 1.59 \\
\hline Dgcr8 & & 0.917 & 0.618 & 1.459 & 0.375 & 1.59 \\
\hline Gm42785 & & 0.902 & 0.612 & 1.433 & 0.379 & 1.589 \\
\hline Gm28756 & & 0.955 & 0.912 & 1.515 & 0.303 & 1.587 \\
\hline Gm21244 & & 0.917 & 0.763 & 1.455 & 0.39 & 1.587 \\
\hline Gm15097 & & 0.967 & 0.939 & 1.535 & 0.258 & 1.586 \\
\hline 4933411E06Rik & & 0.876 & 0.62 & 1.389 & 0.502 & 1.585 \\
\hline Mtus1 & $\mathrm{Y}$ & 0.794 & 0.052 & 1.259 & 0.917 & 1.584 \\
\hline Ppp6r1 & & 1.011 & 0.96 & 1.601 & 0.001 & 1.584 \\
\hline Fen1 & & 0.906 & 0.534 & 1.434 & 0.072 & 1.583 \\
\hline Gm44578 & & 0.989 & 0.984 & 1.564 & 0.229 & 1.582 \\
\hline Gent1 & $\mathrm{Y}$ & 0.799 & 0.044 & 1.263 & 0.501 & 1.581 \\
\hline Pop5 & $Y$ & 0.867 & 0.448 & 1.37 & 0.243 & 1.581 \\
\hline Gm5860 & & 0.81 & 0.262 & 1.278 & 0.828 & 1.579 \\
\hline Gm43498 & & 1.005 & 0.994 & 1.585 & 0.183 & 1.578 \\
\hline Ap1s3 & $\mathrm{Y}$ & 0.927 & 0.705 & 1.462 & 0.39 & 1.577 \\
\hline Cdh22 & $Y$ & 0.808 & 0.18 & 1.274 & 0.666 & 1.576 \\
\hline Rce1 & & 0.809 & 0.081 & 1.275 & 0.69 & 1.576 \\
\hline Gm45159 & & 0.926 & 0.82 & 1.459 & 0.398 & 1.576 \\
\hline Klhl21 & $\mathrm{Y}$ & 0.829 & 0.286 & 1.306 & 0.693 & 1.576 \\
\hline Atg4d & $\mathrm{Y}$ & 0.843 & 0.405 & 1.329 & 0.613 & 1.576 \\
\hline Fgfr1 & $Y$ & 0.747 & 0.012 & 1.175 & 0.999 & 1.574 \\
\hline Zfp488 & $Y$ & 0.924 & 0.734 & 1.454 & 0.428 & 1.574 \\
\hline Olfr1116 & & 0.982 & 0.969 & 1.543 & 0.258 & 1.572 \\
\hline Neurl3 & & 0.691 & 0.005 & 1.086 & 0.999 & 1.571 \\
\hline Ccdc162 & & 0.869 & 0.499 & 1.365 & 0.582 & 1.57 \\
\hline Rabl2 & $\mathrm{Y}$ & 0.82 & 0.098 & 1.287 & 0.878 & 1.569 \\
\hline Stk11ip & & 0.801 & 0.002 & 1.255 & 0.9 & 1.568 \\
\hline Mrpl53 & & 0.981 & 0.958 & 1.538 & 0.105 & 1.567 \\
\hline C1qtnf1 & $\mathrm{Y}$ & 0.729 & 0.024 & 1.143 & 0.999 & 1.567 \\
\hline Frem2 & & 0.739 & 0.05 & 1.159 & 0.999 & 1.567 \\
\hline Ecd & & 0.859 & 0.153 & 1.346 & 0.49 & 1.567 \\
\hline Zfp385a & $\mathrm{Y}$ & 0.735 & 0.01 & 1.15 & 0.999 & 1.565 \\
\hline Vps29 & $\mathrm{Y}$ & 1.106 & 0.536 & 1.73 & 0.001 & 1.564 \\
\hline Ano3 & & 0.673 & 0.008 & 1.053 & 0.999 & 1.564 \\
\hline Spata6 & & 0.958 & 0.869 & 1.494 & 0.358 & 1.56 \\
\hline Olfr338 & & 0.866 & 0.549 & 1.35 & 0.603 & 1.559 \\
\hline Efcab14 & $\mathrm{Y}$ & 0.887 & 0.301 & 1.382 & 0.364 & 1.559 \\
\hline Klf16 & $\mathrm{Y}$ & 0.863 & 0.152 & 1.345 & 0.594 & 1.559 \\
\hline Znhit1 & $Y$ & 0.959 & 0.885 & 1.492 & 0.353 & 1.556 \\
\hline Gm48443 & & 0.875 & 0.404 & 1.361 & 0.533 & 1.556 \\
\hline Churc1 & & 0.993 & 0.986 & 1.545 & 0.234 & 1.555 \\
\hline \begin{tabular}{l|l} 
Cep19 \\
\end{tabular} & & 0.899 & 0.523 & 1.397 & 0.533 & 1.554 \\
\hline $9930111 J 21 R$ il 2 & $Y$ & 0.914 & 0.785 & 1.421 & 0.375 & 1.554 \\
\hline \begin{tabular}{|l|l} 
Cnot6 & \\
\end{tabular} & & 0.83 & 0.168 & 1.289 & 0.144 & 1.553 \\
\hline Pgpep1 & $\mathrm{Y}$ & 0.894 & 0.61 & 1.384 & 0.385 & 1.548 \\
\hline Npc1 & & 0.771 & 0.001 & 1.193 & 0.977 & 1.547 \\
\hline Hdac5 & & 0.809 & 0.151 & 1.25 & 0.942 & 1.544 \\
\hline Ctbp1 & $\mathrm{Y}$ & 0.848 & 0.005 & 1.303 & 0.43 & 1.537 \\
\hline Olfr365 & & 0.979 & 0.954 & 1.505 & 0.353 & 1.537 \\
\hline Cchcr1 & & 0.981 & 0.936 & 1.507 & 0.328 & 1.536 \\
\hline Olfr552 & & 0.967 & 0.94 & 1.485 & 0.345 & 1.536 \\
\hline Sp110 & & 0.871 & 0.609 & 1.337 & 0.648 & 1.535 \\
\hline Lingo1 & $\mathrm{Y}$ & 0.852 & 0.312 & 1.308 & 0.474 & 1.535 \\
\hline Ppp6r3 & $Y$ & 0.939 & 0.618 & 1.438 & 0.023 & 1.531 \\
\hline Wdr25 & $Y$ & 0.9 & 0.551 & 1.377 & 0.533 & 1.53 \\
\hline Prpf18 & & 0.907 & 0.322 & 1.386 & 0.443 & 1.528 \\
\hline 2810039B14Rik & & 0.871 & 0.496 & 1.33 & 0.708 & 1.528 \\
\hline \begin{tabular}{|l|l} 
Rab17 & \\
\end{tabular} & $\mathrm{Y}$ & 0.718 & 0.005 & 1.097 & 0.999 & 1.528 \\
\hline Mob2 & $Y$ & 0.889 & 0.391 & 1.355 & 0.486 & 1.525 \\
\hline 1700082M22Rik & & 0.874 & 0.62 & 1.333 & 0.717 & 1.525 \\
\hline \begin{tabular}{|l|l} 
Cadm1 & \\
\end{tabular} & & 0.872 & 0.385 & 1.33 & 0.366 & 1.525 \\
\hline Triap1 & $Y$ & 0.923 & 0.687 & 1.408 & 0.382 & 1.524 \\
\hline Olfr1328 & & 0.915 & 0.715 & 1.394 & 0.366 & 1.523 \\
\hline Gm4117 & & 0.878 & 0.609 & 1.337 & 0.639 & 1.523 \\
\hline Nmnat1 & $Y$ & 0.852 & 0.408 & 1.297 & 0.819 & 1.523 \\
\hline Gm43577 & & 0.94 & 0.864 & 1.431 & 0.465 & 1.523 \\
\hline Gm42927 & & 0.972 & 0.941 & 1.479 & 0.328 & 1.522 \\
\hline Zfp697 & $\mathrm{Y}$ & 0.888 & 0.597 & 1.35 & 0.689 & 1.519 \\
\hline Bmf & $Y$ & 0.623 & 0 & 0.946 & 0.999 & 1.519 \\
\hline Gm45038 & & 0.93 & 0.795 & 1.412 & 0.401 & 1.518 \\
\hline C130073E24Rik & & 0.979 & 0.963 & 1.487 & 0.36 & 1.518 \\
\hline E130309D02Rik & $\mathrm{Y}$ & 0.924 & 0.716 & 1.4 & 0.366 & 1.516 \\
\hline \begin{tabular}{l|l} 
Coro2a & \\
\end{tabular} & $Y$ & 0.656 & 0 & 0.994 & 0.999 & 1.514 \\
\hline Mdga1 & $Y$ & 0.794 & 0.193 & 1.201 & 0.999 & 1.513 \\
\hline \begin{tabular}{|l|l} 
Mogs \\
\end{tabular} & & 0.772 & 0.05 & 1.167 & 0.857 & 1.512 \\
\hline 4632415L05Rik & $Y$ & 0.886 & 0.414 & 1.339 & 0.713 & 1.511 \\
\hline \begin{tabular}{|l|l} 
Gm43190 \\
\end{tabular} & & 0.978 & 0.96 & 1.477 & 0.375 & 1.511 \\
\hline Prdm11 & $Y$ & 0.907 & 0.683 & 1.369 & 0.648 & 1.51 \\
\hline Dhtkd1 & & 0.991 & 0.986 & 1.496 & 0.345 & 1.509 \\
\hline Vps4b & $Y$ & 0.784 & 0.053 & 1.183 & 0.999 & 1.509 \\
\hline Inpp4b & & 0.779 & 0.076 & 1.174 & 0.999 & 1.508 \\
\hline Oraov1 & $\mathrm{Y}$ & 0.898 & 0.369 & 1.354 & 0.637 & 1.508 \\
\hline Gm43660 & & 0.916 & 0.76 & 1.382 & 0.419 & 1.508 \\
\hline Tcp11/2 & & 0.711 & 0.019 & 1.072 & 0.999 & 1.508 \\
\hline Olfr374 & & 0.87 & 0.551 & 1.31 & 0.786 & 1.506 \\
\hline Sned1 & $\mathrm{Y}$ & 0.921 & 0.808 & 1.387 & 0.348 & 1.505 \\
\hline Gm16892 & & 0.958 & 0.925 & 1.441 & 0.375 & 1.504 \\
\hline Akap2 & $\mathrm{Y}$ & 0.97 & 0.944 & 1.458 & 0.286 & 1.502 \\
\hline Kcnn2 & & 0.734 & 0.052 & 1.102 & 0.999 & 1.501 \\
\hline
\end{tabular}


Figure 4

a

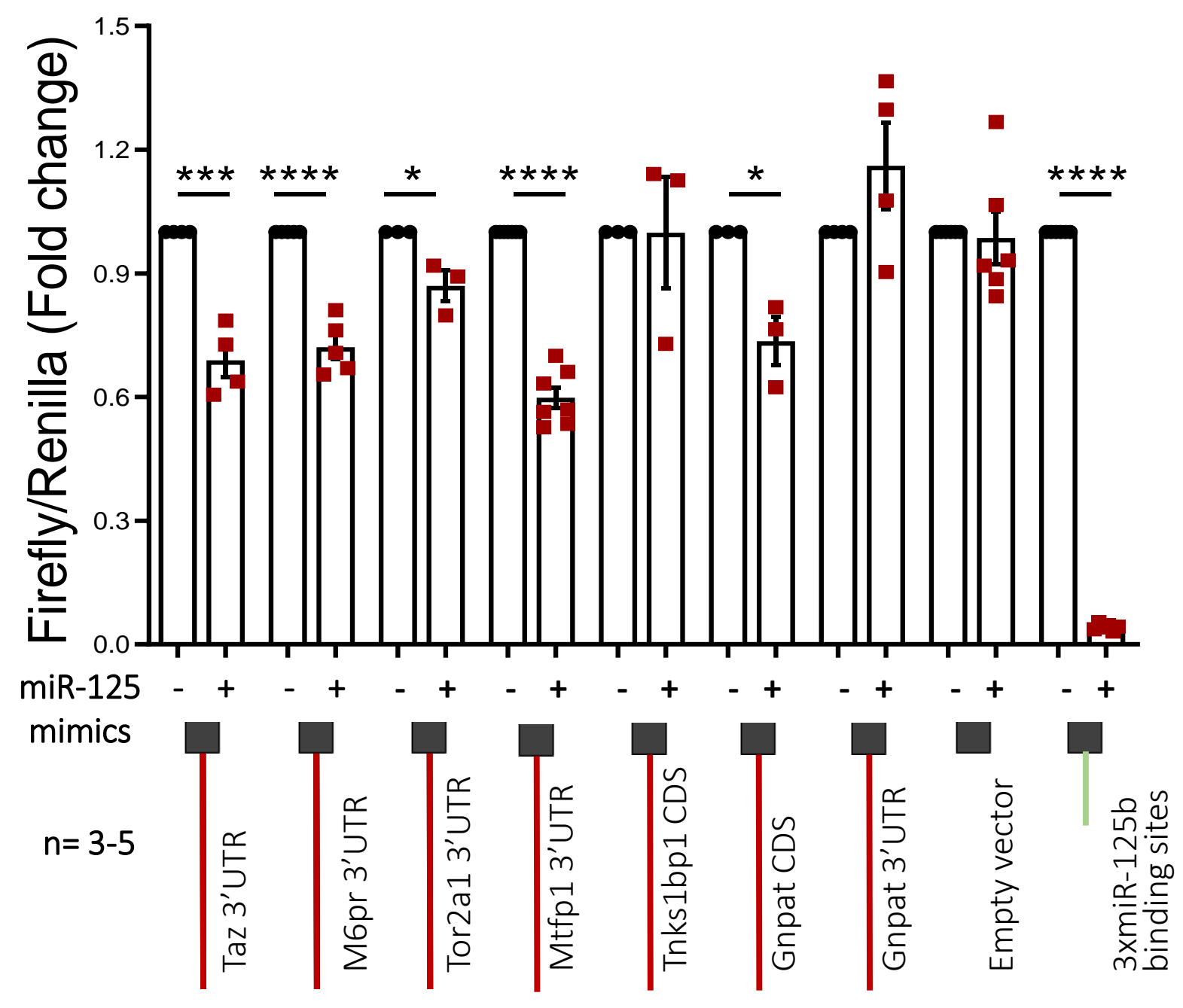

b

Enrichment Score (padj<0.05)

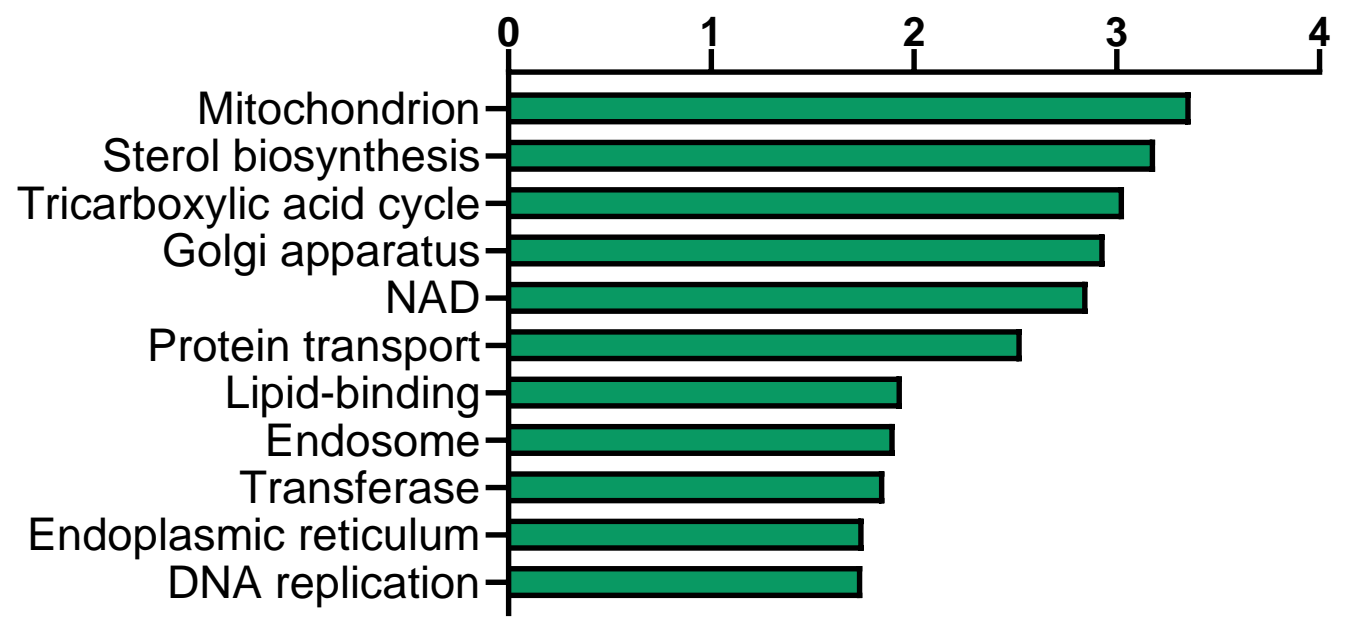




\section{Figure 5}

a

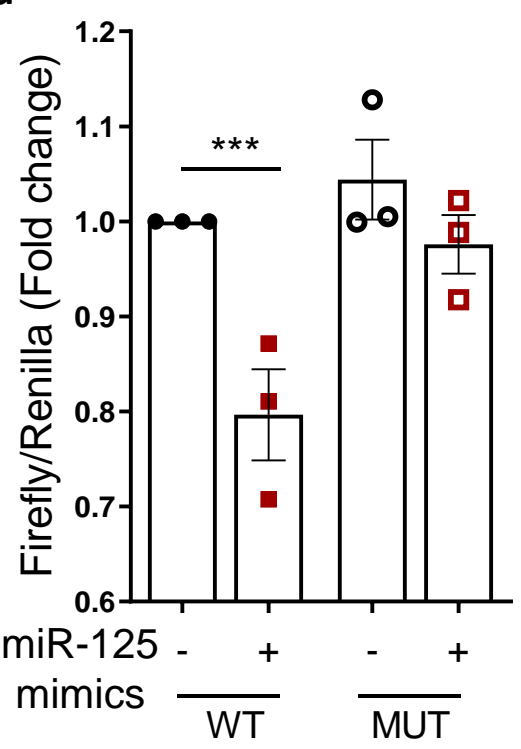

c

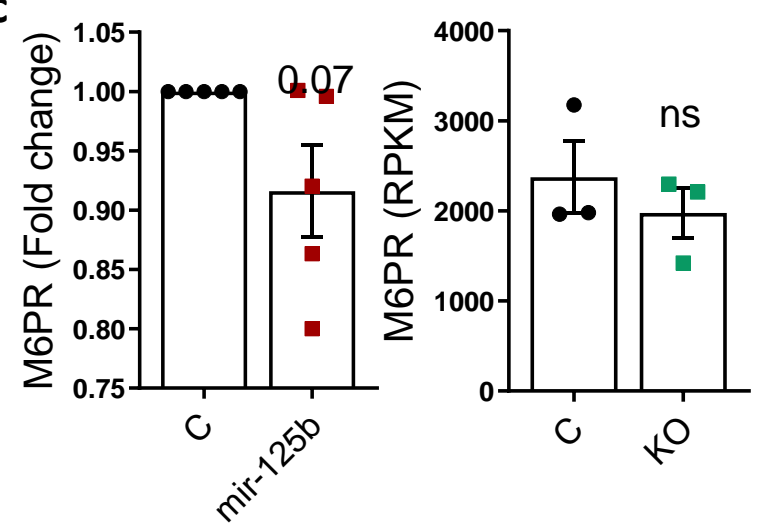

b
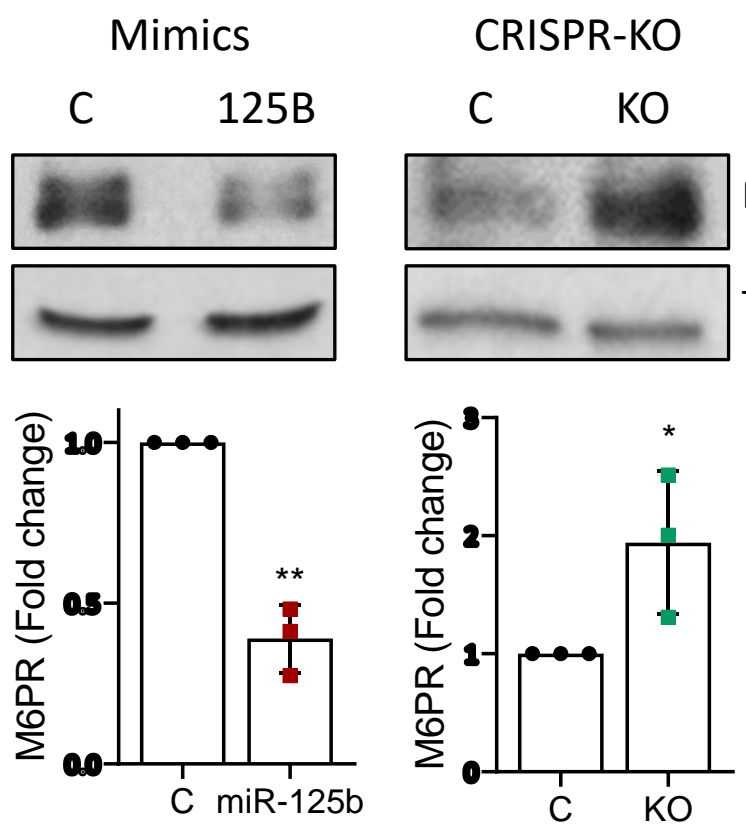

d
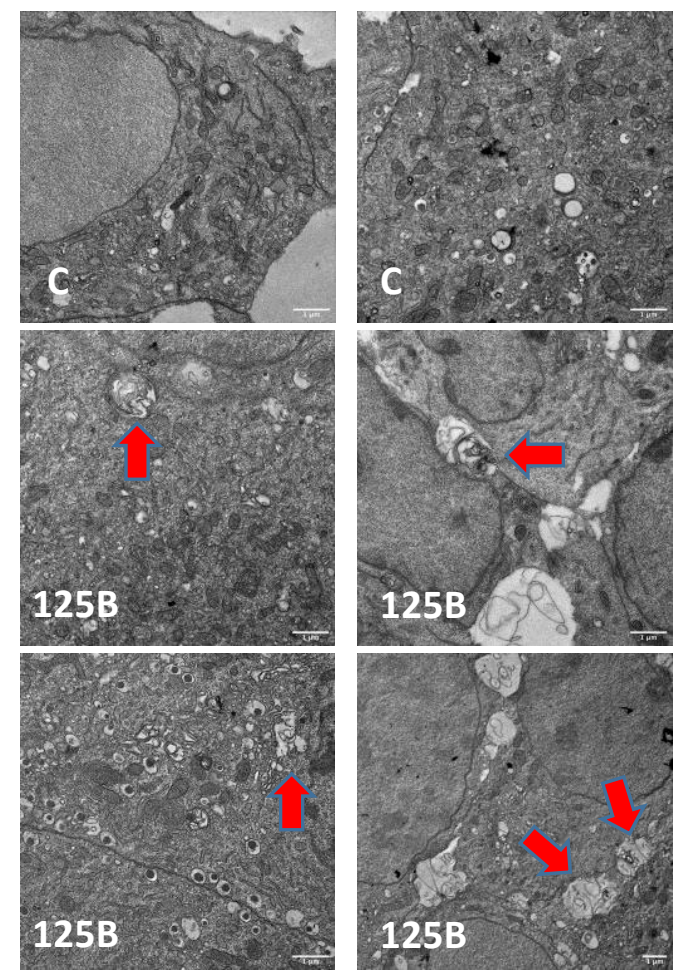


\section{Figure 6}
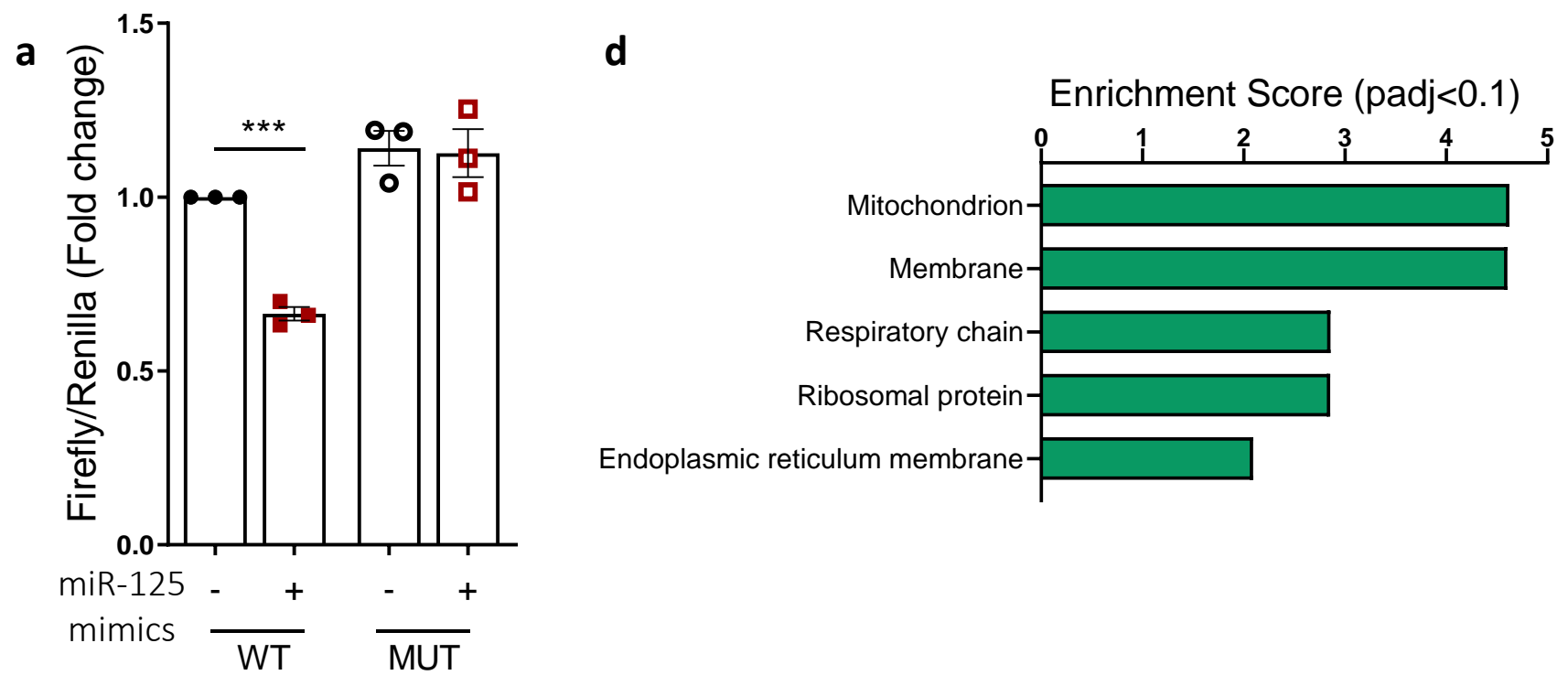

b

MIN6- miR-125b OE

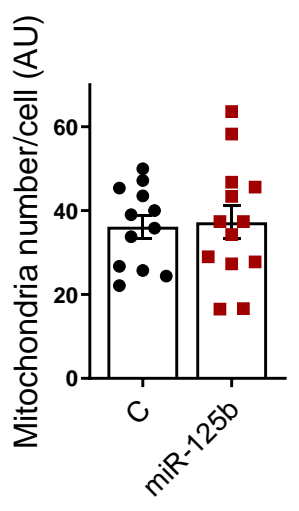

C
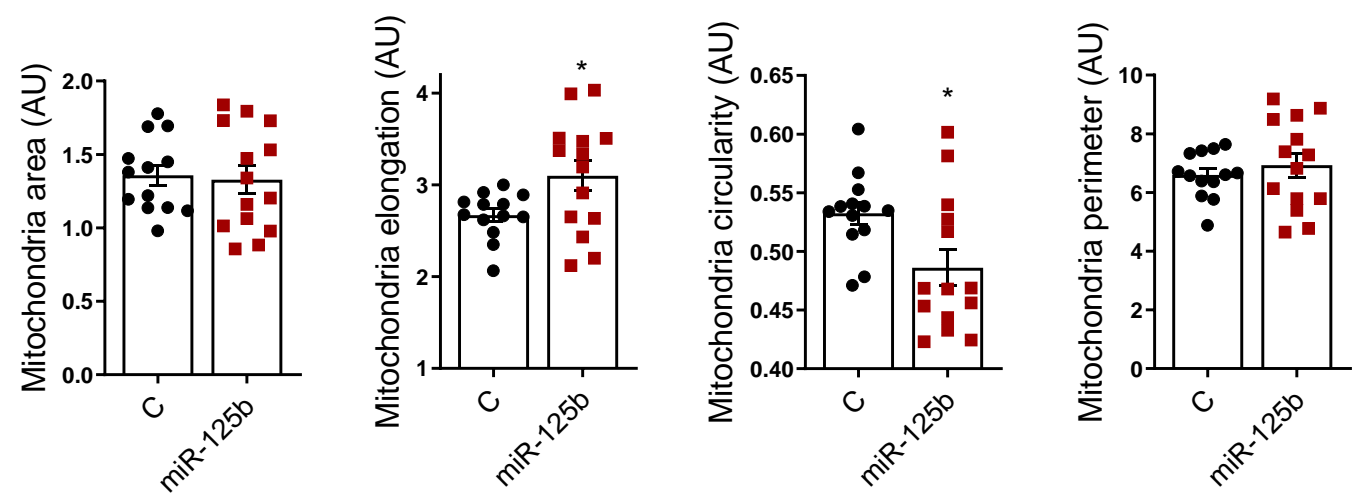

EndoC $\beta-H 1-m i R-125 b$ KO
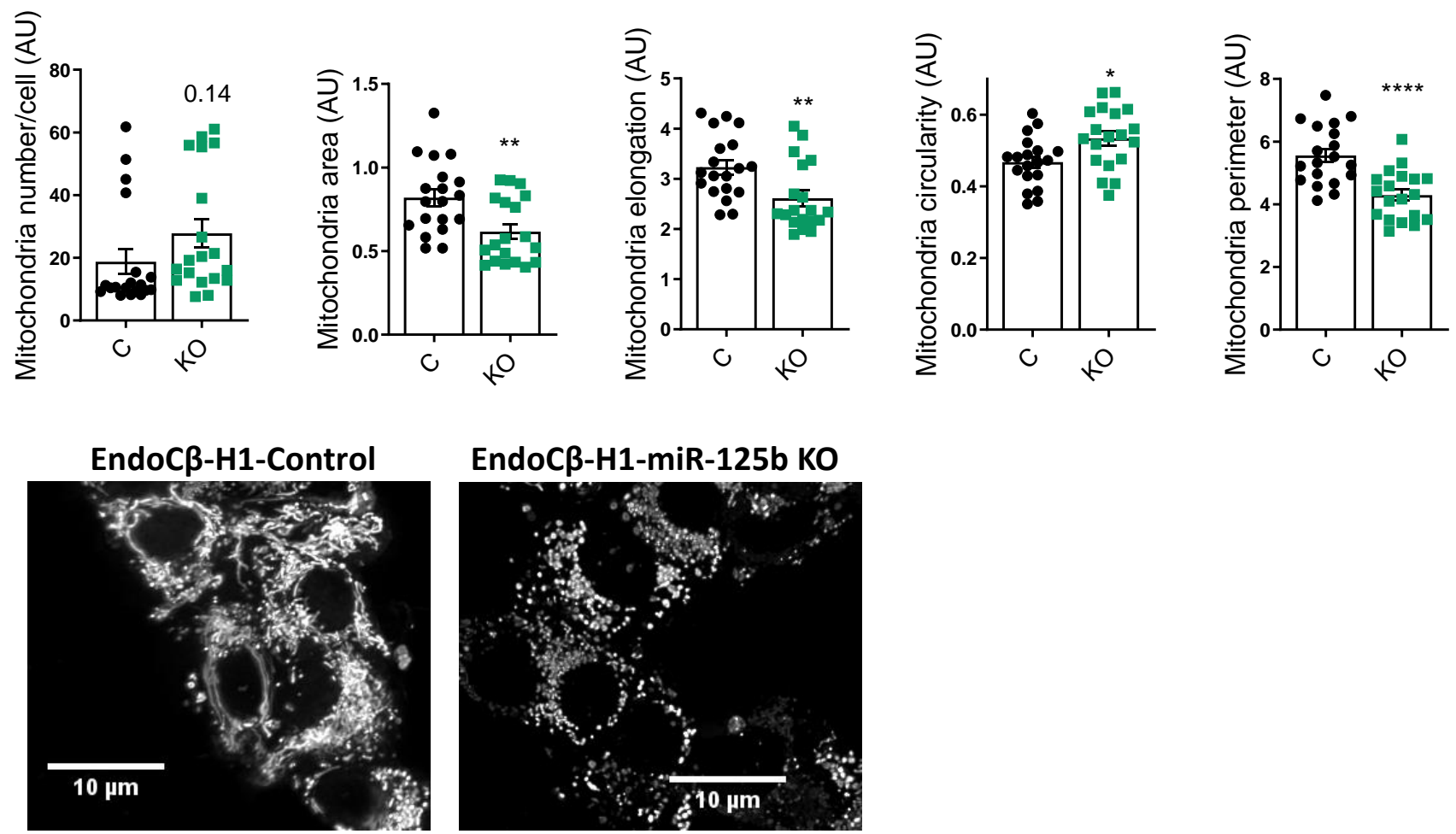
Figure 7

a

Islets

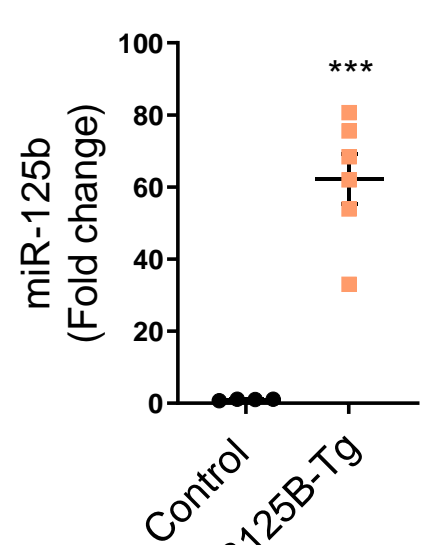

b

Male
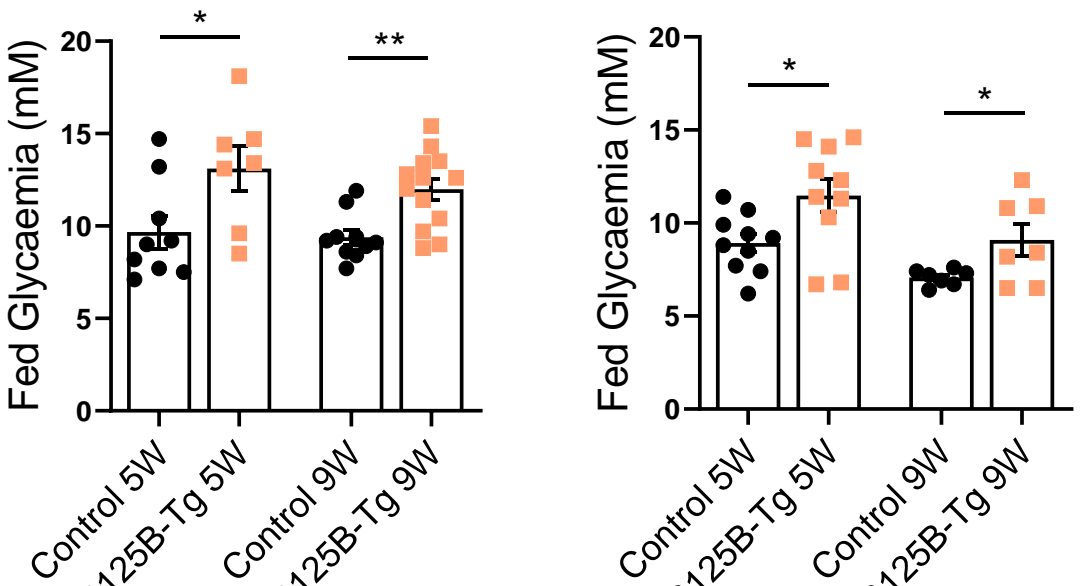

C
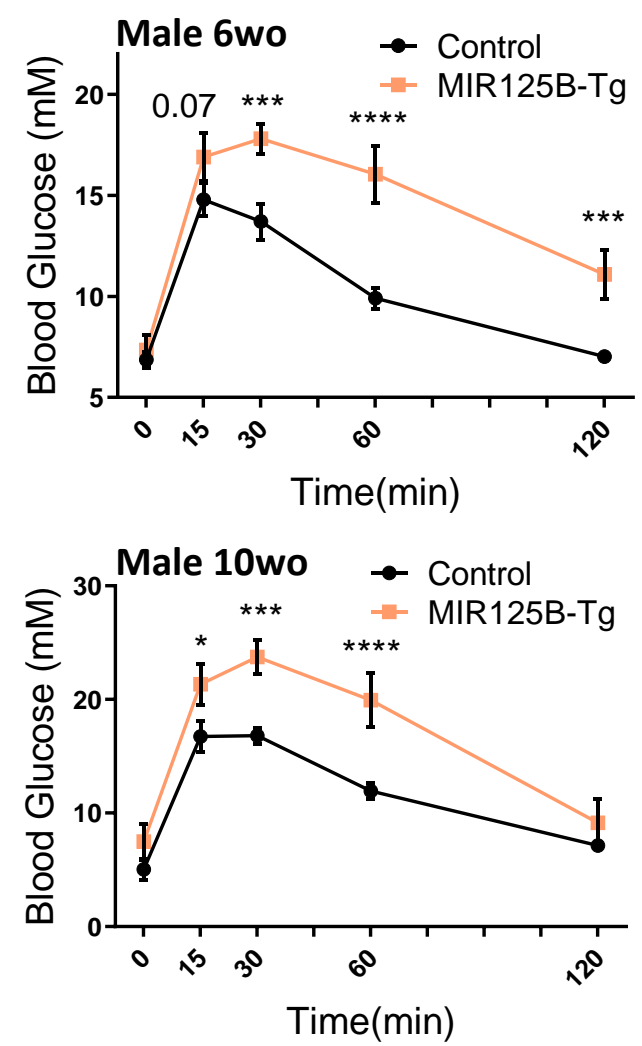

e

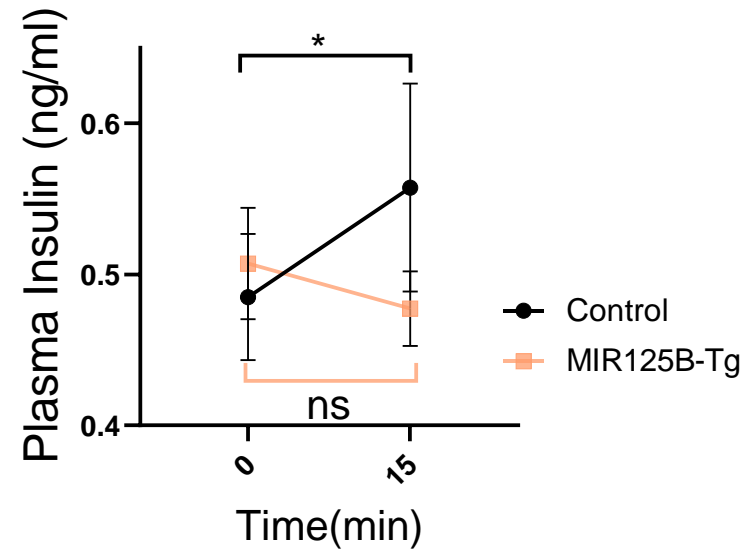

d
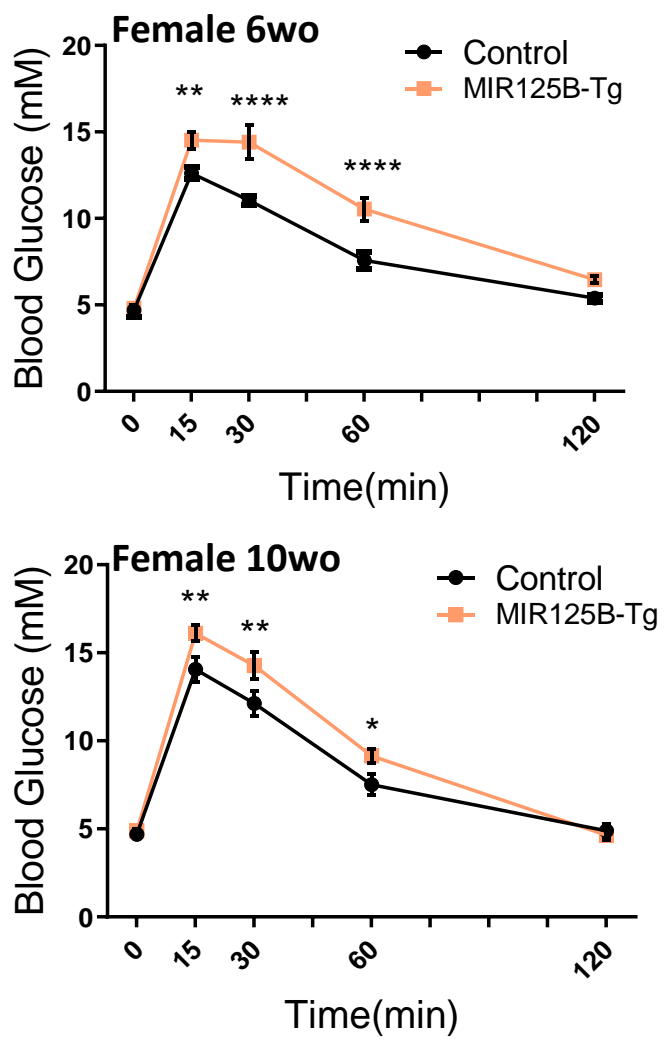

f
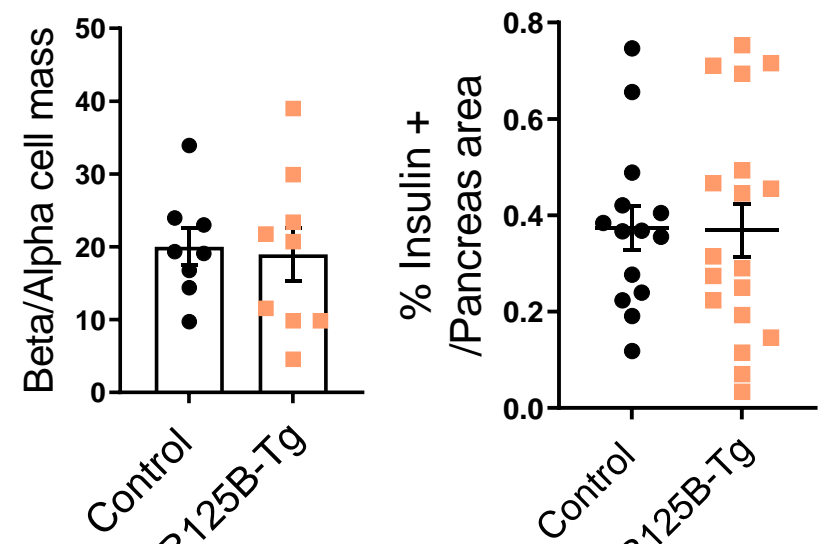


\section{Figure 8}

a

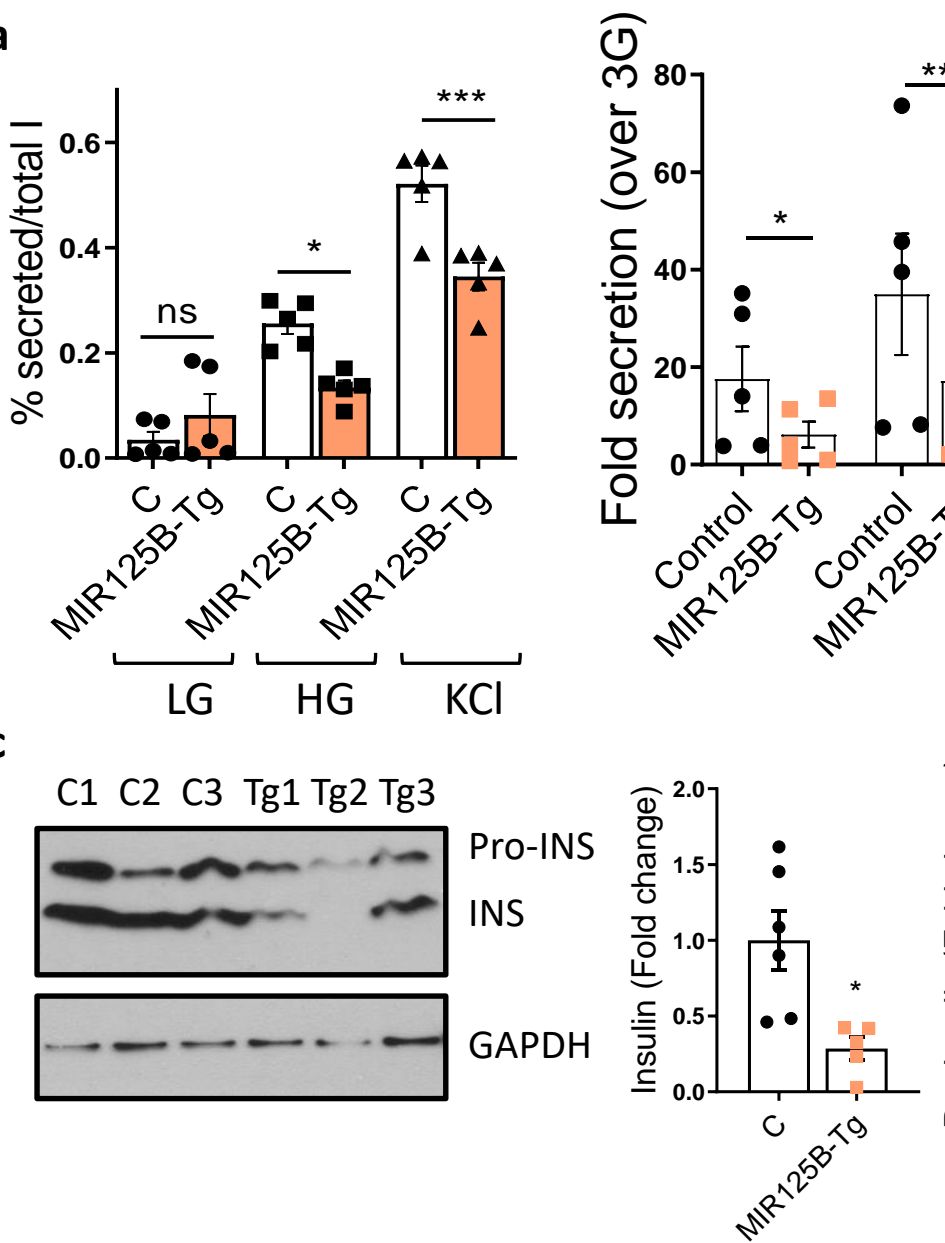

d

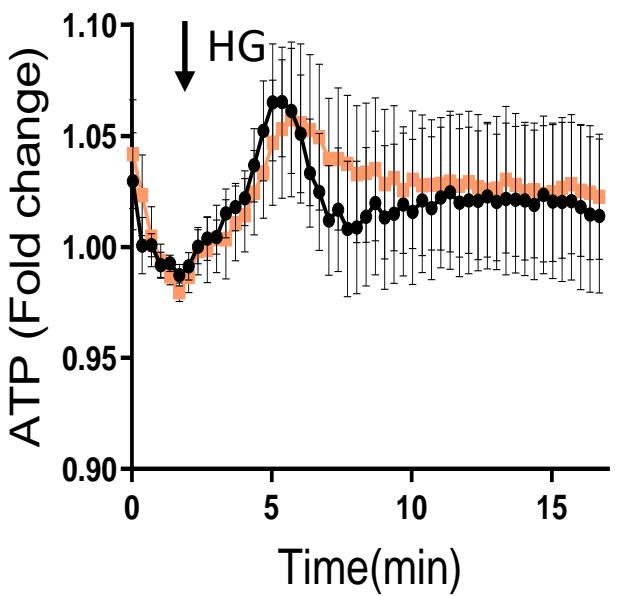

f

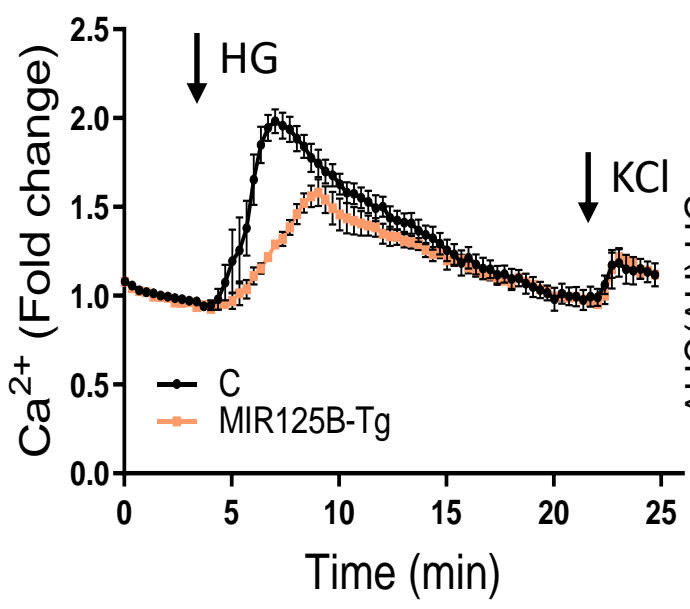

b

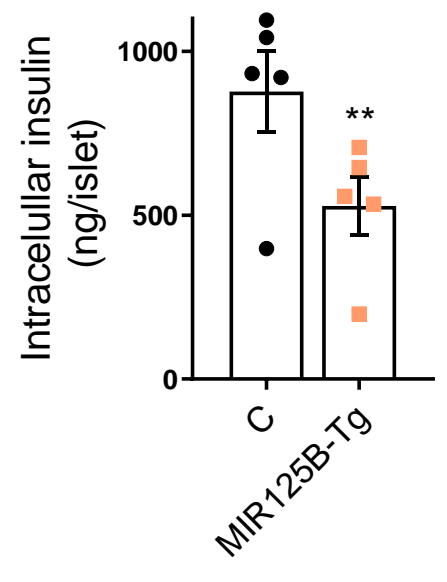

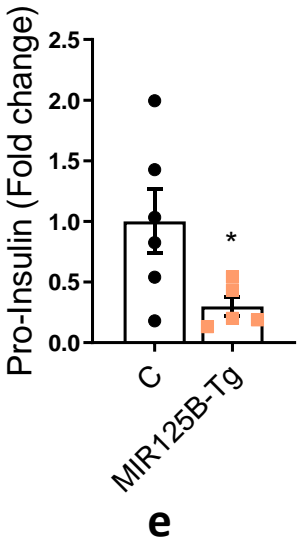

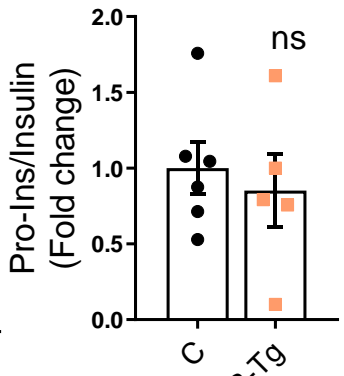

e
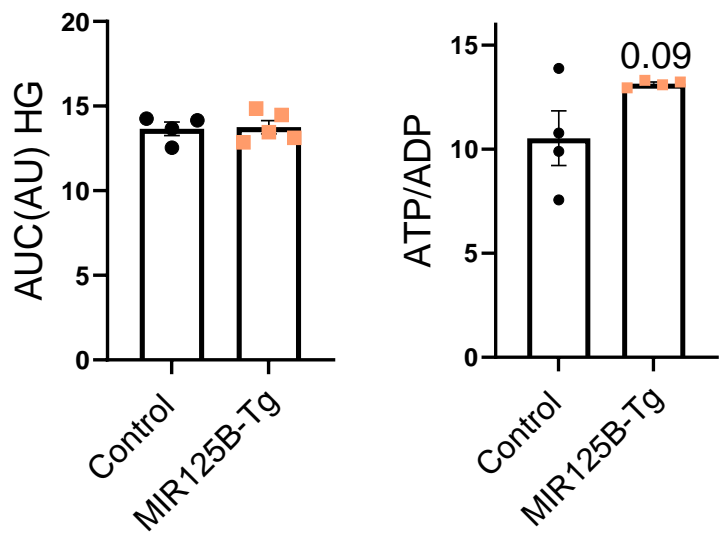

g

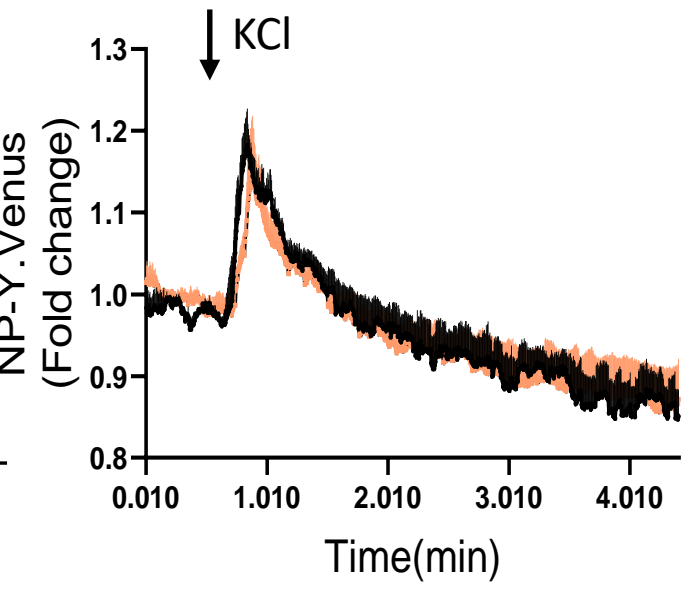




\section{Figure 9}

a

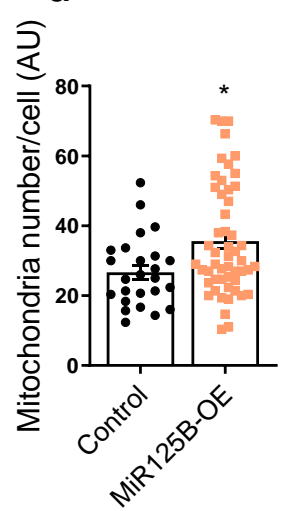

C
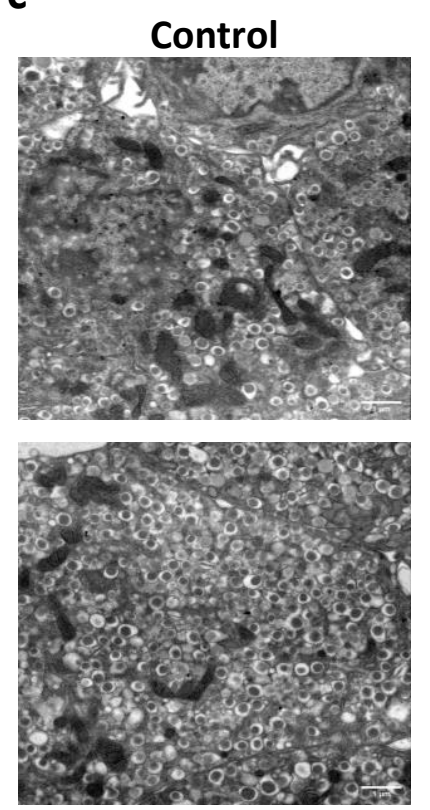
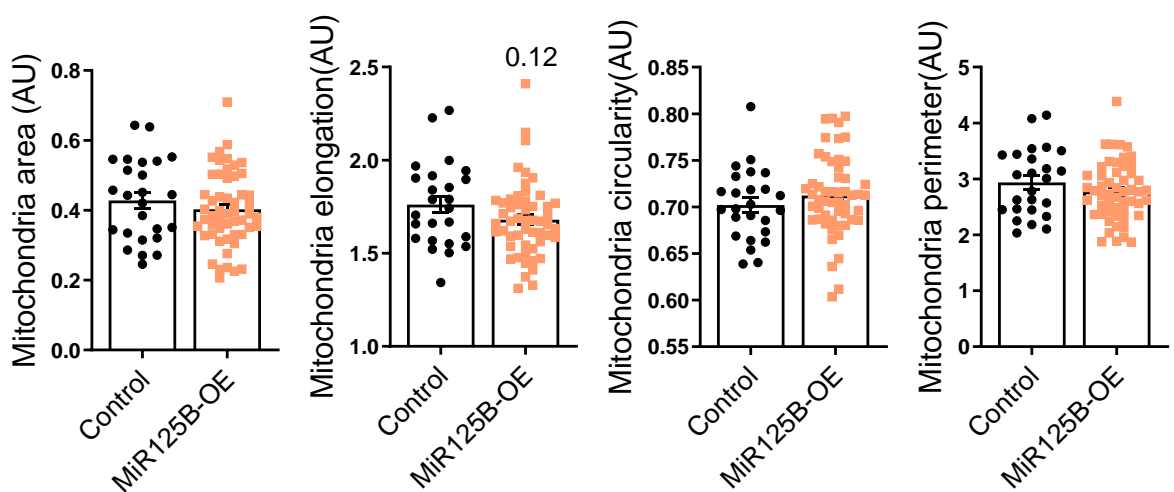

b

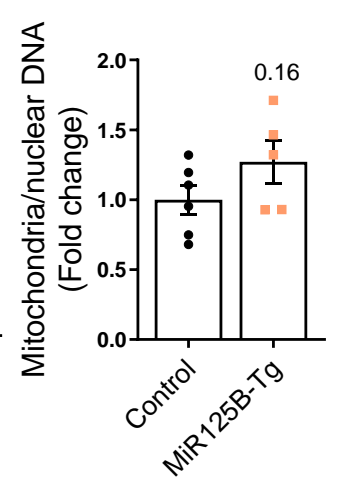

d
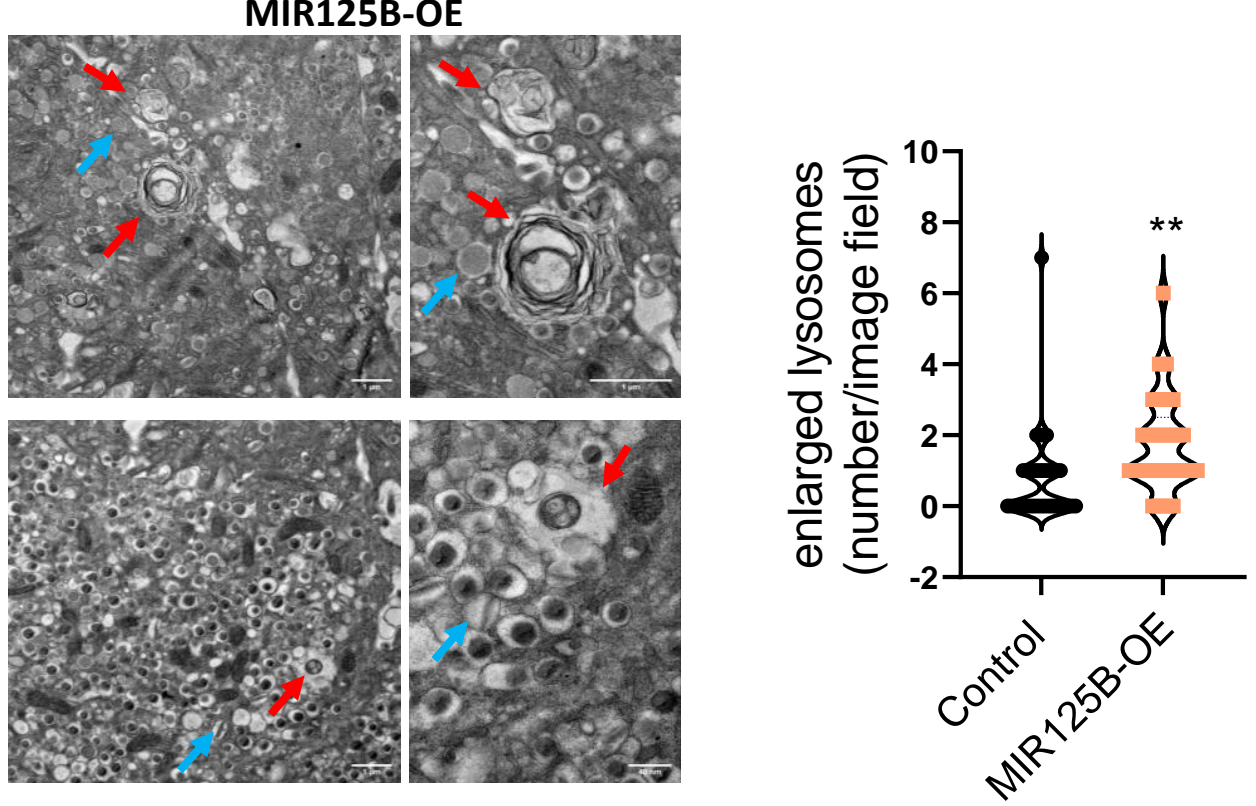

e
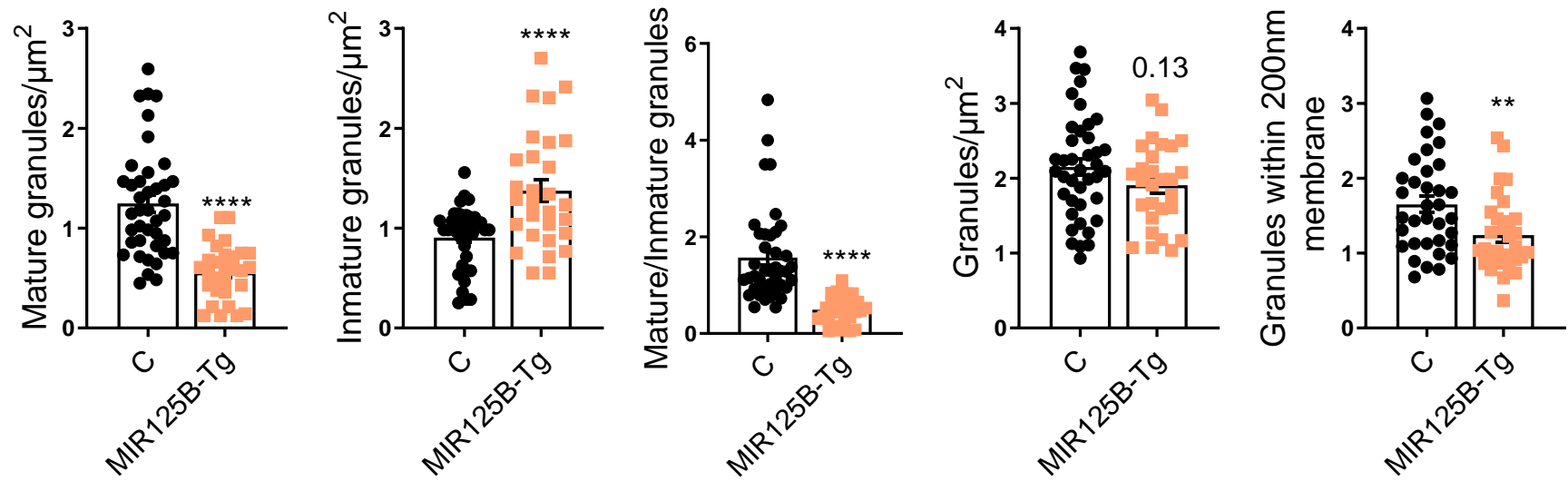
Figure 10

\section{a MIR12B-Tg mouse islets- GO/Functional enrichment}

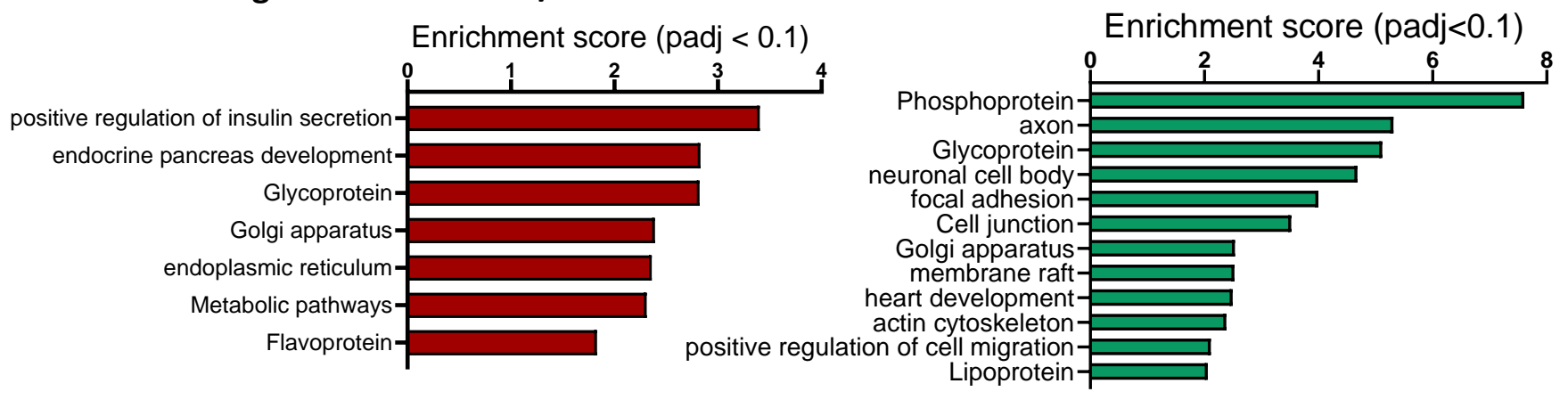

b MIR12B-Tg mouse islets

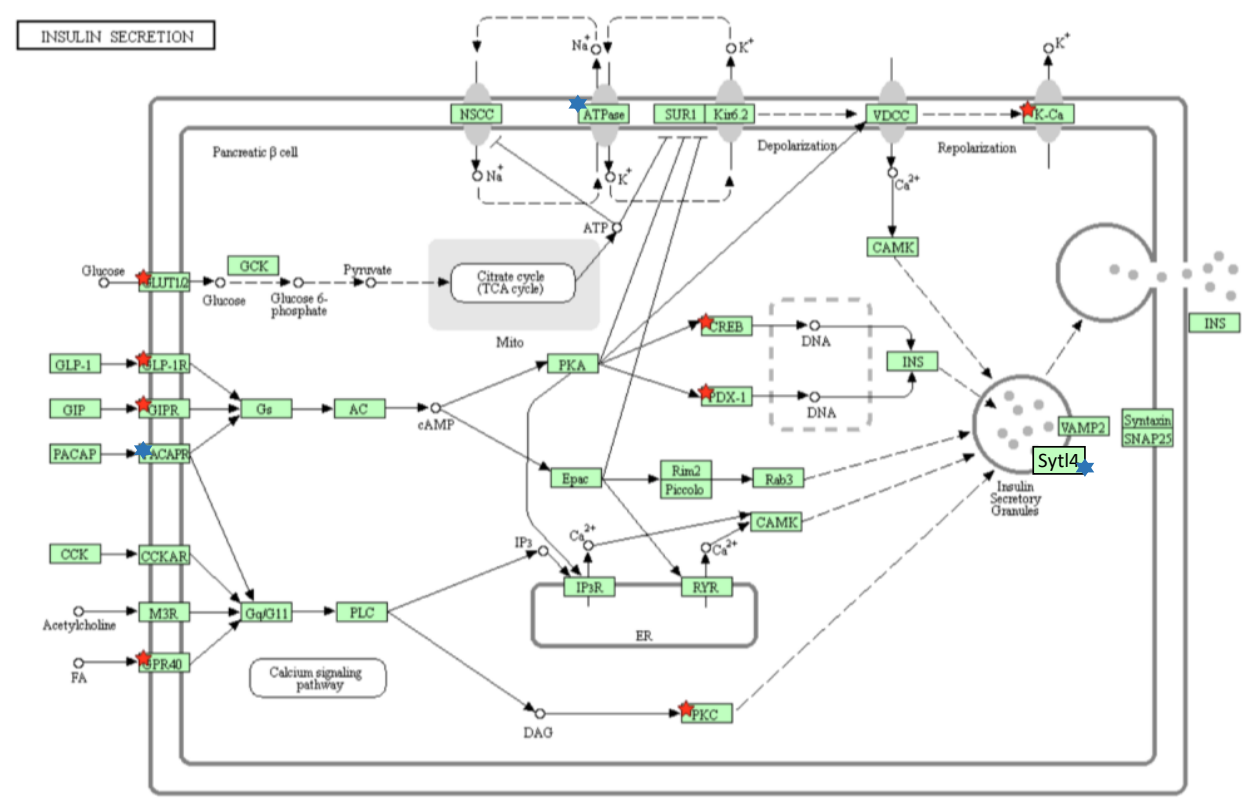

C AD-MIR12B human islets- GSEA

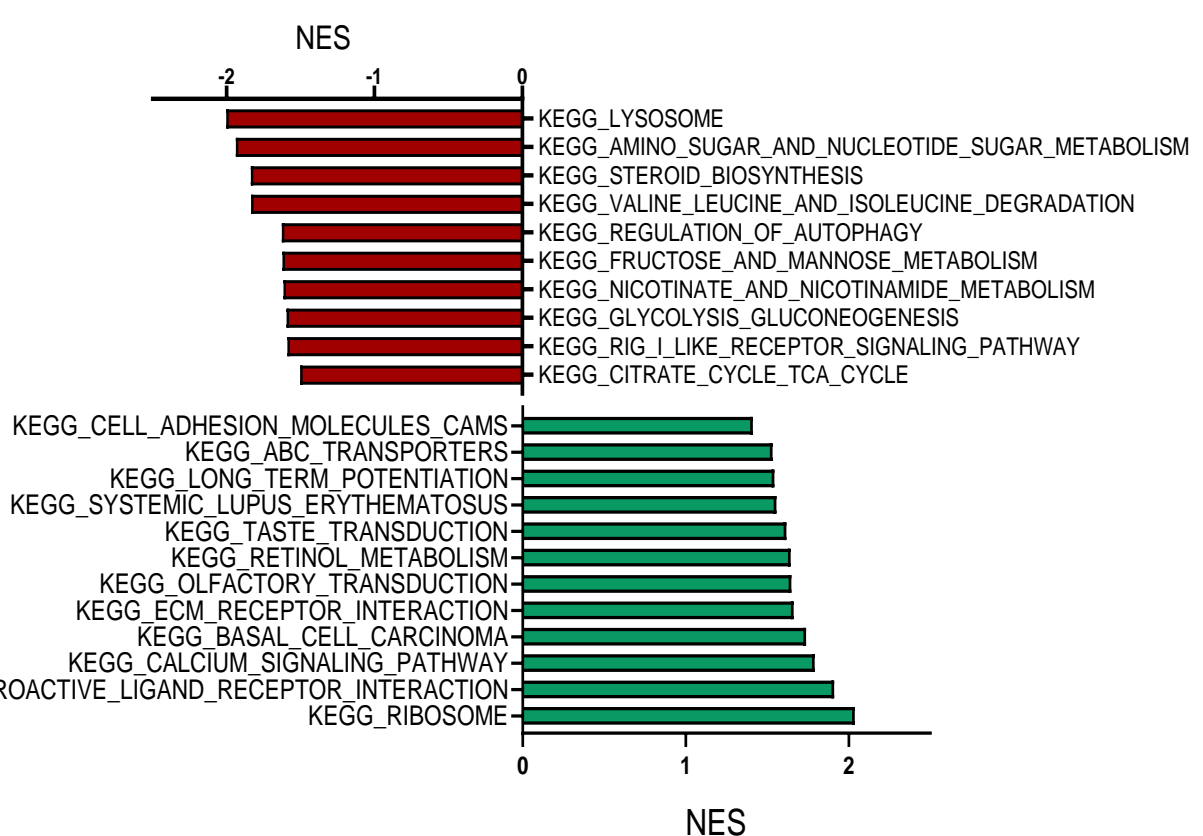

d

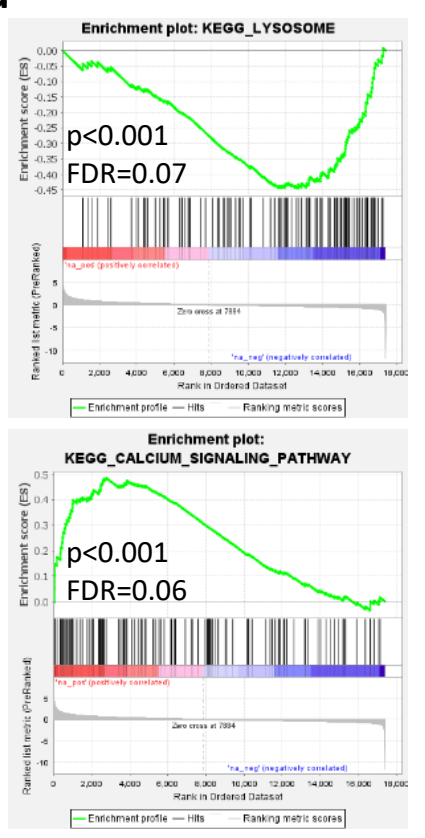




\section{Supplemental Figure 1}

a

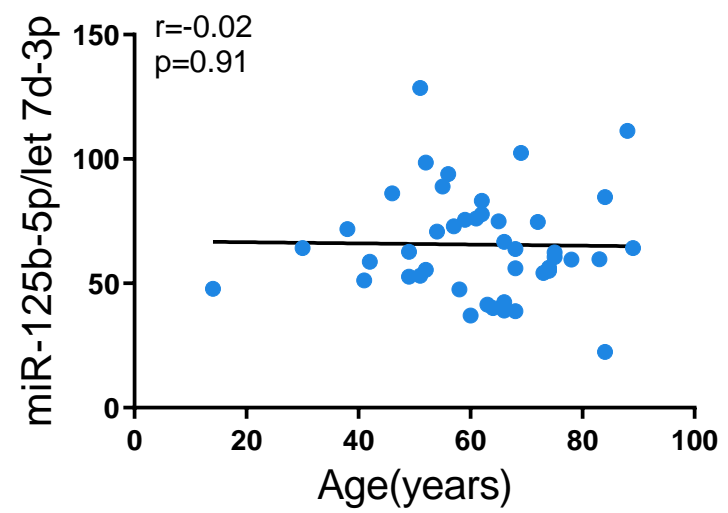

b

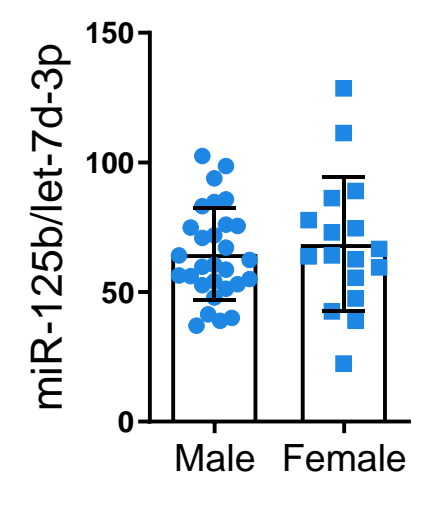




\section{Supplemental Figure 2}

a
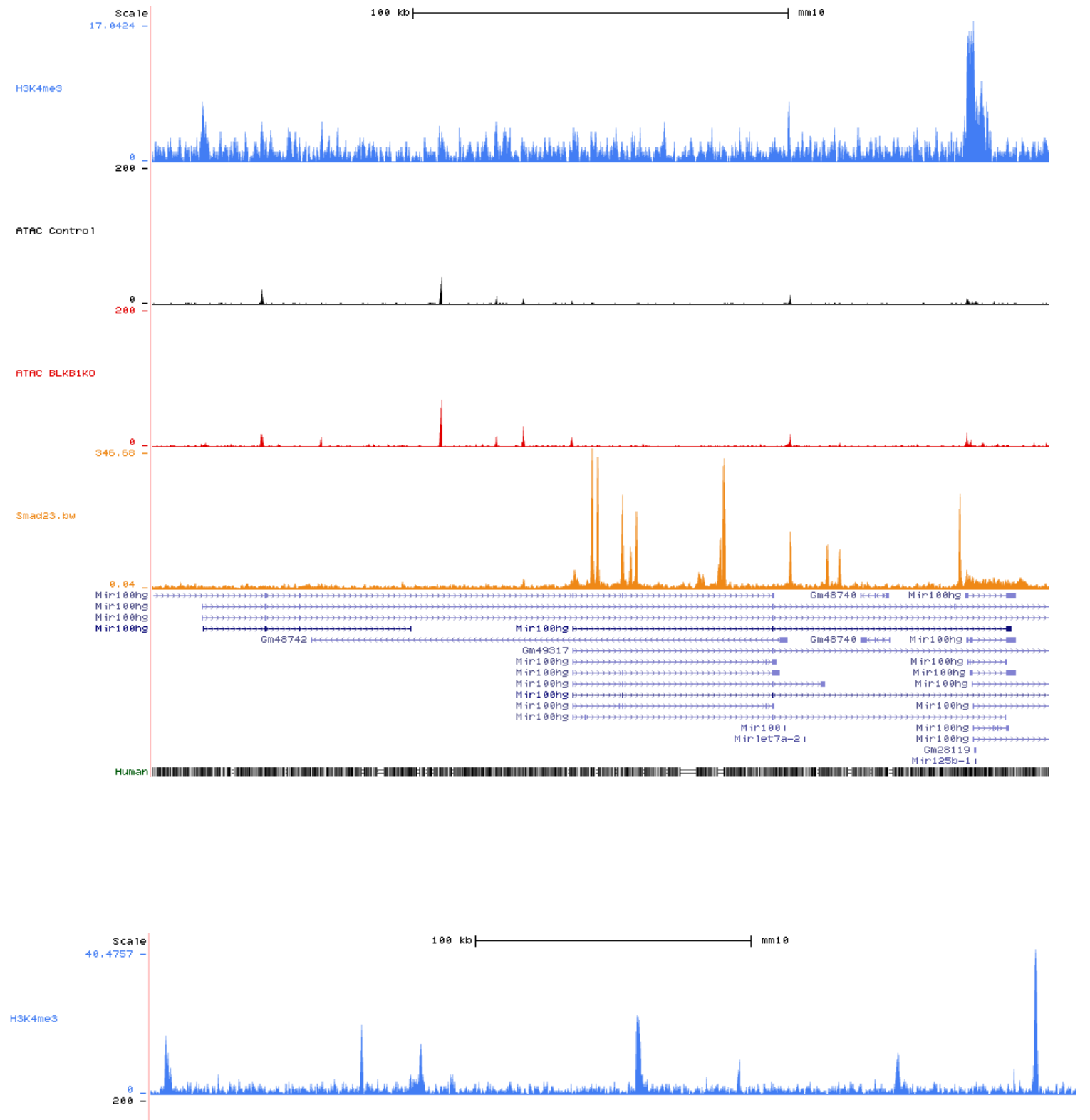

ATAC control

ATAC BLKB1KO
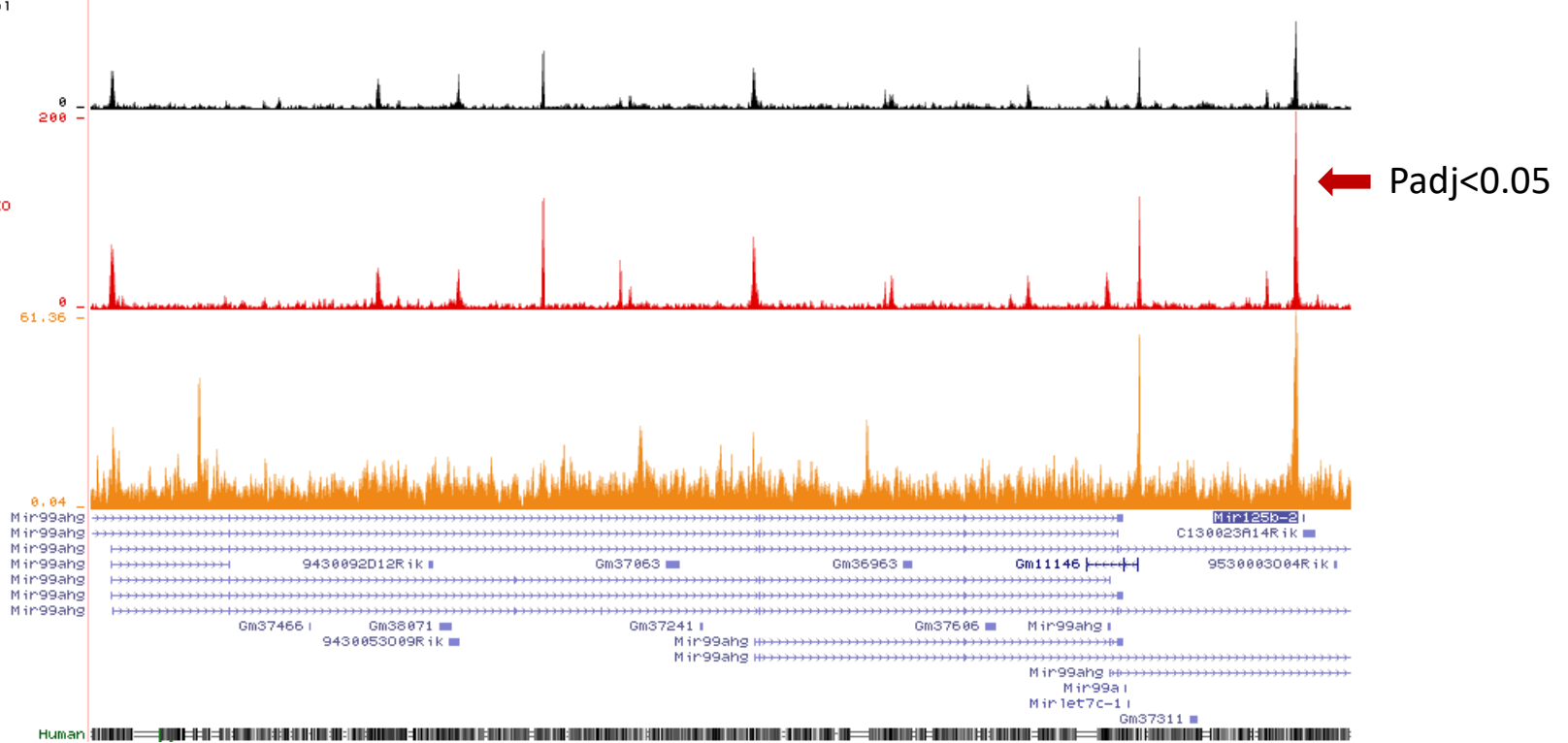


\section{Supplemental Figure 3}

a

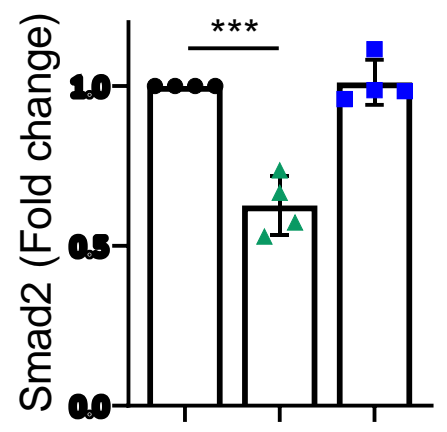

siRNA: b

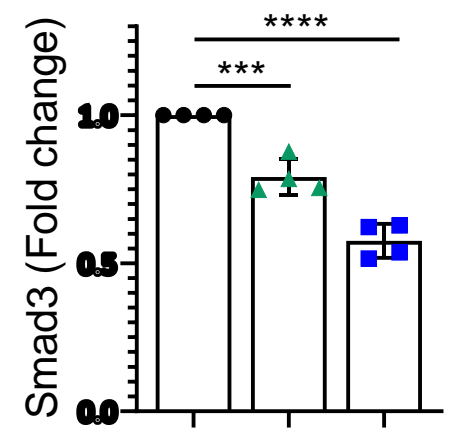

siRNA:
C

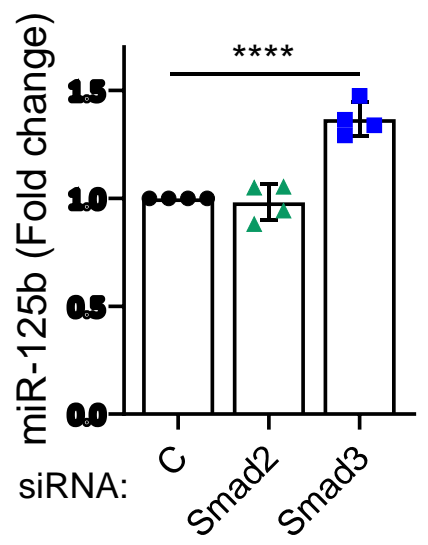




\section{Supplemental Figure 4}

a

MIR125B-1

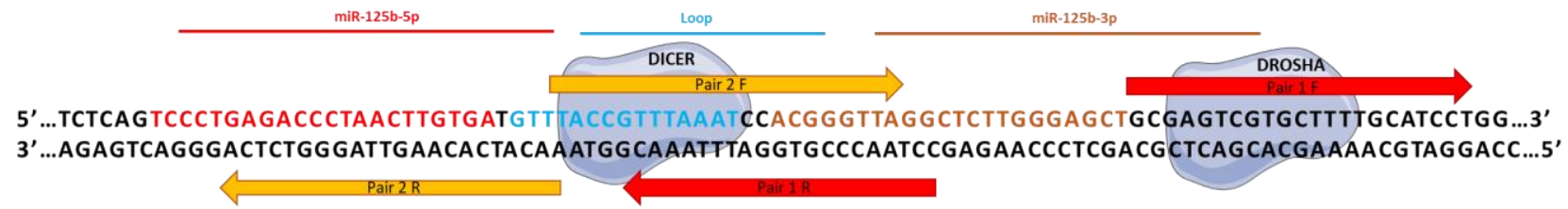

MIR125B-2

miR-125b-5p

Loop

miR-125b-3p

b

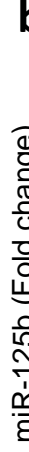

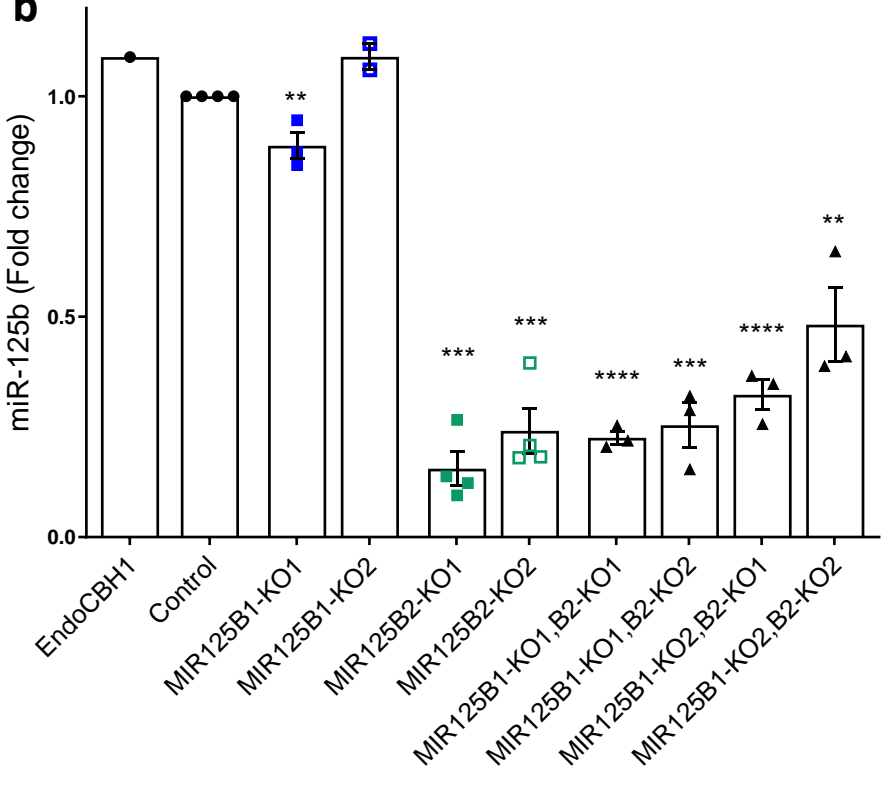

C

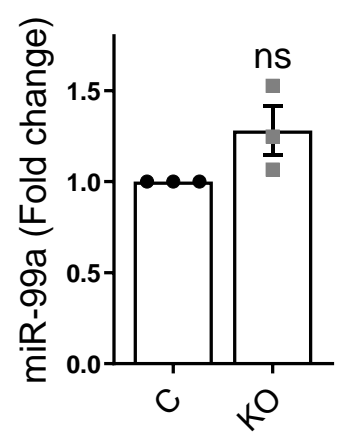




\section{Supplemental Figure 5}

a

Hypothalamus

Male

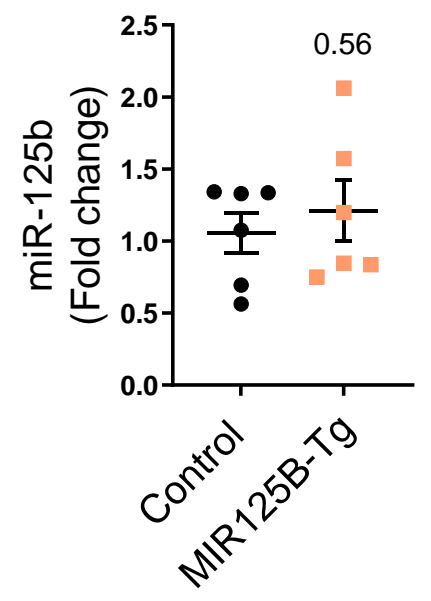

C

Male 6wo

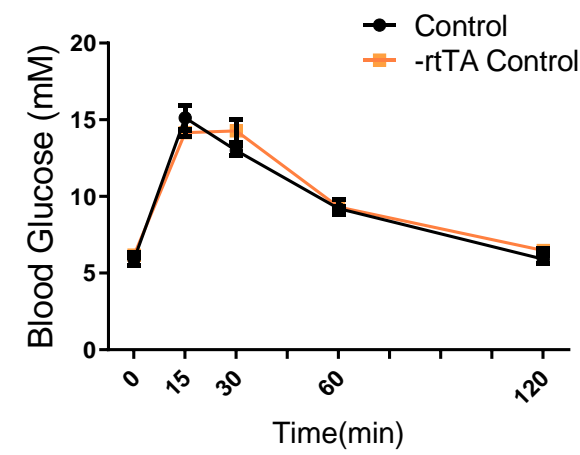

d

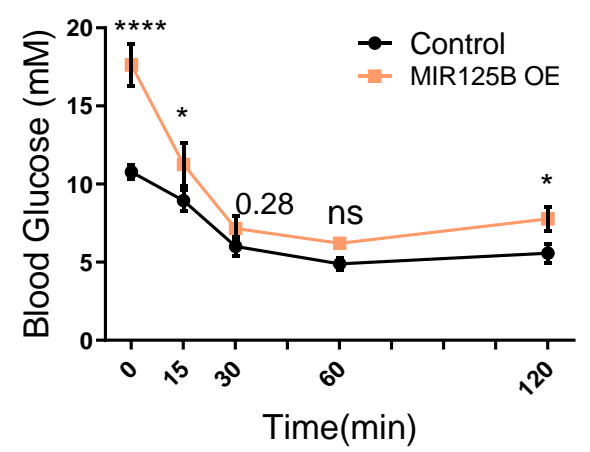

Male 7wo
Female

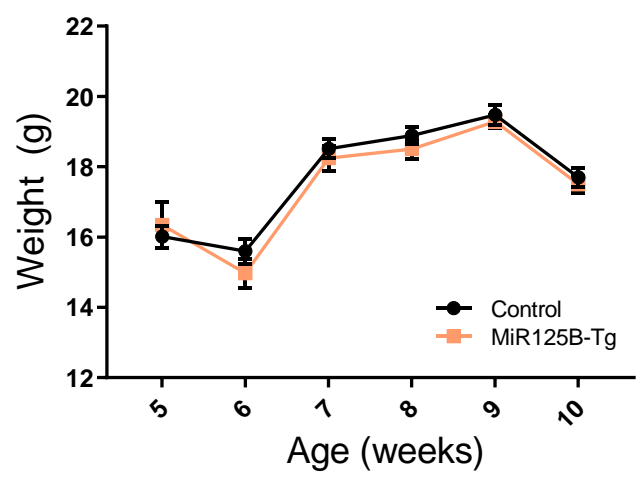

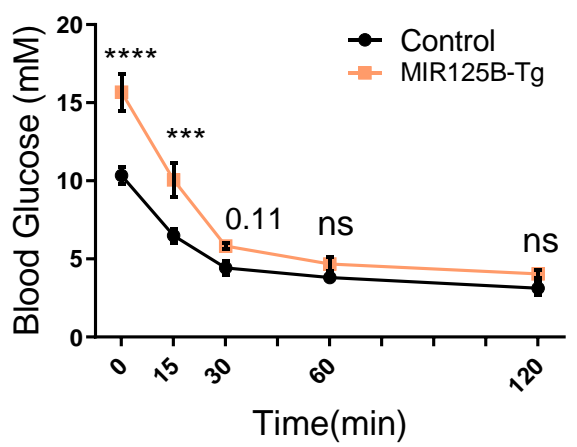

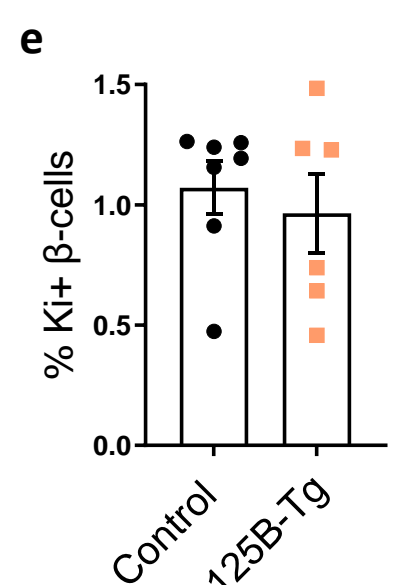

f

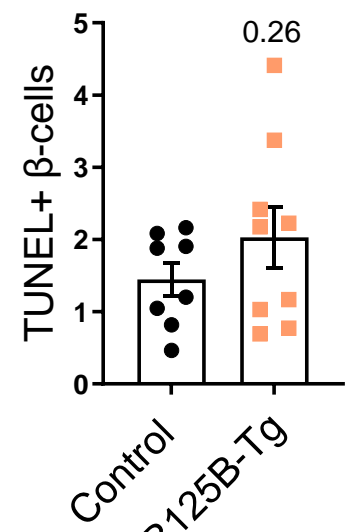

g

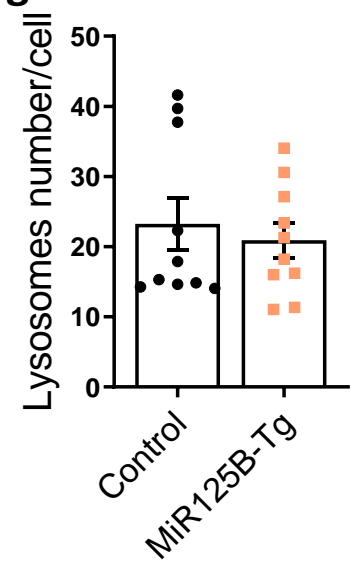

Female 7wo

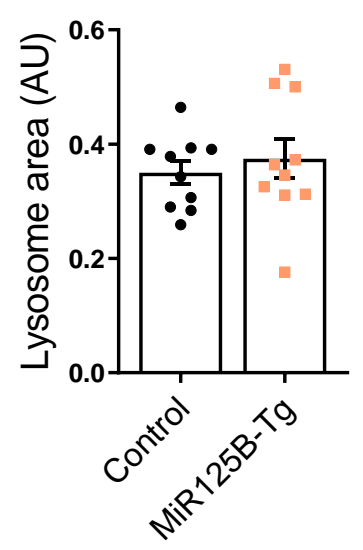




\section{Supplemental Figure 6}

a

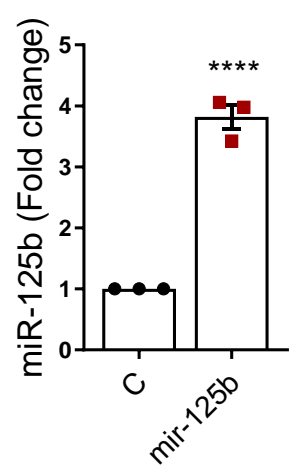

b

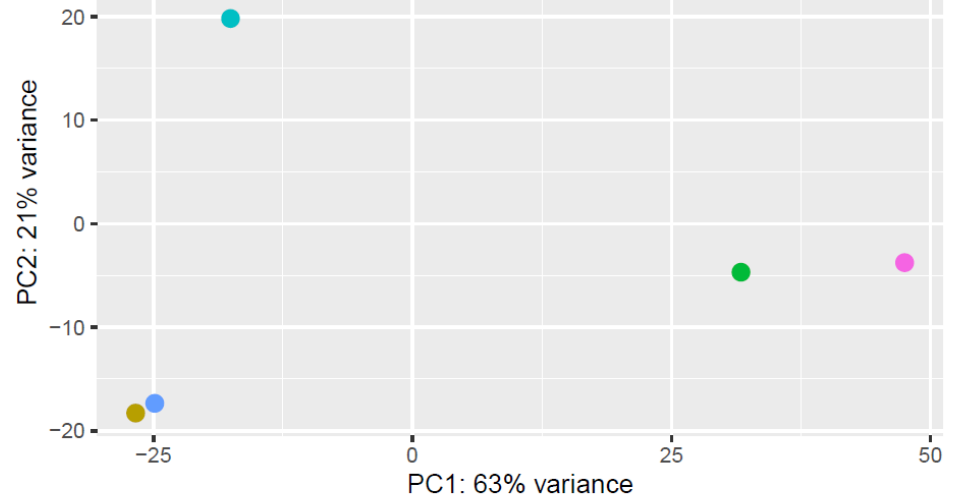

pAd-Empty: HI-1

pAd-Empty: HI-2

- pAd-Empty: HI-3

pAd-MIR125B: HI-1

( pAd-MIR125B: HI-2

pAd-MIR125B: HI-3 